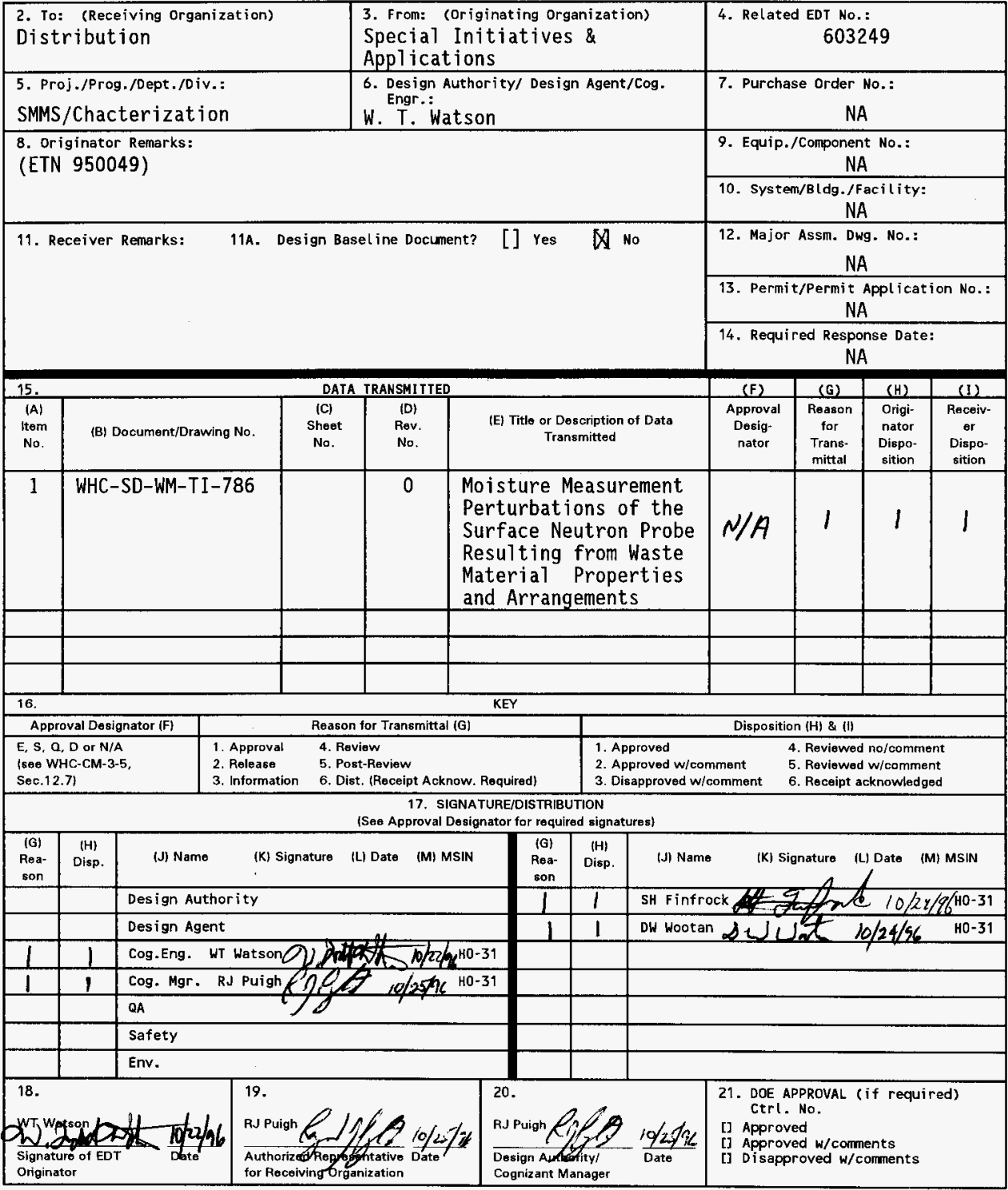


WHC-SD-WM-TI-786, Rev. 0

\title{
Moisture Measurement Perturbations of the Surface Neutron Probe Resulting from waste Material Properties and Arrangements
}

\author{
W. T. Watson \\ S. H. Finfrock \\ Westinghouse Hanford Company, Richland, WA 99352
}

October 1996

U.S. Department of Energy Contract DE-AC06-87RL10930

EDT/ECN: $618553 \quad$ UC: 606

Org Code: 8M720 Charge Code: N2208

B\&R Code: EW3120074 Total Pages: 99

(ETN 950049)

Key Words: moisture measurement, neutron moisture probe, tank safety, SMMS, calibration

Abstract: Experimental tests and computer simulations of a surface neutron moisture measurement probe have been performed to determine the effects that different material variations and arrangements are expected to have upon probe moisture measurement error. This work supplements the existing probe calibration to changes in waste moisture concentration and should aid in the selection of the best in-tank measurement locations.

TRADEMARK DISCLAIMER. Reference herein to any specific comnercial product, process, or service by trade name, trademark, manufacturer, or otherwise, does not necessarily constitute or imply its endorsement. recommendation, or favoring by the United states Government or any agency thereof or its contractors or subcontractors.

Printed in the United states of America. To obtain copies of this document, contact: WHC/BCs Document Control Services, P.0. Box 1970. Mailstop H6-08. Richland WA.99352 Phong $509+372-2420$ :

Fax $(509) \quad 376-4989$.
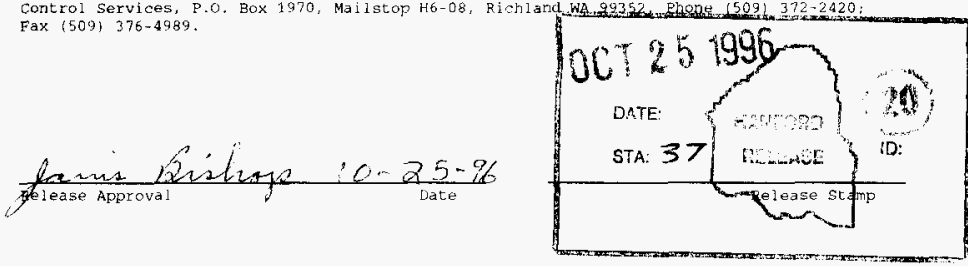

Approved for Public Release 
WHC-SD-WM-TI-786, Rev, 0

Contents

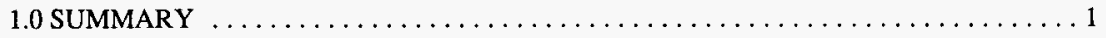

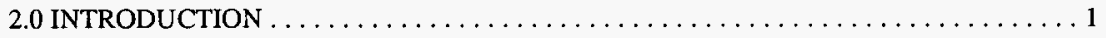

3.0 WASTE MATERIAL PROPERTIES AND ARRANGEMENTS $\ldots \ldots \ldots \ldots \ldots \ldots 2$

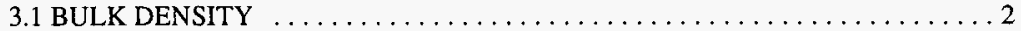

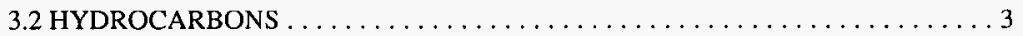

3.3 STRONG THERMAL NEUTRON ABSORBERS $\ldots \ldots \ldots \ldots \ldots \ldots \ldots 7$

3.4 PHYSICAL GEOMETRIC WASTE ARRANGEMENT $\ldots \ldots \ldots \ldots \ldots \ldots \ldots 8$

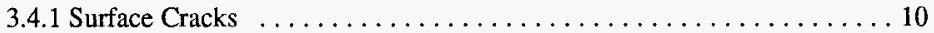

3.4 .2 Large Holes . . . . . . . . . . . . . . . . . . . . 11

3.4.3 Hills or Protrusions Above Surrounding Waste Level . . . . . . . . 15

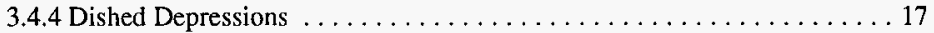

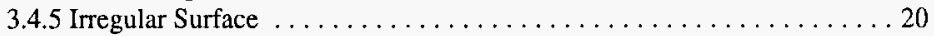

3.4.6 Waste Surface to Probe Suspension or Submersion $\ldots \ldots \ldots \ldots \ldots 20$

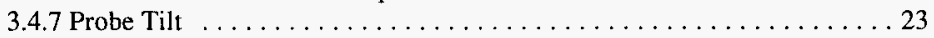

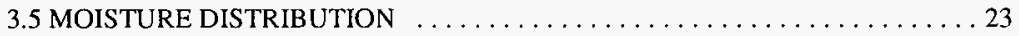

4.0 PLANNED MOISTURE INTERPRETATION AND UNCERTAINTY BOUNDS . . . . 25

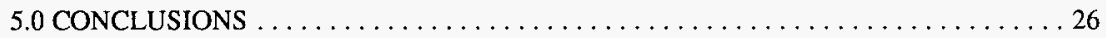

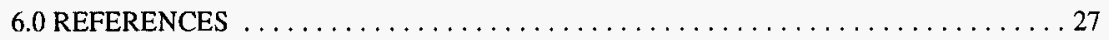

Appendix A. Model predicted and experimentally measured detector response data . . . . . 28

Appendix B. Computer model (MCNP) input files $\ldots \ldots \ldots \ldots \ldots \ldots \ldots \ldots \ldots \ldots \ldots$ 


\subsection{SUMMARY}

Experimental tests and computer simulations of a surface neutron moisture measurement probe have been completed to determine the effects that different material variations and arrangements are expected to have upon probe moisture measurement error. Many possible tank waste material anomalies, including variations in material composition, density and geometric arrangement, may be encountered. Some of these anomalies may significantly affect the probe moisture measurement accuracy. If the anomaly can be visually identified, recommendations have been made that provide guidance for avoiding these situations during in-tank probe deployment. For anomalies that can not be visually identified, the effect upon the moisture measurement error has been partially characterized and possible plans for potentially correcting the data to compensate for the anomaly are discussed. It is expected that there will be in-tank locations that are suitable for moisture measurement and that, for those cases, a moisture concentration, gradient with depth, and uncertainty bound can be established. To more accurately determine moisture measurement interpretations for cases where an anomaly is indicated, additional simulation analyses may be required.

\subsection{INTRODUCTION}

The surface moisture measurement system (SMMS) has been developed to deploy a neutron moderation-based moisture measurement probe to the tank waste surface (Stokes et al, 1995). This SMMS neutron probe has been tested, computer simulated, and calibrated to changes in moisture concentration of underlying materials (Watson and Bussell 1996). The calibration tests and simulations have focussed upon the simplest material arrangement and composition. The arrangement considered for these tests had the probe resting on a flat smooth material surface where the material contained no non-water hydrogen and little presence of strong thermal neutron absorbing elements. It is known that the response of the probe may be altered by changes in the surrounding waste geometry and composition. The in-tank waste surface geometry is known to be more irregular than the moisture standards used in the probe calibration. The waste composition is generally understood, but is not well characterized. This report is intended to document experimental tests and computer simulations performed to assess the effects of potential in-tank waste anomalies, deviations from the idealized calibration, upon the response of the probe. This information will be used both to avoid obtaining in-tank measurements in locations that would be likely to yield moisture data that is significantly compromised and to aid in data interpretation and uncertainty analyses.

The probe is mechanically housed within a nearly cylindrical stainless steel container (WHC 1996) with an outer diameter in the sensor region of about 3.3 inches. The main sensor portion of the probe consists of three detectors, each of which is at least partially shielded with cadmium and or polyethylene, and a californium-252 neutron source. Figure 2-1 shows a sketch, not to scale, identifying the major components of the sensor portion of the probe. The housing is designed to be deployed upright on the surface being investigated with the flat bottom in firm contact with the material. Detector 1 is positioned horizontally in the bottom of the housing 
nearest to the neutron source and is surrounded with a thick $(0.16 \mathrm{~cm})$ outer cadmium shield and a partial inner layer of polyethylene. This detector is designed to detect epithermal neutrons returning to the probe. Epithermal neutrons will have, on average, undergone fewer collisions than lower energy neutrons and, therefore, will have traveled less deep in the media. Detector 2 is surrounded with a very thin $(0.01 \mathrm{~cm})$ cadmium shield and a polyethylene wrap and is vertically positioned near the probe bottom opposite the source. This detector detects a mix of thermal and epithermal neutrons that have, on average, traveled more deeply into the material that those detected by detector 1 . Detector 3 is not surrounded with shielding, but rather is placed directly centered above a thick cadmium disk. This detector captures mainly thermalized neutrons that have traveled, on average, most deeply in the waste and exited the waste a short distance outside the probe housing.

\subsection{WASTE MATERIAL PROPERTIES AND ARRANGEMENTS}

\subsection{BULK DENSITY}

The neutron probe measures moisture by obtaining a measure of the average neutron moderation properties of the medium. In general, increasing the bulk density of the medium will decrease the neutron path length between collisions, thereby more quickly moderating the neutrons. An increase in the bulk density of the material under the probe is expected to provide the probe with an increased signal, equivalent to some change in moisture concentration. Computer simulations, using the radiation transport code Monte Carlo N-Particle (MCNP), were performed to assess the expected magnitude of this effect (LANL 1993). Throughout this report the model predictions have been scaled by a multiplicative calibration constant determined during calibration tests for each detector (Watson and Bussell 1996). Model input files and difference files comparing similiar cases may be found in Appendix B. Analyses of tank waste salt cake samples and estimates of the waste density in the 20 Organic Watch-List tanks indicates that the expected density of waste near the surface of single shell tanks is about $1.5 \mathrm{~g} / \mathrm{cm}^{3}$ (WASTREN 1993) (Agnew 1996). Figure 3-1 shows the predicted response of each of the three detectors in the neutron probe to changes in waste bulk density at a constant moisture concentration of 15 weight percent (wt\%) water. The error bars shown on individual points in this figure are representative of the stochastic precision for each value. In general, model predicted responses were calculated throughout this report with precision uncertainties of less than 2 to 3 percent. To obtain the best understanding of how the deviations in detector responses presented in Figure 3-1 relate to uncertainty in the moisture measurement the responses should be compared with those expected for changes in moisture at a constant density. Figure 3-2 shows the waste moisture as a function of the computer model predicted detector responses. A polynomial least-square fit to the data (presented in Appendix A) for each detector was produced to obtain the moisture as a function of response rate for each detector:
Detector 1: Moisture $=-14.615+0.4194 \cdot($ response $)$
Detector 2: $\quad$ Moisture $=-4.44+0.1254 \cdot($ response $)+0.0006 \cdot(\text { response })^{2}$
Detector 3: Moisture $=0.6047+0.0955 \cdot($ response $)+0.0023 \cdot(\text { response })^{2}$ 
If the density perturbation detector responses from Figure 3-1 are substituted in the above equations, then the equations will give apparent moisture concentration values that would be calculated if the waste were assumed to have a density of $1.5 \mathrm{~g} / \mathrm{cm}^{3}$. If this apparent moisture is averaged for the three detectors a simple indication of the effect of density upon the moisture measurement may be obtained. Over the density range from about 1 to $2 \mathrm{~g} / \mathrm{cm}^{3}$, it is expected that the moisture prediction will be in error about $1.5 \mathrm{wt} \%$ moisture for each $0.1 \mathrm{~g} / \mathrm{cm}^{3}$ that the actual density deviates from an assumed density of $1.5 \mathrm{~g} / \mathrm{cm}^{3}$. If, for instance, the actual waste bulk density is $1.7 \mathrm{~g} / \mathrm{cm}^{3}$, then the moisture prediction from the probe data will likely be about 3 wt $\%$ higher than the actual moisture concentration. Given information about the waste bulk density, the interpretation of the data could easily be corrected to eliminate this error.

\subsection{HYDROCARBONS}

The moderation properties of the waste are strongly dependant upon its hydrogen concentration. Because the probe measures the moderation properties of the waste and the data interpretation assumes that nearly all hydrogen is from water, the presence of significant hydrogen from sources other than water will affect the moisture interpretation. Hydrocarbons are known to have been present in the tank waste streams. While there is no way for the neutron probe to distinguish between hydrogen from various mixed sources, it is important to understand the expected magnitude of the effects caused by non-water hydrogen.

The waste composition in the computer simulation was varied by adding a mixture of equal amounts (by weight) of 6 organic compounds to the standard waste composition while maintaining the moisture concentration. The six organic compounds, intended to be representative of those used in the waste streams, are hexone, dibutyl phosphate, tributyl phosphate, trisodium citrate, hexadecanoic acid, and sodium ethylenediaminetetraacetic acid. Figure 3-3 shows the computer model predicted detector responses to changing total organic concentration at a constant moisture concentration of $15 \mathrm{wt} \%$. Using the moisture response equations presented in section 3.1, an indication of the apparent moisture interpretation was derived and is shown in figure 3-4. From figure 3-4 one can conclude that each weight percent of total additional organic is expected to increase the apparent moisture concentration by about one weight percent. This result will vary according to the chosen mix of hydrocarbons.

Hydrocarbons that have a smaller weight or atom fraction of hydrogen will contribute a reduced offset signal to the detectors. 
Figure 2-1. Sketch of the Sensor/Source Portion of the Neutron Probe (Cross-Sectional View).

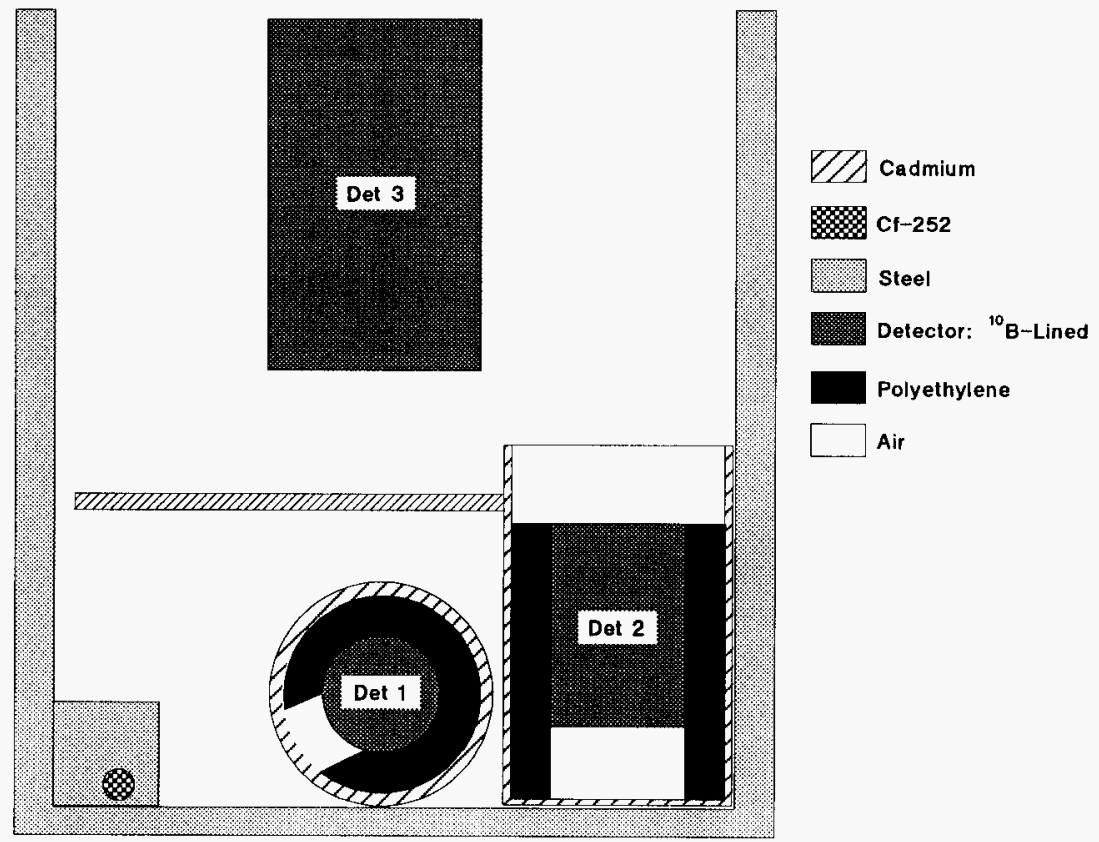


WHC-SD-WM-TI-786, Rev. 0

Figure 3-1. Computer model predicted response of each detector as a function of tank waste bulk density at 15 wto moisture.

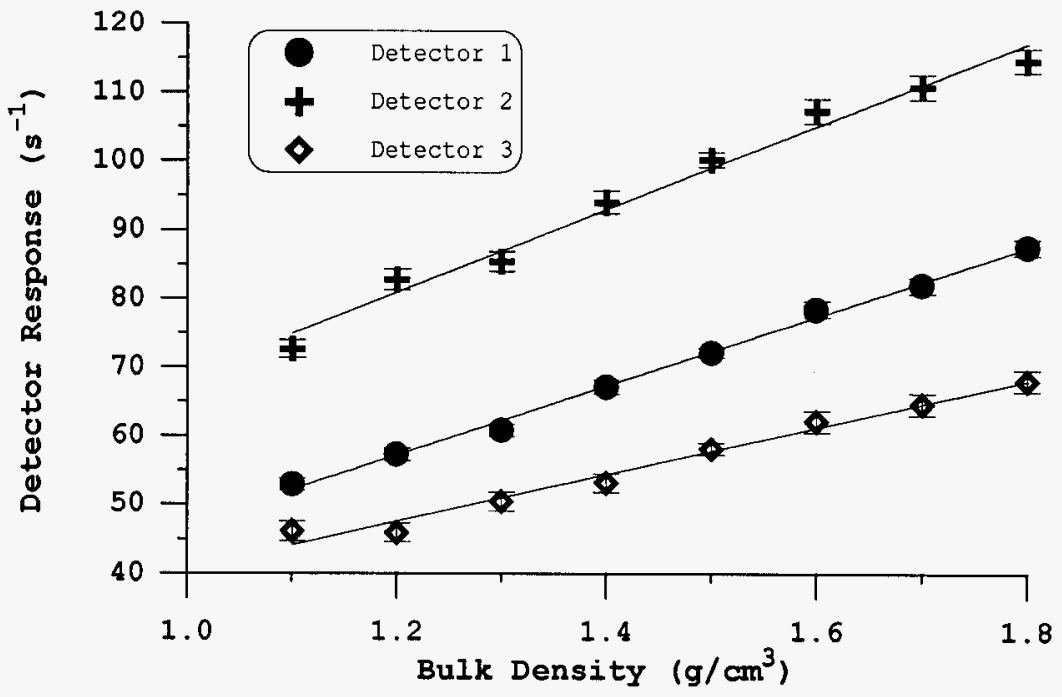

Figure 3-2. Simulant matrix moisture concentration as a function of model predicted detector responses (probe 3 ).

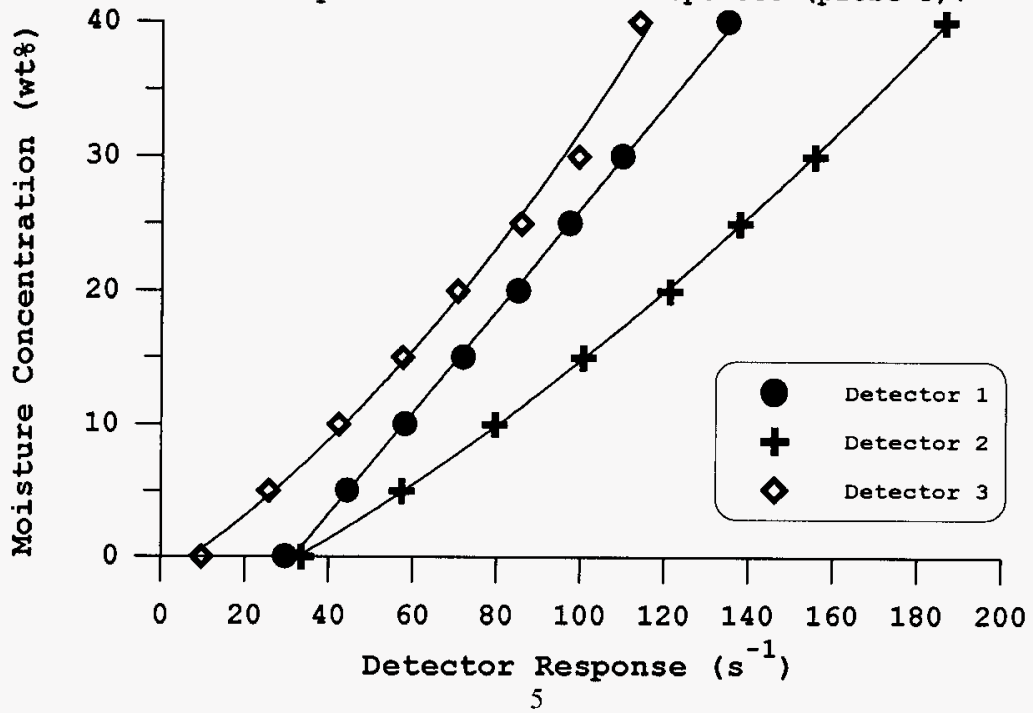


Figure 3-3. Model predicted detector responses as a function of organic concentration at 15 wto moisture concentration.

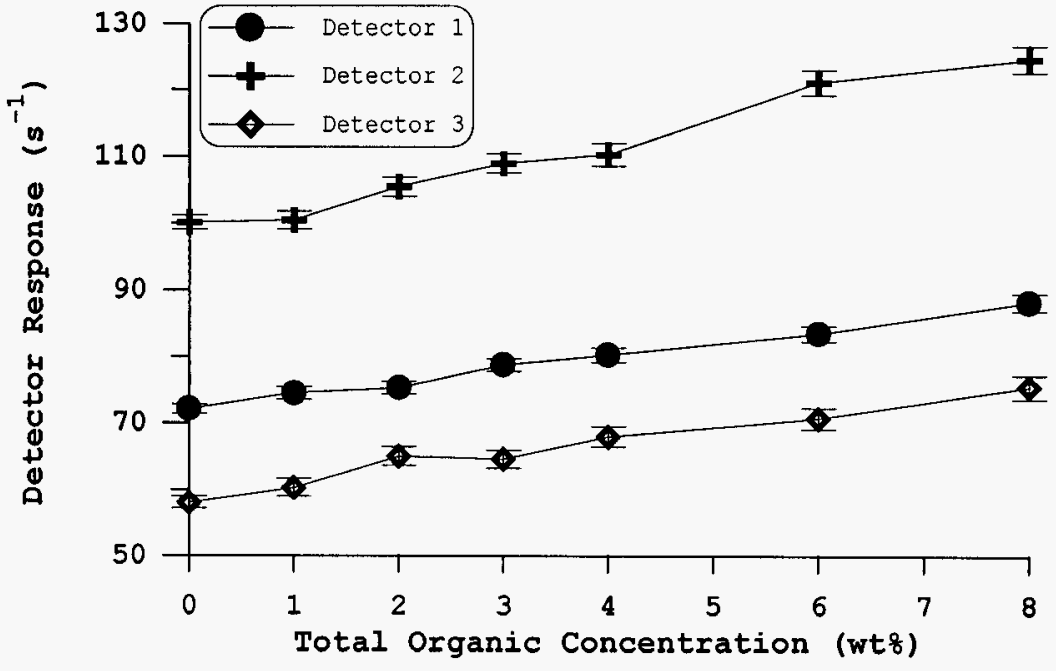

Figure 3-4. Apparent moisture concentration as a function 年 of organic concentration at actual 15 wto moisture.

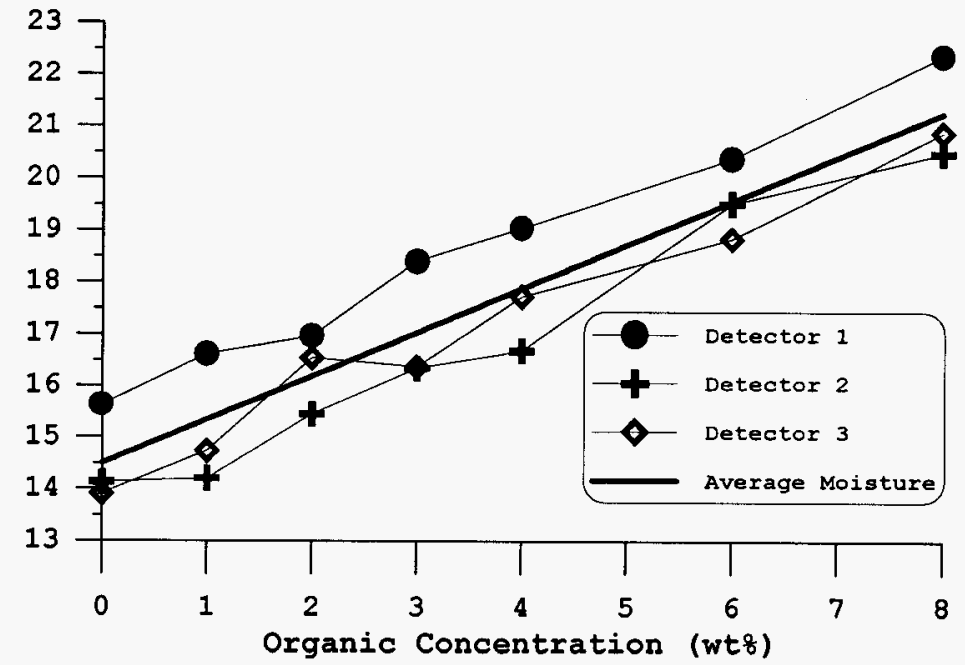




\subsection{STRONG THERMAL NEUTRON ABSORBERS}

Since the neutron probe detectors primarily detect thermal and epithermal neutrons, the presence of significant quantities of strong thermal neutron absorbers in the waste could reduce flux of the measurable portion of the neutron spectrum returning to the probe. Cadmium and or boron, two strong thermal neutron absorbers, are expected to be present in relatively low quantities in some of the tank wastes (WASTREN 1993). The response from detector 1 is expected to be nearly unaffected by the presence of strong thermal neutron absorbers in the waste. Detector 1 is shielded with thick layers of polyethylene and cadmium that adsorb nearly all thermal neutrons incident upon the probe.

Approximately 30 Hanford Site waste tanks, on a critical list for surface moisture inspection, were researched to determine the amount of neutron absorbing material within the tanks. Of these tanks, tank S-111 is expected to contain the greatest amount of neutronabsorbing material (WASTREN 1993). The neutron absorption properties of the waste in this tank are dominated by nitrogen and very small amounts of cadmium. Nitrogen is a weak thermal neutron absorber, but large concentrations of this element are present. Less than one-tenth of the neutron absorber concentration found in S-111 is expected for about $50 \%$ of the tanks, and less than about one-half of the $S-111$ absorber concentration is expected for $80 \%$ of the tanks. During the calibration of the neutron probe, two moisture standards were constructed that were spiked with boron concentrations typical of those that are expected in these tank wastes (Watson and Bussell 1996). One of these standards contained $0.0018 \mathrm{wt} \%$ boron and the other contained $0.0036 \mathrm{wt} \%$ boron uniformly mixed into the matrix. Both of the standards contained approximately $19 \mathrm{wt} \%$ moisture so that the response of the probe to these standards could be compared with one another and with the response to a $19 \mathrm{wt} \%$ moisture standard that contained no added boron. The bulk density of these standards varied slightly so that a correction was needed to directly compare the responses obtained from them. The bulk density of the standard without boron was $1.636 \pm .006 \mathrm{~g} / \mathrm{cm}^{3}$, while the density of the added boron standards was $1.601 \pm .005 \mathrm{~g} / \mathrm{cm}^{3}$ and $1.603 \pm .015 \mathrm{~g} / \mathrm{cm}^{3}$. Using the results from section 3.1 , a correction was applied to the experimentally measured responses from the added boron standards. In order to relate the observed changes in detector response to apparent changes in moisture concentration, relationships giving the responses as functions of moisture for each detector in each probe are needed. Data presented in Figures 5-6 through 5-14 of the calibration report (Watson and Bussell 1996) were used to derive such relationships by performing polynomial least-square fits to the experimental data measured on moisture standards 1-6. These six moisture standards contain uniform moisture in a range from about 4 to $35 \mathrm{wt} \%$ water. Using these moisture/detector response relationships the fractional differences in the measured moisture concentrations between the added boron standards and the control standard were determined and are presented in table 31.

For in-tank data interpretation, the best estimate waste compositions will be used to determine the moisture concentrations. This moisture interpretation could be corrected, if needed, given better available characterization data. The results in table 3-1 indicate that only small effects upon the moisture interpretation would be expected unless the concentration of strong thermal neutron absorbers near the waste surface was greatly underestimated. For 
example, if the surface waste contains $15 \mathrm{wt} \%$ moisture and contains strong neutron absorbers in quantities equivalent to the presence of an additional $0.0018 \mathrm{wt} \%$ boron, then the moisture concentrations predicted by detectors 1 through 3 would be about $14.9,14.5$ and $13.6 \mathrm{wt} \%$, respectively. The average error, in this example, is only $0.7 \mathrm{wt} \%$ moisture. Detectors 1,2 , and 3 are designed to investigate different average depths into the underlying waste with detector 1 investigating the shallowest and detector 3 the deepest. Because detectors 1 and 2 are less affected by the presence of absorbers, the interpretation of data taken in a region with unexpectedly high concentrations of neutron absorbers will be that the moisture concentration decreases with depth in the waste. Primarily because of gravity induced liquid drainage, the waste, in general, is not expected to contain less moisture with increasing depth. If the data interpretation indicates that the waste has a moist layer above a more dry layer, the presence of an increased concentration of strong thermal neutron absorbers will be suspected. While there is no simple way to confirm this suspicion, the data can be reanalyzed not considering the data from detector 3, whose response is most affected by the absorbers. The moisture analyses would likely contain both results as possible interpretations.

Table 3-1. Average estimated fractional change in the moisture measurement for each detector using the boron containing moisture standards.

\begin{tabular}{|l|c|c|}
\hline \multirow{2}{*}{} & \multicolumn{2}{|c|}{ Fractional Error Introduced into Moisture Concentration } \\
\cline { 2 - 3 } & $0.0018 \mathrm{wt} \%$ Boron & $0.0036 \mathrm{wt} \%$ Boron \\
\hline Detector 1 & -0.0045 & -0.035 \\
\hline Detector 2 & -0.033 & -0.095 \\
\hline Detector 3 & -0.093 & -0.12 \\
\hline
\end{tabular}

\subsection{PHYSICAL GEOMETRIC WASTE ARRANGEMENT}

The in-tank waste surface will, in general, be irregular in shape. However, because the wastes were substantially liquid at one time, the waste surface is expected to have some small areas where the surface is somewhat flat. Because the SMMS neutron probe will be deployed with an in-tank camera, operations will be able to visually select the probe measurement locations. The SMMS deployment arm allows the probe to be placed anywhere within a $1.8 \mathrm{~m}$ radius of the deployment riser centerline. The information in this section will be used by scientists to provide guidance in selecting the best measurement locations where the probe signals are likely to be least affected by the waste geometry and arrangement.

While an almost infinite number of possible variations in the waste surface may be encountered, we have consolidated these variations into a few major categories. In these major categories of possible waste variations, only a few, relatively simple examples have been evaluated here. These simple cases should be representative of more complicated, but similar, types of waste arrangements expected in the waste tank. 
These scenarios were evaluated both by making some experimental measurements and/or by performing MCNP calculations to determine the effects of the geometry variations. The experimental arrangements all utilized the same moisture standard filled with a mixture of silica sand and hydrate alumina containing $19.1 \mathrm{wt} \%$ water uniformly distributed throughout and chemically bound to the mixture. A thin aluminum lid, which had been sealed on top of the moisture standard after it was constructed, was removed for these anomaly experiments. For the experimental measurements, the responses from each detector are compared with those obtained when no material anomaly was present. The difference in the response rate is then related to the moisture error introduced by the anomaly. This error is calculated using linear least-square fit equations produced from the final moisture calibration data for probe 2, found in figures 5-16,517 , and 5-18 of the calibration report (Watson and Bussell 1996). These simple linear relationships provide constants of proportionality, listed in Table 3-2, between the change in detector response and the change in moisture interpretation for each detector. These same constants are applicable for converting the changes in MCNP predicted detector responses to the these same anomalies for the experimentally measured configurations. For some cases only a model prediction of the expected magnitude of the effect is available. This modeling work was completed prior to the completion of the probe calibration and used a slightly different model of the SMMS neutron probe. This model also utilized best estimate salt cake waste composition rather than moisture standard simulant for the material matrix and modeled a larger volume of waste matrix. The trends and results from these calculations should be accurate predictions of the effects of these anomalies, but these results require different constants (provided in Table 3-3) to obtain estimates of the effects upon the moisture measurement.

Table 3-2. The constants used to convert experimental changes in detector responses to estimate moisture errors for each detector. These constants are also applied to computer model prediction of the experimental arrangements.

\begin{tabular}{|c|c|}
\hline \multirow{2}{*}{ Detector } & $\frac{\Delta \text { Moisture }}{\text { DDetector Response }}($ wt $\%-s)$ \\
\hline 1 & 0.27 \\
\hline 2 & 0.20 \\
\hline 3 & 0.33 \\
\hline
\end{tabular}


Table 3-3. The constants used to convert computer modeled (older probe model) changes in detector responses to estimate moisture errors for each detector.

\begin{tabular}{|c|c|}
\hline \multirow{2}{*}{ Detector } & $\frac{\Delta \text { Moisture }}{\text { DDetector Response }}(w t \%-s)$ \\
\hline 1 & 0.32 \\
\hline 2 & 0.20 \\
\hline 3 & 0.14 \\
\hline
\end{tabular}

\subsubsection{Surface Cracks}

The surface of the waste may have large or small cracks or air-filled gaps. Many small cracks in the surface are expected to effect the probe response much like that predicted for a reduced bulk density of the waste (section 3.1). Large cracks, on the order of several centimeters or larger, will be readiliy visible and may be avoided or will cause effects similar to those discussed in section 3.4.2. Here we investigate cracks with widths in the range from about 0.3 to $1 \mathrm{~cm}$.

One experimental arrangement was used to obtain an estimate of the effects of multiple cracks directly beneath the probe. Three aluminum slats $(30.5 \times 0.32 \times 5.1 \mathrm{~cm})$ were placed in the moisture matrix spaced about $2.8 \mathrm{~cm}$ apart and level with the matrix surface. The aluminum excludes the moisture containing matrix from the volume it occupies and provides very little perturbation of the matrix moderation properties. The slats were oriented to simulate vertical surface cracks $0.32 \mathrm{~cm}$ wide and $5.1 \mathrm{~cm}$ deep. The probe was placed in the center of the slats as sketched in figure 3-5. The experimental data was processed using the Curvecut code (Version 1.0) to produce detector count rates that are included in Appendix A (Finfrock 1996). Based upon the differences in these count rates from those obtained without th anomaly, the estimated experiment-based moisture measurement error was:

$$
\begin{array}{ll}
\text { detector 1 } & \Delta M=-1.1 \mathrm{wt} \% \\
\text { detector } 2 & \Delta M=-1.8 \mathrm{wt} \% \\
\text { detector } 3 & \Delta M=-3.0 \mathrm{wt} \%
\end{array}
$$

while the computer model predicted moisture measurement error for this arrangement was:

$$
\begin{aligned}
& \text { detector } 1 \quad \Delta M=-2.6 w t \% \\
& \text { detector } 2 \Delta M=-2.2 w t \% \\
& \text { detector } 3 \Delta M=-0.8 w t \%
\end{aligned}
$$

As expected, multiple small cracks beneth the probe will lower the probe moisture prediction by a couple of weight percent, much like a small reduction in the overal bulk density of the waste. 
In addition to this single experimental arrangement, computer modeling of several arrangements of a single but wider crack was completed. The crack $(1 \mathrm{~cm}$ wide) was located either under the probe source or under detector 1 and crack depths of both 5 and $10 \mathrm{~cm}$ were used. Figure 3-6 shows a diagram of the modeled arrangements. For all of these modeled arrangements the length of the crack was essentially infinite and the crack was filled with air. The waste matrix was modeled containing $10 \mathrm{wt} \%$ moisture. The results of this modeling, summarized in table 3-4, indicated that a single, medium sized crack in the waste surface under the probe is expected to cause the moisture measurement to have an negative error of about 1 wt\%.

Table 3-4. Summary of modeled predicted moisture measurement error for a $1 \mathrm{~cm}$ wide air crack under the probe for two crack locations and two crack depths.

\begin{tabular}{|c|c|c|c|c|}
\hline \multirow{3}{*}{ Detector } & \multicolumn{2}{|c|}{ Crack Under Detector 1} & \multicolumn{2}{c|}{ Crack Under Neutron Source } \\
\cline { 2 - 5 } & Depth: $5 \mathrm{~cm}$ & Depth: $10 \mathrm{~cm}$ & Depth: $5 \mathrm{~cm}$ & Depth: $10 \mathrm{~cm}$ \\
\cline { 2 - 5 } & $\Delta \mathrm{M}(\mathrm{wt} \%)$ & $\Delta \mathrm{M}(\mathrm{wt} \%)$ & $\Delta \mathrm{M}(\mathrm{wt} \%)$ & $\Delta \mathrm{M}(\mathrm{wt} \%)$ \\
\hline 1 & -0.5 & -0.8 & -0.8 & -0.9 \\
\hline 2 & -0.1 & -0.1 & -0.3 & -0.3 \\
\hline 3 & -0.3 & -0.4 & 0.0 & -0.1 \\
\hline
\end{tabular}

\subsubsection{Large Holes}

In addition to smaller cracks, the waste surface is expected to have some locations with larger holes or wider, deeper depressions. Such holes are expected to be visually identified and avoided. Experimental tests and computer modeling were performed to obtain estimates of how far the probe should be placed from holes of different sizes so that the detector signals are no longer significantly affected.

The experimental arrangements utilized rectangular aluminum baking pans to form a hole in the moisture matrix next to the probe. One or two of these baking pans were inserted into the moisture matrix level with the surface and the standard was mechanically vibrated to recompact the matrix around the pan. The vibration technique was similar to that used to assemble all moisture standards as described in the calibration report (Watson and Bussell 1996). The pans were about $23 \mathrm{~cm}$ long, $12 \mathrm{~cm}$ wide, and $6.6 \mathrm{~cm}$ high with a wall thickness of about $0.06 \mathrm{~cm}$. The width and length of the pans was slightly tapered toward the base. For the first arrangement, a 
Figure 3-5. Sketch of the experimental multiple surface crack simulation arrangment (top and side views).
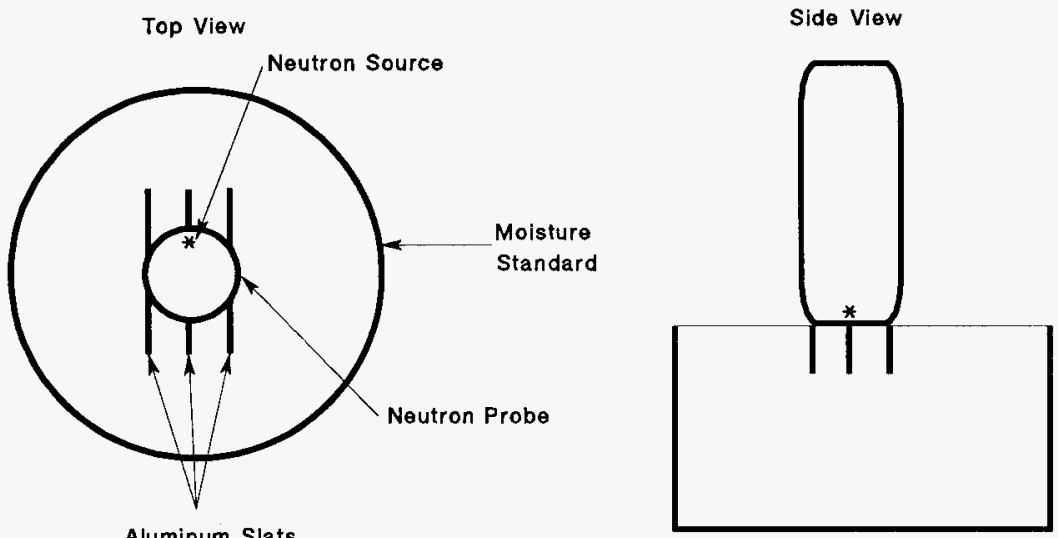

Figure 3-6. Sketch of two modeled surface crack arrangements (side views).

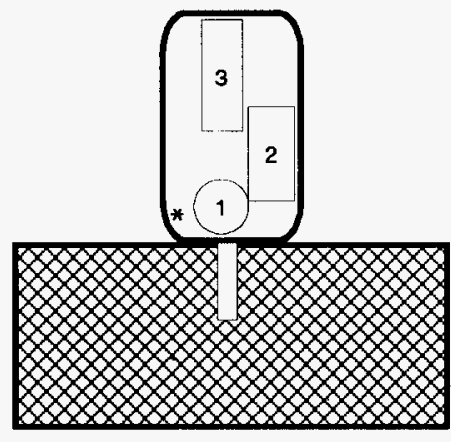

Crack Under Detector 1

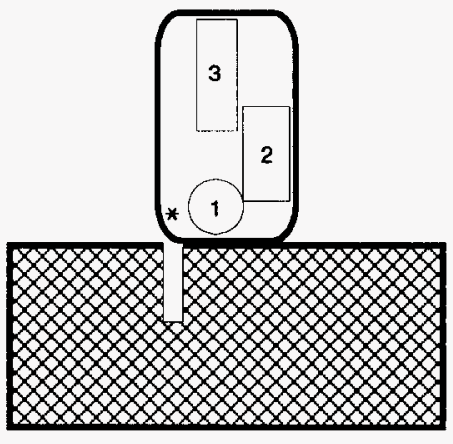

Crack Under Source 
single pan was submerged at a location near the center of the standard so that when the probe was centered on the standard its outer casing would be tangent to the side of the long axis of the pan. The probe was rotated to place the neutron source opposite the side tangent to the pan. For the second experimental arrangement, two pans were inserted in the waste, end to end, so that the probe would be tangent to their edge at the ends where the pans touched. Figure 3-7 shows a diagram of the two experimental arrangements. The estimated experiment-based moisture measurement errors and computer model predicted moisture measurement errors for these two arrangements are compared in Table 3-5. In general, the experimental results indicate that the response of detector 3 is most affected by the large hole very close to the probe, while the response of detector 1 has not been significantly affected.

Table 3-5. Comparison of the experimental and model predicted moisture measurement errors resulting from the two experimental surface hole arrangements.

\begin{tabular}{|c|c|c|c|c|}
\hline \multirow{2}{*}{ Detector } & \multicolumn{2}{|c|}{ Single Pan Hole } & \multicolumn{2}{c|}{ Double Pan Hole } \\
\cline { 2 - 5 } & Experiment $\Delta \mathrm{M}(\mathrm{wt} \%)$ & Model $\Delta \mathrm{M}(\mathrm{wt} \%)$ & Experiment $\Delta \mathrm{M}(\mathrm{w} t \%)$ & Model $\Delta \mathrm{M}(\mathrm{wt} \%)$ \\
\hline 1 & 0.3 & -2.0 & -1.1 & -2.1 \\
\hline 2 & -2.6 & -3.7 & -3.8 & -5.4 \\
\hline 3 & -5.0 & -2.4 & -6.9 & -3.2 \\
\hline
\end{tabular}

The effects of similar large holes more distant from the probe were investigated by computer simulation for waste containing $10 \mathrm{wt} \%$ moisture. Rectangular holes or canyons were modeled both 20 and $40 \mathrm{~cm}$ away from the probe. The canyons were $10 \mathrm{~cm}$ deep and $10 \mathrm{~cm}$ wide with a length of either $50 \mathrm{~cm}$ or $10 \mathrm{~cm}$. The computer model predicted moisture measurement errors for these arrangements are summarized in Table $3-6$. A $50 \mathrm{~cm}$ long hole that is $40 \mathrm{~cm}$ away from the probe is not expected to be detectable, while the same sized hole $20 \mathrm{~cm}$ from the probe will perturb the overall moisture measurement by only about $1 \mathrm{wt} \%$. It appears that about a $20 \mathrm{~cm}$ or greater spacing is desired between the probe and large surface holes to minimize the effects upon the moisture measurement. Shorter spacings will cause the probe, primarily detector 3 , to underestimate the waste moisture. 
Figure 3-7. Sketches of Experimental Hole Arrangements.

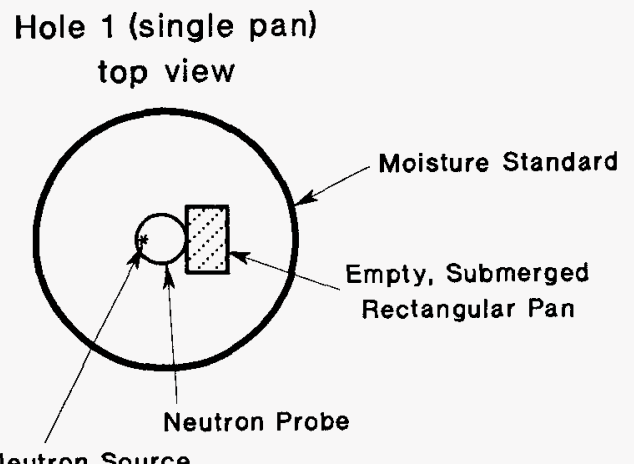

Hole 2 (double pan)

Neutron Source

Hole 1 (side view)

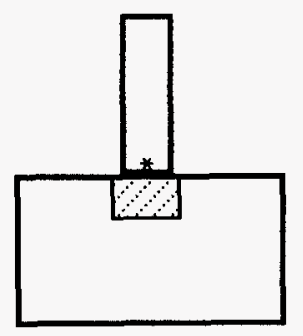

Hole 2 (side view)

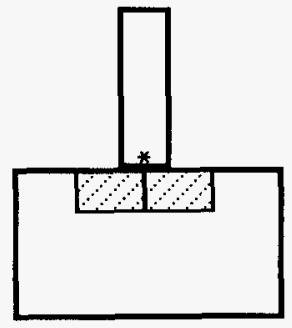


Table 3-6. Summary of computer model predictions of moisture measurement error caused by large surface hole located far from the probe.

\begin{tabular}{|c|c|c|c|}
\hline \multirow{2}{*}{ Detector } & $20 \mathrm{~cm}$ away, $10 \mathrm{~cm}$ long & $20 \mathrm{~cm}$ away, $50 \mathrm{~cm}$ long & $40 \mathrm{~cm}$ away, $50 \mathrm{~cm}$ long \\
\cline { 2 - 4 } & $\Delta \mathrm{M}(\mathrm{wt} \%)$ & $\Delta \mathrm{M}(\mathrm{wt} \%)$ & $\Delta \mathrm{M}(\mathrm{wt} \%)$ \\
\hline 1 & -0.1 & -0.3 & 0.0 \\
\hline 2 & -0.1 & -0.4 & 0.0 \\
\hline 3 & -0.1 & -1.4 & 0.0 \\
\hline
\end{tabular}

\subsubsection{Hills or Protrusions Above Surrounding Waste Level}

The settling of the waste as the liquids were removed from many tanks caused the waste surface to buckle or slump in various locations, leaving hills or waste protusions above the general level of the waste surface. Experimental arrangements were devised to determine the spacing required between the probe and different sized hills to nearly eliminate the effects of these hills upon the moisture measurement.

The hills were experimentally arranged by filling rectangular aluminum pans, identical to those used in the surface hole tests, with $19 \mathrm{wt} \%$ moisture simulant. The volume of each pan was measured by weighing the water required to completely fill each pan. The weight of simulant added to each pan was measured so that the bulk density of the contents of each pan could be determined. The probe was placed at the center of the moisture standard and one or more pan filled with simulant were placed at a given distance from the probe and oriented so that the long side of the pan was parrellel to a line tangent to the nearest point on the probe housing. Measurements were taken for six different arrangements of 1,2, or 4 simulant-filled pans, shown in figure 3-8. Comparisons of the experimental and computer modeled moisture errors introduced by these hill arrangements for each detector are summarized in table 3-7. In general, the measured and modeled results are in agreement. The modeled results for the change in response of detectors 2 and 3 to the hill 6 arrangement are the only results that are beyond acceptable agreement. Given the experimental increase in detector responses between hill 3 and hill 5 , one would have expected the measured responses from hill 6 (additional filled pans at the same distance from the probe) to have been greater. The lack of agreement is likely from some experimental anomaly that might be corrected by repeating the measurement. The overall results seem to indicate that for a small hill (single pan) the probe should be placed about $20 \mathrm{~cm}$ or more from the hill to reduce the moisture measurement error below $1 \mathrm{wt} \%$. It is expected that for larger hills (equivalent to 2 or more pans) the probe will need to be placed $30-40 \mathrm{~cm}$ from these hills to reduce the effect upon all detector responses below about $1 \mathrm{wt} \%$. To confirm this expectation, the probe responses to a large rectangular hill $(10 \mathrm{~cm} \mathrm{high,} 10 \mathrm{~cm}$ wide, $50 \mathrm{~cm}$ long) 
WHC-SD-WM-TI-786, Rev. 0

Figure 3-8. Sketches of Experimental Hill Arrangements.

Hill 1

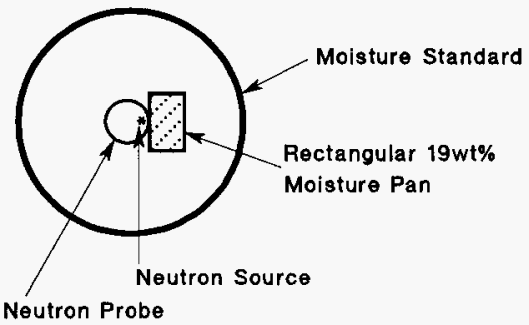

Hill 3

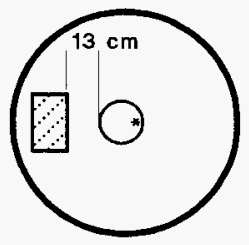

Hill 5

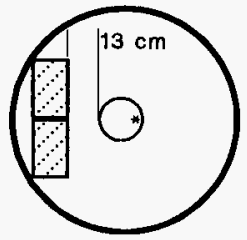

Hill 6

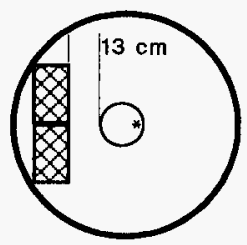

Hill 2

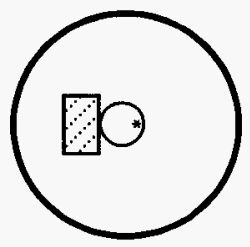

Hill 4

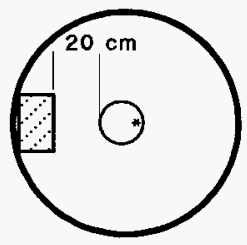

Hill 6 (side view)

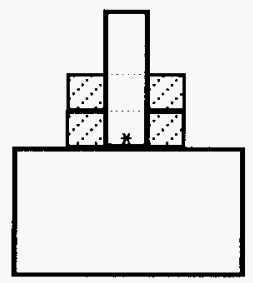


placed $40 \mathrm{~cm}$ from the probe were computer modeled for $10 \mathrm{wt} \%$ moisture throughout the waste matrix. For this arrangement the predicted detector moisture errors were $0.9 \mathrm{wt} \%$ (detector 1 ), $0.9 \mathrm{wt} \%$ (detector 2), and $0.5 \mathrm{wt} \%$ (detector 3 ). Hills are usually expected to affect the response of the detector 3 the greatest.

Table 3-7. Summary of the experimental and model predicted detector moisture measurement errors obtained for six experimental hill arrangements (see figure 3-8).

\begin{tabular}{|l|c|c|c|c|c|c|}
\hline \multirow{2}{*}{ Arrangement Description (Hill Number) } & \multicolumn{3}{|c|}{ Experiment $\Delta \mathrm{M}(\mathrm{wt} \%)$} & \multicolumn{3}{|c|}{ Model $\Delta \mathrm{M}(\mathrm{wt} \%)$} \\
\cline { 2 - 8 } & 1 & 2 & 3 & 1 & 2 & 3 \\
\hline pan next to probe on source side (1) & 10.1 & 12.6 & 25.6 & 15.8 & 18.3 & 29.3 \\
\hline pan next to probe, side opposite source (2) & 3.1 & 20.6 & 10.4 & 5.7 & 27.2 & 12.7 \\
\hline pan $13 \mathrm{~cm}$ from probe, side opposite source (3) & 0.1 & 1.8 & 2.8 & 0.3 & 2.2 & 2.6 \\
\hline pan $20 \mathrm{~cm}$ from probe, side opposite source (4) & 0.7 & 0.6 & 0.8 & 0.1 & 0.4 & 1.0 \\
\hline 2 pans $13 \mathrm{~cm}$ from probe, opposite source (5) & 1.2 & 4.8 & 6.1 & 0.4 & 2.8 & 4.2 \\
\hline 4 pans $13 \mathrm{~cm}$ from probe, opposite source (6) & 0.4 & 2.0 & 1.8 & 1.0 & 6.0 & 9.1 \\
\hline
\end{tabular}

\subsubsection{Dished Depressions}

Large scale or small scale depressions in the waste surface or areas where the waste has slumped slightly below the general surrounding waste level will affect the probe detector responses. The effects of large scale depressions were investigated with experimental measurements. The effects of shallow, small scale (about the diameter of the probe) depressions were only investigated using computer modeling.

Large scale depressions were experimentally arranged using different diameter cylindrical aluminum pans that were inserted below the level of the moisture matrix. The pan inner diamters were $15.2,20.3$, and $25.4 \mathrm{~cm}$ and the wall thickness of each was $0.06 \mathrm{~cm}$. Each pan was inserted about $1.9 \mathrm{~cm}$ into the matrix at the center of the moisture standard and then the probe was placed inside the pan at its center. These arrangements essentially placed the probe at the center of shallow, cylindrical depressions in the matrix surface. With the probe more fully surrounded by the moisture matrix, the detector responses were expected to increase. Table 3-8 summarizes the experimental and computer model predicted error in the moisture from these arrangements. The results show that placing the probe in a large depression with diameter less than about $40 \mathrm{~cm}$ will have siginificant effects upon the probe responses, especially detectors 2 and 3. This arrangement is similar to completely surrounding the probe with a small height hill. Very large diameter surface depressions or very shallow surface depressions are expected to cause little perturbation upon the moisture measurement. 
Table 3-8. Summary of the experimental and model predicted detector moisture measurement errors obtained for the three cylindrical pan depression arrangements.

\begin{tabular}{|c|c|c|c|c|c|c|}
\hline \multirow{2}{*}{$\begin{array}{c}\text { Cylindrical Pan } \\
\text { Inner Diameter }(\mathrm{cm})\end{array}$} & \multicolumn{3}{|c|}{ Experiment $\Delta \mathrm{M}(\mathrm{wt} \%)$} & \multicolumn{3}{c|}{ Model $\Delta \mathrm{M}(\mathrm{wt} \%)$} \\
\cline { 2 - 7 } & 1 & 2 & 3 & 1 & 2 & 3 \\
\hline 15.2 & 3.2 & 10 & 23 & 4 & 9.6 & 17 \\
\hline 20.3 & 0.8 & 6.4 & 21 & 2.3 & 6.9 & 15 \\
\hline 25.4 & -2.2 & 4.0 & 25 & 1.1 & 4.2 & 12 \\
\hline
\end{tabular}

Small scale depressions in the surface that might exist under the probe but be too small to allow the probe to fit inside the depression were computer simulated. The two arrangements were modeled: a spherical shaped dished depression with surface diameter equal to the probe diameter and maximum depth equal to $1.27 \mathrm{~cm}$, and a cylindrical depression with side equal to the probe diameter and with a depth of $1.27 \mathrm{~cm}$. For both arrangements, sketched in figure 3-9, the probe was modeled directly over, but not submerged into the depressions. These arrangements are similar to having large cracks beneath the probe and were expected to result in negative moisture errors. The computer model predicted moisture measurement errors from these arrangements are summarized in table 3-9. Detector 1 is most affected by shallow depressions beneath the probe because it is designed to investigate the smallest volume and shortest depth into the underlying medium. Small shallow depressions directly under the probe are not expected to have a significant effect upon the overall probe moisture measurement.

Table 3-9. Summary of the model predicted detector moisture measurement errors obtained for the small surface depression arrangements.

\begin{tabular}{|l|c|c|c|}
\hline \multirow{2}{*}{ Arrangement Description } & \multicolumn{3}{|c|}{ Model $\Delta \mathrm{M}(\mathrm{wt} \%)$} \\
\cline { 2 - 4 } & 1 & 2 & 3 \\
\hline Spherical dished depression $1.27 \mathrm{~cm}$ deep & -1.5 & -0.4 & -0.2 \\
\hline Cylindrical depression $1.27 \mathrm{~cm}$ deep & -1.7 & -0.6 & -0.1 \\
\hline
\end{tabular}


Figure 3-9. Sketch of two modeled small surface depressions underneath the probe (side views).

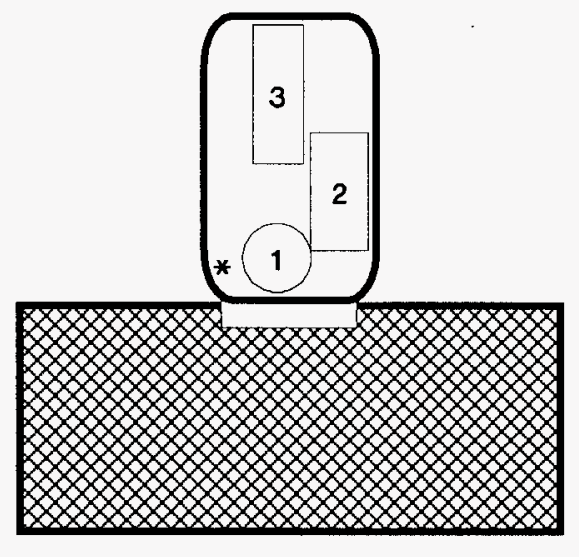

Cylindrical Depression Under Probe

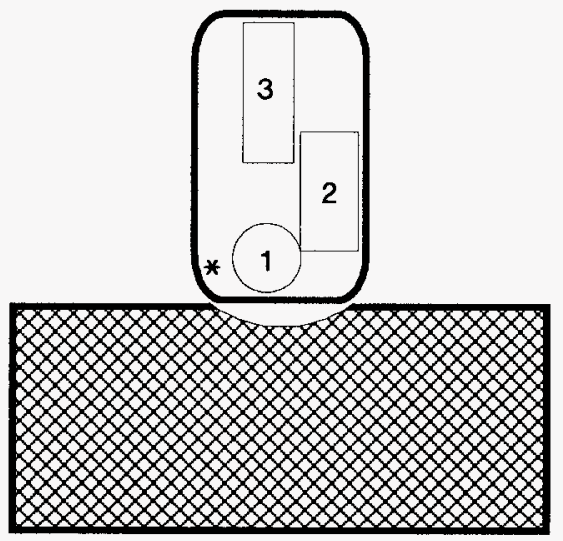

Dished Depression Under Probe 


\subsubsection{Irregular Surface}

The surface of the waste is irregular to some degree in most areas. Even if no large hills or canyons are present, there is likely to be some variation or roughness to the surface. In an effort to quantify the probes sensitivity to this irregularity a computer model was constructed with alternating bands of higher and lower surfaces. The area under the probe, and in a surrounding $5.0 \mathrm{~cm}$ wide annulus, was level. This was surrounded by an annulus $5.0 \mathrm{~cm}$ wide and $2.54 \mathrm{~cm}$ high filled with waste. There followed another $5.0 \mathrm{~cm}$ annulus of level surface and then another waste annulus. The results of this calculation are shown in Table 3-10.

Table 3-10. Summary of the model predicted detector moisture measurement errors obtained for the irregular surface arrangements.

\begin{tabular}{|l|c|c|c|}
\hline \multirow{2}{*}{ Arrangement Description } & \multicolumn{3}{|c|}{ Model $\Delta \mathrm{M}(\mathrm{wt} \%)$} \\
\cline { 2 - 4 } & 1 & 2 & 3 \\
\hline Alternating annuli of waste, $2.54 \mathrm{~cm}$ high & 2.6 & 3.0 & 4.0 \\
\hline
\end{tabular}

\subsubsection{Waste Surface to Probe Suspension or Submersion}

The probe will be lowered to the surface by a cable on the SMMS deployment system. Although the waste surface is expected to often be firm enough to support the probe, if the surface yields under the probe weight, the deployment operator will need to attempt to raise the probe so that its bottom is even with and just touching the waste surface. Horizontal stripes have been painted on the probe base to visually facilitate this operation. It is possible that the probe may be slightly submerged below the level of the waste or even slightly suspended above the waste level during this positioning. Although it is expected that the probe can be positioned within a very small distance (less than $0.5 \mathrm{~cm}$ ) of the waste surface, the effects of probe standoff and submersion were investigated by experimental arrangements and or modeling.

Both experimental measuremnts and modeling were performed to assess the effects of standoff (probe suspension above the surface) upon probe responses. The probe is placed upon the simulant surface using an aluminum deployment stand. This stand grasps the probe from its top using an arm that has a pivot. The arm can be used to raise or lower the probe to a fixed height in relationship to the simulant surface. Measurements were taken with the probe resting on the moisture simulant surface and with the probe suspended $1.3,2.5$, and $3.8 \mathrm{~cm}$ above the surface. Table 3-10 summarizes the moisture errors for the experimental standoff arrangements and computer predictions of the errors for those arrangements. For the large measured standoff distances the effect upon probe responses is significant. 
Table 3-10. Summary of the experimental and model predicted detector moisture measurement errors obtained for probe standoff arrangements.

\begin{tabular}{|c|c|c|c|c|c|c|}
\hline \multirow{2}{*}{$\begin{array}{l}\text { Probe Distance } \\
\text { Above Matrix }(\mathrm{cm})\end{array}$} & \multicolumn{3}{|c|}{ Experiment $\Delta \mathrm{M}(\mathrm{wt} \%)$} & \multicolumn{3}{c|}{ Model $\Delta \mathrm{M}(\mathrm{wt} \%)$} \\
\cline { 2 - 7 } & 1 & 2 & 3 & 1 & 2 & 3 \\
\hline 1.3 & -6.8 & -7.8 & -9.6 & -6.4 & -6.3 & -6.7 \\
\hline 2.5 & -11 & -12 & -16 & -8.9 & -10 & -12 \\
\hline 3.8 & -14 & -15 & -21 & -11 & -13 & -14 \\
\hline
\end{tabular}

The computer modeling of the experimental liftoff arrangements was extended to predict the moisture measurement errors as a function of probe submersion in the $19 \mathrm{wt} \%$ moisture matrix. Figure 3-10 shows the model predicted moisture error as a function of probe height above (or below) the moisture matrix surface. The modeled response data for each detetector was fitted by a polynomial using the least-square method. Realistic standoff or submersion distances are expected to be very small because of the quality camera surveillance system used to deploy the probe. Table 3-11 provides the model predicted moisture measurement error for small standoff and submersion distances calculated using the polynomial fits shown in figure 3-10. Except for detector 1, slight standoffs seem to perturb the moisture signals less than equal distance submersions of the probe. The overall moisture error is expected to be lower if the probe is slightly above the surface than if it is slightly submerged below the surface.

Table 3-11. Model predicted detector moisture measurement errors obtained for realistic probe standoff and submersion distances. (Calculated from polynomial fit to modeled data, Figure 3-10)

\begin{tabular}{|c|c|c|c|}
\hline \multirow{2}{*}{$\begin{array}{c}\text { Probe Distance } \\
\text { Above Matrix }(\mathrm{cm})\end{array}$} & \multicolumn{3}{|c|}{ Detector Moisture Errors $\Delta \mathrm{M}(\mathrm{wt} \%)$} \\
\cline { 2 - 4 } & Detector 1 & Detector 2 & Detector 3 \\
\hline 0.3 & -1.9 & -1.6 & -1.6 \\
\hline 0.2 & -1.4 & -1.0 & -0.8 \\
\hline 0.1 & -1.0 & -0.3 & 0.0 \\
\hline-0.1 & -0.1 & 1.0 & 1.8 \\
\hline-0.2 & 0.4 & 1.6 & 2.7 \\
\hline-0.3 & 0.8 & 2.3 & 3.8 \\
\hline
\end{tabular}


Figure 3-10. Estimated moisture error from model predicted detector responses to changes in the probe distance relative to the moisture matrix surface. (polynomial curve fits are plotted)

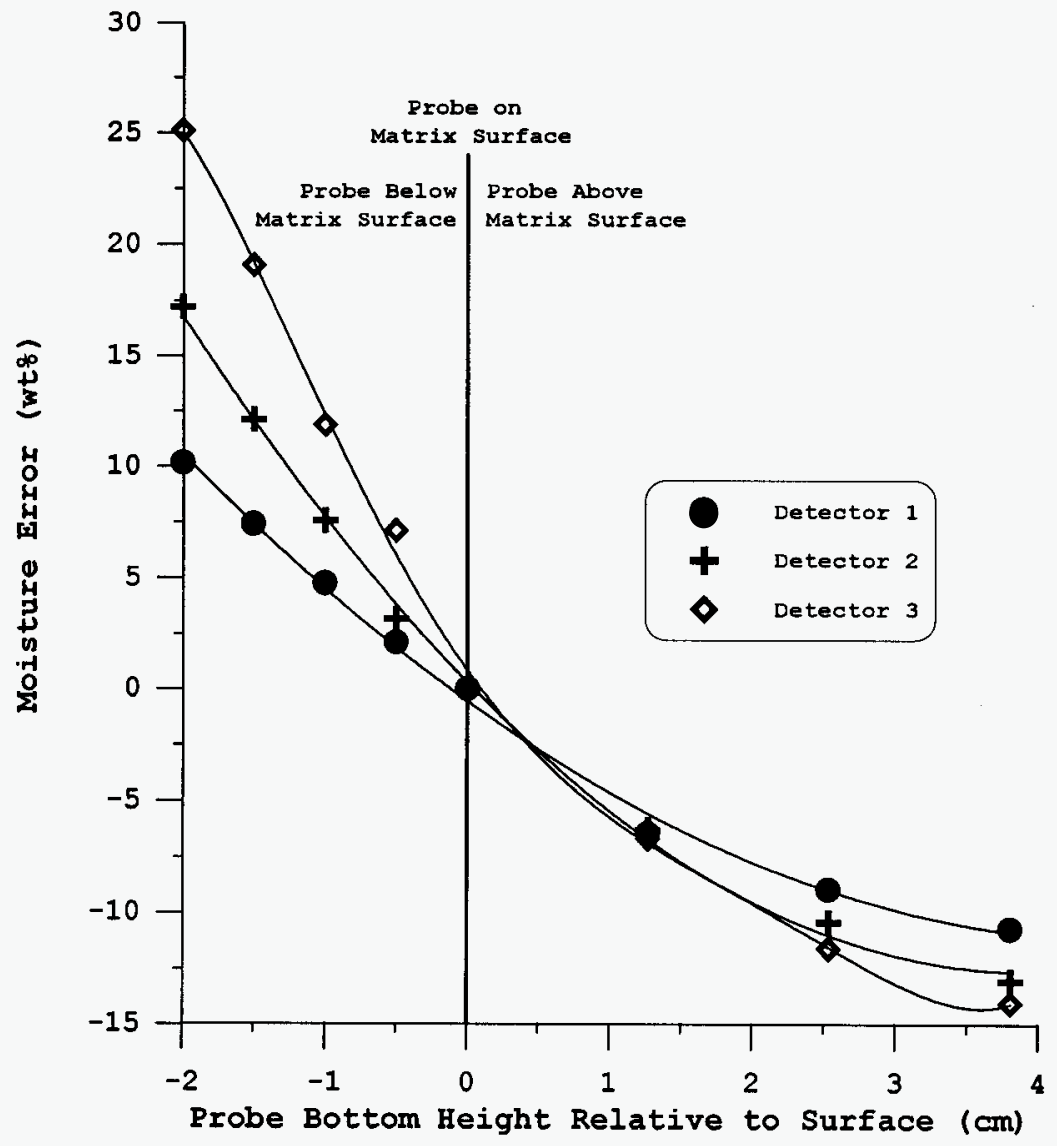




\subsubsection{Probe Tilt}

The surface of the tank waste is not always level. Because the probe is deployed from a hanging cable, the probe will tilt so that the base of the probe may be parallel to the waste surface at the deployment location. If the surface is far from level (greater than about $10^{\circ}$ ), then the deployment operator will likely need to adjust the probe height, thereby adjusting the angle that the probe bottom makes with the waste surface. Because the deploment camera only has one view of the probe it is difficult to visually confirm that the probe bottom is parallel to an inclined surface. Deployment tests with a probe on irregular surfaces inclined between 5 and 30 degrees demonstrated that the probe would be placed, on average, about 2 degrees from and almost always less than 5 degrees from perpendicular to the surface (Ritter 1996). These tests were performed using the actual deployment system, probe, and by only viewing the probe placement from the deployment camera video monitors.

Experimental tests were performed to determine the effect of probe inclination with respect to the matrix surface upon moisture measurement error. The probe placement fixure was used to hold the probe at a given angle with respect to the simulant surface and a digital inclinometer, attached to the side of the probe housing, was used to measure the angle of inclination. The angle of inclination of the probe housing was measured to be 89.8 degrees when the probe rested flat upon the matrix surface. For the measurements, the probe was tilted about an axis parallel to the longitudinal axis of detector 1 so that for positive tilt angles the portion of the probe below the neutron source remained in contact with the surface. Figure 3-11 shows a graph of the predicted detector moisture measurement errors as a function of the angle between the probe base and the matrix surface. For tilt angles less than or equal to about 2 degrees, the moisture measurement error for all detectors will likely be below $1 \mathrm{wt} \%$. For tilt angles between 2 and 5 degrees, the expected moisture measurement error rises to between 1 and $3 \mathrm{wt} \%$ for the different detectors.

\subsection{MOISTURE DISTRIBUTION}

It is expected that the moisture will not necessarily be uniformly distributed throughout the volumes investigated by the probe detectors. Gravitational and capillary forces and surface air exposure make it likely that the moisture concentration of the waste will increase as a function of depth in the waste. Because no validated model of the moisture concentration currently exists, we plan to assume that the moisture concentration as a function of depth is a zero or positive linear gradient near the waste surface. This assumption allows us to obtain computer model predictions of the detector responses as a function of moisture gradient for boundary surface moistures ranging from 0 to at least $40 \mathrm{wt} \%$. 
Figure 3-11. Experimentally determined moisture measurement error as a function of the angle between the probe base and matrix surface.

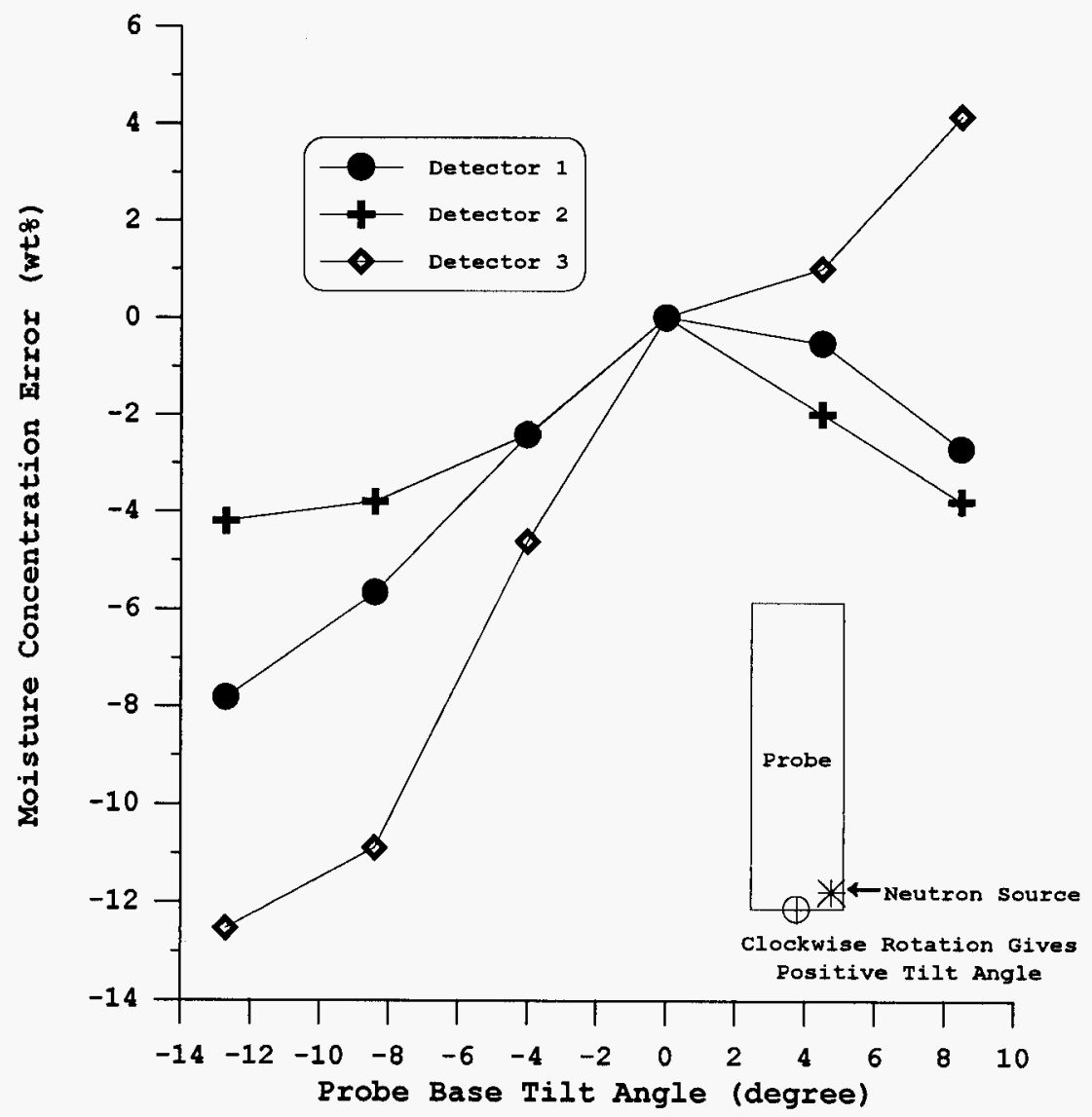


The assumption of a linear moisture gradient will introduce uncertainty into the moisture interpretation of the data. This uncertainty will primarily come from how the shape of the moisture gradient differs from linear. A computer code, TMAD, has been developed that will aid scientists in determining the surface moisture concentration and moisture gradient from the measured in-tank data (Finfrock 1995). This code will compare the measured detector count rates with those predicted by computer modeling for different moisture concentrations and gradients to determine a best fit. Allowing only for uniform moisture or increasing moisture with depth may make it easier for some type of anomalies to be identified. For instance, the responses that would be obtained from the presence of unexpectedly large quantities of strong thermal neutron absorbers would yield moisture interpretations with very large errors.

\subsection{PLANNED MOISTURE INTERPRETATION AND UNCERTAINTY BOUNDS}

The moisture interpretation of in-tank data will be accomplished using the aid of the TMAD code. This code will compare the measured data with libraries of predicted detector responses for different moisture concentrations and gradients. The initial libraries will be created using a flat waste surface geometry (no anomaly), at a single assumed bulk density, and for a single waste matrix composition. The TMAD code provides the user with an estimate of the uncertainty in the moisture interpretation based solely upon how well the measured data agrees with the best-fit modeled response set.

If the TMAD moisture uncertainty is low (less than about $3 \mathrm{wt} \%$ moisture) then one might assume that data unaffected by anomalies was obtained and that the moisture interpretation is valid. It is also possible that, even though TMAD found a good fit modeled response set, the data has been compromised by a tank waste anomaly. An anomaly might produce detector signals similar to those expected from legitimate non-anomaly moisture arrangements. During the deployment process, in-tank video of each probe deployment will be taken. Also, notes should be maintained by test personnel describing any concerns about observed evidence of material anomalies near each deployment measurement location. While the TMAD code provides an automated moisture interpretation based upon available data libraries, each individual measurement location and corresponding moisture interpretation will need to be carefully evaluated by a scientist. While the moisture interpretation provided by the TMAD code may be the best available, the scientist will need to estimate additional uncertainty or identify any suspected bias in the results based upon consideration of the data and the in-tank video of each deployment.

In cases where the TMAD moisture uncertainty is high (greater than about 5 wt $\%$ moisture) it is likely that either a material anomaly was present or that an assumption made in the moisture analyses, such as waste composition, density, or moisture gradient description, does not accurately describe reality. In some cases, the response of one of the detectors may be eliminated from consideration in the moisture interpretation. This elimination could be based upon visual evidence of a given type of anomaly. As shown in this document, many anomaly types will more significantly affect the response of one of the three detectors, leaving the moisture prediction based upon the remaining two detectors reasonably accurate. The solution for obtaining the most 
accurate moisture interpretation may be to individually analyze each measurement location using available information or indications of an anomaly. This solution, while desirable, would require significant time and effort to perform the needed computer simulations of each individual situation. Available resources may limit the ability to better analyse data that may have been influenced by an anomaly. Information presented in this report may be used to apply rough corrections to the data assuming a given anomaly type and magnitude. These data are being collected to help determine whether some Hanford wastes meet available moisture concentration criteria for safe storage. If the measurement, even given the large uncertainty, strongly indicates that the moisture concentration is either well above or below established safety criteria, then more analyses may not be warranted.

\subsection{CONCLUSIONS}

Experimental tests and simulation modeling have been performed for the SMMS neutron probe. The results indicate that different anomalies or variations in the waste composition or arrangement are expected to affect the accuracy of the moisture concentration interpretation derived from data acquired with the probe. Because many of the physical waste arrangements that might affect the probe response should be observable using the in-tank camera system during deployment, it should of ten be possible to place the probe to avoid these anomalies. The results in this report indicate that placing the probe a great enough distance from large hole or hill shaped anomalies will eliminate their effects upon the measured probe signals. Many other possible types of material anomalies, such as small cracks or shallow depressions in the waste surface are expected to have very small effects upon the measured probe signal. 


\subsection{REFERENCES}

Agnew, S. F., 1996, Hanford Tank Chemical and Radionuclide Inventories: HDW Model Rev. 3, LA-UR-96-858, Los Alamos National Laboratory, Los Alamos, New Mexico.

Finfrock, S. H., 1996, The CURVECUT Neutron Spectrum Processing Code, WHC-SD-WMCSUG-011, Westinghouse Hanford Company, Richland, Washington.

Finfrock, S. H., 1995, System Design Description for the TMAD Code, WHC-SD-WM-CSRS028, Westinghouse Hanford Company, Richland, Washington.

LANL, 1993, MCNP - A General Monte Carlo N-Particle Transport Code, Version 4A, LA-12625, (J. F. Briesmeister, Ed.), Los Alamos National Laboratory, Los Alamos, New Mexico.

Ritter, G. A., 1996, Surface Moisture Measurement System Hardware Acceptance Test Report, WHC-SD-WM-ATR-153, Rev. 0, Westinghouse Hanford Company, Richland, Washington.

Stokes, T. I., W. T. Watson, M. Gimera, J. H. Bussell, A. Dabiri, D. T. Holslin, F. Johansen, 1995, Design Requirements Document (DRD) for Surface Moisture Measurement System (SMMS), WHC-SD-WM-DRD-002, Rev. 0., Westinghouse Hanford Company, Richland, Washington.

WASTREN, Inc., 1993, Radionuclide and Chemical Inventories for the Single-Shell Tanks, WHC-SD-WM-TI-565, Rev 1, Westinghouse Hanford Company, Richland, Washington.

Watson, W. T. and J. H. Bussell, 1996, Results of Experimental Tests and Calibrations of the Surface Neutron Moisture Probe, WHC-SD-WM-TRP-260, Rev. 0., Westinghouse Hanford Company, Richland, Washington.

WHC, 1996, SMMS Neutron Probe Assembly, Rev 0., May 1996, drawing H-14-100483, Westinghouse Hanford Company, Richland, Washington. 
WHC-SD-WM-TI-786, Rev. 0

Appendix A. Model predicted and experimentally measured detector response data.

Table A-1. Model predicted response of each detector as a function of tank waste bulk density at a moisture concentration of $15 \mathrm{wt} \%$ (Figure 3-1).

\begin{tabular}{|c|c|c|c|}
\hline Density $\left(\mathrm{g} / \mathrm{cm}^{3}\right)$ & Detector $1\left(\mathrm{~s}^{-1}\right)$ & Detector $2\left(\mathrm{~s}^{-1}\right)$ & Detector $3\left(\mathrm{~s}^{-1}\right)$ \\
\hline 1.1 & 52.9 & 72.6 & 46.1 \\
\hline 1.2 & 57.2 & 82.8 & 45.9 \\
\hline 1.3 & 60.8 & 85.4 & 50.4 \\
\hline 1.4 & 67.1 & 93.9 & 53.1 \\
\hline 1.5 & 72.1 & 100 & 58.1 \\
\hline 1.6 & 78.5 & 107 & 62.1 \\
\hline 1.7 & 81.9 & 111 & 64.6 \\
\hline 1.8 & 87.4 & 115 & 68.0 \\
\hline
\end{tabular}

Table A-2. Model predicted responses for different matrix simulant moisture concentrations (Figure 3-2).

\begin{tabular}{|c|c|c|c|}
\hline $\begin{array}{c}\text { Moisture } \\
\text { Concentration } \\
(w \mathrm{w} \%)\end{array}$ & Detector $1\left(\mathrm{~s}^{-1}\right)$ & Detector 2 $\left(\mathrm{s}^{-1}\right)$ & Detector 3 $\left(\mathrm{s}^{-1}\right)$ \\
\hline 0 & 29.7 & 33.5 & 9.7 \\
\hline 5 & 44.5 & 57.3 & 25.7 \\
\hline 10 & 58.3 & 79.5 & 42.3 \\
\hline 15 & 72.2 & 101 & 57.6 \\
\hline 20 & 85.1 & 121 & 70.7 \\
\hline 25 & 97.5 & 138 & 85.7 \\
\hline 30 & 110 & 156 & 99.5 \\
\hline 40 & 135 & 187 & 114 \\
\hline 50 & 153 & 208 & 132 \\
\hline 65 & 183 & 247 & 145 \\
\hline
\end{tabular}


WHC-SD-WM-TI-786, Rev. 0

Table A-3. Model predicted detector responses for different total waste organic concentrations at 15 wt\% moisture (Figure 3-3)

\begin{tabular}{|c|c|c|c|}
\hline $\begin{array}{c}\text { Total Organic } \\
\text { Concentration } \\
(\text { wt\%) }\end{array}$ & Detector $1\left(\mathrm{~s}^{-1}\right)$ & Detector $2\left(\mathrm{~s}^{-1}\right)$ & Detector $3\left(\mathrm{~s}^{-1}\right)$ \\
\hline 0 & 72.1 & 100 & 58.1 \\
\hline 1 & 74.5 & 100 & 60.3 \\
\hline 2 & 75.3 & 105 & 65.0 \\
\hline 3 & 78.7 & 109 & 64.6 \\
\hline 4 & 80.2 & 110 & 68.0 \\
\hline 6 & 83.4 & 121 & 70.7 \\
\hline 8 & 88.1 & 125 & 75.4 \\
\hline
\end{tabular}

One experimental arrangement was used to obtain an estimate of the effects of multiple cracks directly beneath the probe. The Curvecut-derived experimental detector count rates and model predicted count rates are listed in Table A-4.

Table A-4. Comparison of base (no anomaly) case and multiple crack case experimental and model predicted detector responses (probe 3 )

\begin{tabular}{|l|c|c|c|c|c|c|}
\hline \multirow{2}{*}{$\begin{array}{l}\text { Data } \\
\text { Source }\end{array}$} & \multicolumn{3}{|c|}{ Base (No Anomaly) Case $\left(\mathrm{s}^{-1}\right)$} & \multicolumn{3}{|c|}{ Multiple Crack Case $\left(\mathrm{s}^{-1}\right)$} \\
\cline { 2 - 7 } & Det 1 & Det 2 & Det3 & Det 1 & Det 2 & Det3 \\
\hline Experiment & 106 & 160 & 128 & 102 & 151 & 119 \\
\hline Modeled & 124 & 169 & 95 & 114 & 158 & 92 \\
\hline
\end{tabular}


WHC-SD-WM-TI-786, Rev. 0

Table A-5. Model predicted detector responses (count rates) for a $1 \mathrm{~cm}$ wide air crack under the probe for two crack locations and crack depths.

\begin{tabular}{|c|c|c|c|c|c|c|}
\hline & \multicolumn{3}{|c|}{ Crack Under Detector 1 } & \multicolumn{3}{c|}{ Crack Under Neutron Source } \\
\hline Detector & none & $5 \mathrm{~cm}$ depth & $10 \mathrm{~cm}$ depth & none & $5 \mathrm{~cm}$ depth & $10 \mathrm{~cm}$ depth \\
\hline 1 & 62 & 61 & 60 & 62 & 59 & 59 \\
\hline 2 & 68 & 68 & 67 & 70 & 68 & 68 \\
\hline 3 & 93 & 90 & 90 & 93 & 93 & 92 \\
\hline
\end{tabular}

Table A-6. Comparison of the experimental and model predicted detector responses resulting from the two experimental surface hole arrangements.

\begin{tabular}{|c|c|c|c|c|c|}
\hline \multirow{2}{*}{ Detector } & \multirow{2}{*}{$\begin{array}{c}\text { Exp. No } \\
\text { Anomaly }\end{array}$} & \multicolumn{2}{|c|}{ Single Pan Hole } & \multicolumn{2}{c|}{ Double Pan Hole } \\
\cline { 3 - 6 } & & Experiment $\left(\mathrm{s}^{-1}\right)$ & Model $\left(\mathrm{s}^{-1}\right)$ & Experiment $\left(\mathrm{s}^{-1}\right)$ & Model $\left(\mathrm{s}^{-1}\right)$ \\
\hline 1 & 106 & 107 & 72.9 & 102 & 72.3 \\
\hline 2 & 160 & 147 & 112 & 141 & 104 \\
\hline 3 & 128 & 113 & 88.4 & 113 & 86.0 \\
\hline
\end{tabular}

Table A-7. Summary of computer model predictions of detector responses to arrangements with a large surface hole located far distances from the probe.

\begin{tabular}{|c|c|c|c|c|}
\hline Detector & No Anomaly & $\begin{array}{c}\text { Hole } 20 \mathrm{~cm} \text { away, } \\
10 \mathrm{~cm} \text { long }\end{array}$ & $\begin{array}{c}\text { Hole } 20 \mathrm{~cm} \text { away, } \\
50 \mathrm{~cm} \text { long }\end{array}$ & $\begin{array}{c}\text { Hole } 40 \mathrm{~cm} \text { away, } \\
50 \mathrm{~cm} \text { long }\end{array}$ \\
\hline 1 & 62 & 62 & 61 & 62 \\
\hline 2 & 69 & 69 & 67 & 69 \\
\hline 3 & 93 & 92 & 83 & 93 \\
\hline
\end{tabular}


WHC-SD-WM-TI-786, Rev. 0

Table A-8. Summary of the experimental and model predicted detector responses obtained for six experimental hill arrangements using probe 1 (see figure 3-8).

\begin{tabular}{|l|c|c|c|c|c|c|}
\hline \multirow{2}{*}{$\begin{array}{l}\text { Pan (Hill) } \\
\text { Arrangement } \\
\text { Description }\end{array}$} & \multicolumn{3}{|c|}{ Experiment (s-1) } & \multicolumn{3}{c|}{ Model (s $\left.^{-1}\right)$} \\
\cline { 2 - 7 } & 1 & 2 & 3 & 1 & 2 & 3 \\
\hline No anomaly & 126 & 169 & 87.5 & 124 & 169 & 94.8 \\
\hline $\begin{array}{l}\text { next to probe on } \\
\text { source side }\end{array}$ & 163 & 232 & 165 & 182 & 261 & 184 \\
\hline $\begin{array}{l}\text { next to probe, } \\
\text { opposite source }\end{array}$ & 137 & 272 & 119 & 145 & 306 & 133 \\
\hline $\begin{array}{l}13 \text { cm from probe, } \\
\text { opposite source }\end{array}$ & 126 & 178 & 96 & 125 & 180 & 103 \\
\hline $\begin{array}{l}\text { 20 cm from probe, } \\
\text { opposite source }\end{array}$ & 128 & 172 & 90 & 124 & 172 & 97.7 \\
\hline $\begin{array}{l}2 \text { pans 13 cm from } \\
\text { probe, opposite } \\
\text { source }\end{array}$ & 130 & 193 & 106 & 125 & 183 & 107 \\
\hline $\begin{array}{l}4 \text { pans 13 cm from } \\
\text { probe, opposite } \\
\text { source }\end{array}$ & 127 & 179 & 93 & 128 & 199 & 122 \\
\hline
\end{tabular}

Table A-9. Summary of the experimental and model predicted detector count rates obtained for the three cylindrical pan depression arrangements.

\begin{tabular}{|c|c|c|c|c|c|c|}
\hline \multirow{2}{*}{$\begin{array}{c}\text { Cylindrical Pan } \\
\text { Inner Diameter (cm) }\end{array}$} & \multicolumn{3}{|c|}{ Experiment $\left(\mathrm{s}^{-1}\right)$} & \multicolumn{3}{c|}{ Model $\left(\mathrm{s}^{-1}\right)$} \\
\cline { 2 - 7 } & 1 & 2 & 3 & 1 & 2 & 3 \\
\hline No Anomaly & 100 & 146 & 98 & 80.2 & 130 & 95.6 \\
\hline 15.2 & 112 & 197 & 168 & 95.0 & 179 & 146 \\
\hline 20.3 & 103 & 178 & 162 & 88.6 & 165 & 142 \\
\hline 25.4 & 92 & 166 & 174 & 84.1 & 151 & 132 \\
\hline
\end{tabular}


WHC-SD-WM-TI-786, Rev. 0

Table A-10. Summary of the model predicted detector responses obtained for the small surface depression arrangements.

\begin{tabular}{|l|c|c|c|}
\hline \multirow{2}{*}{ Arrangement Description } & \multicolumn{3}{|c|}{ Modeled Detector Reponses $\left(\mathrm{s}^{-1}\right)$} \\
\cline { 2 - 4 } & 1 & 2 & 3 \\
\hline No Anomaly & 62 & 70 & 92 \\
\hline Spherical dished depression $1.27 \mathrm{~cm}$ deep & 58 & 68 & 93 \\
\hline Cylindrical depression $1.27 \mathrm{~cm}$ deep & 57 & 67 & 91 \\
\hline
\end{tabular}

Table A-11. Summary of the model predicted detector responses obtained for the irregular surface arrangement.

\begin{tabular}{|l|c|c|c|}
\hline \multirow{2}{*}{ Arrangement Description } & \multicolumn{3}{|c|}{ Modeled Detector Reponses $\left(\mathrm{s}^{-1}\right)$} \\
\cline { 2 - 4 } & 1 & 2 & 3 \\
\hline No Anomaly & 61 & 70 & 93 \\
\hline Concentric annuli of waste, $2.54 \mathrm{~cm}$ high & 70 & 85 & 122 \\
\hline
\end{tabular}

Table A-11. Summary of the experimental and model predicted detector responses obtained for the probe standoff distances.

\begin{tabular}{|c|c|c|c|c|c|c|}
\hline \multirow{2}{*}{$\begin{array}{l}\text { Probe Distance } \\
\text { Above Matrix }(\mathrm{cm})\end{array}$} & \multicolumn{2}{|c|}{ Experiment Detector Reponses $\left(\mathrm{s}^{-1}\right)$} & \multicolumn{3}{c|}{ Model Detector Reponses $\left(\mathrm{s}^{-1}\right)$} \\
\cline { 2 - 7 } & 1 & 2 & 3 & 1 & 2 & 3 \\
\hline No Anomaly & 106 & 160 & 128 & 80.2 & 130 & 95.6 \\
\hline 1.3 & 81 & 121 & 99 & 56.4 & 98.9 & 78.4 \\
\hline 2.5 & 66 & 99 & 78 & 47.2 & 78.4 & 60.5 \\
\hline 3.8 & 55 & 84 & 65 & 40.6 & 65.4 & 53.1 \\
\hline
\end{tabular}


WHC-SD-WM-TI-786, Rev. 0

Table A-12. Summary of the experimental and model predicted detector responses obtained for different probe tilt angles.

\begin{tabular}{|c|c|c|c|c|c|c|}
\hline \multirow{2}{*}{$\begin{array}{l}\text { Probe Tilt Angle } \\
\text { (degree) }\end{array}$} & \multicolumn{2}{|c|}{ Experiment Detector Reponses $\left(\mathrm{s}^{-1}\right)$} & \multicolumn{3}{c|}{ Model Detector Reponses $\left(\mathrm{s}^{-1}\right)$} \\
\cline { 2 - 7 } & 1 & 2 & 3 & 1 & 2 & 3 \\
\hline-12.7 & 79 & 139 & 80 & 58.8 & 112 & 76.7 \\
\hline-8.4 & 87 & 141 & 85 & 64.0 & 116 & 78.3 \\
\hline-4 & 99 & 148 & 104 & 68.2 & 123 & 87.3 \\
\hline 0 (no anomaly) & 108 & 160 & 118 & 80.2 & 130 & 95.6 \\
\hline 4.5 & 106 & 150 & 121 & 75.3 & 123 & 94.3 \\
\hline 8.5 & 98 & 141 & 131 & 71.4 & 112 & 99.7 \\
\hline
\end{tabular}




\section{Appendix B. Computer model (MCNP) input files}

input file for base case for hole under probe:

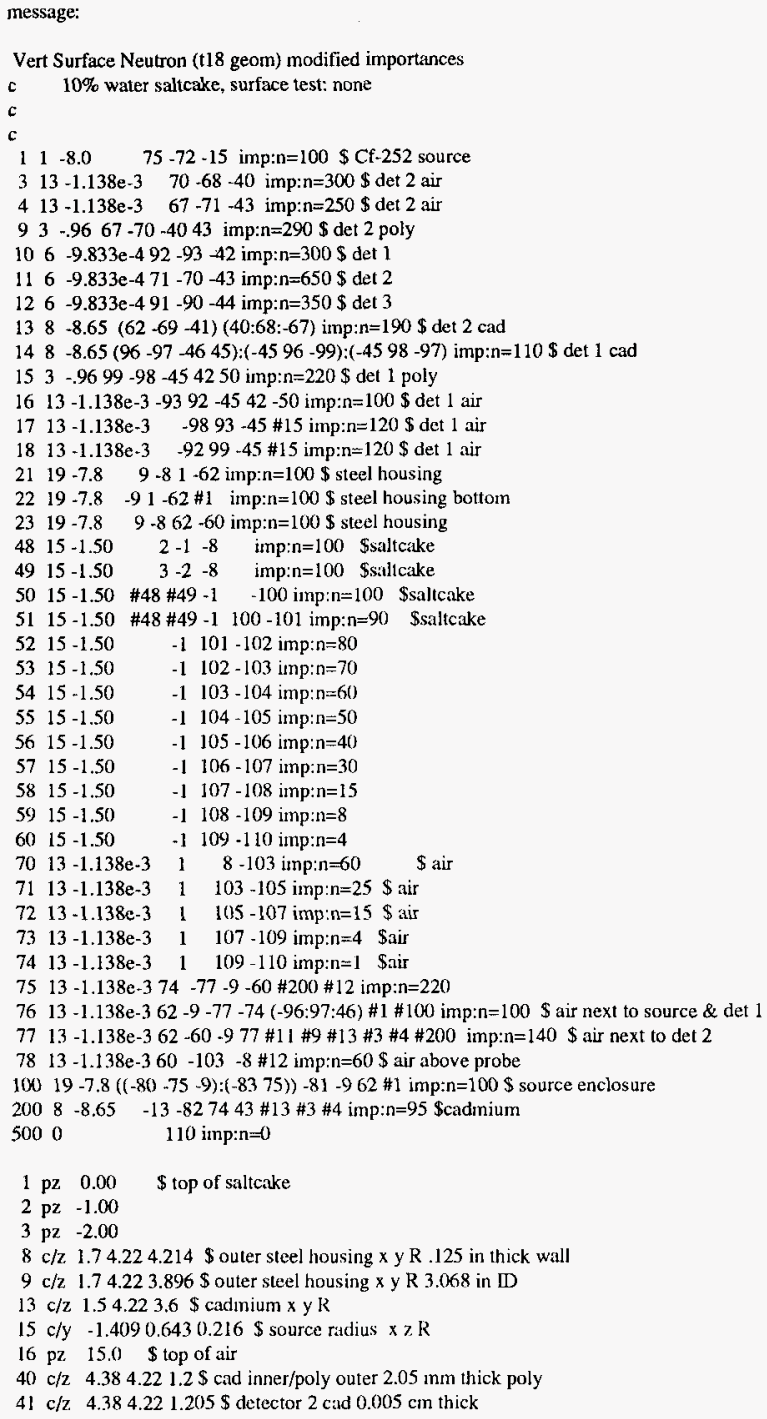


WHC-SD-WM-TI-786, Rev. 0

$42 \mathrm{c} / \mathrm{y} \quad 1.651 .8370 .79 \$$ detector 1 radius (.62"OD) x z R

$43 \mathrm{c} / \mathrm{z} 4.384 .220 .79$ \$ detector 2 radius (.62"OD) $x$ y $R$

$44 \mathrm{c} / \mathrm{z} \quad 1.754 .221 .27 \$$ detector 3 radius (.62"OD) $x$ y $R$

$45 \mathrm{c} / \mathrm{y} \quad 1.651 .8371 .29 \$$ det 1 poly

$46 \mathrm{c} / \mathrm{y} \quad 1.651 .8371 .455 \$$ det cad

$50 \mathrm{p} 1.14 .221 .051 .151 .051 .24 .221 .9 \$$ det 1 poly

$60 \mathrm{pz} 14.5 \$$ imp plane

$62 \mathrm{pz} \quad 0.381 \$$ top of housing bottom

$67 \mathrm{pz} 0.386$ \$ top of det $2 \mathrm{Cd} 0.005 \mathrm{~cm}$ thick

$68 \mathrm{pz} 5.4818 \$$ top of $\operatorname{det} 2 \mathrm{Cd}$

$69 \mathrm{pz} 5.4868$ \$ top of det $2 \mathrm{Cd} 0.005 \mathrm{~cm}$ thick

$70 \mathrm{pz} 4.5284 \$$ top of $\operatorname{det} 2$

$71 \mathrm{pz} 1.3484 \mathrm{~S}$ bottom of det 2

72 py $4.220001 \$$ top of source

$74 \mathrm{pz} 4.8 \$$ bottom of cadnium disk

75 py $4.219999 \$$ bottom of source

$77 \mathrm{px} \quad 3.12$ \$ left side of iron block

$80 \mathrm{px}-.479 \$$ source enclosure (side)

$81 \mathrm{pz} 1.65$ \$ source enclosure (top)

$82 \mathrm{pz} 4.965 \$$ top of cadmium

$83 \mathrm{px}-.873 \$$ thin side of source enclosure

$90 \mathrm{pz} 11.569 \$$ end of top $\operatorname{det} 3$

$91 \mathrm{pz} 6.489$ \$ end of top det 3

92 py $2.93 \mathrm{~S}$ end of det 1

93 py 6.11 send of det 1

96 py $1.5 \$ \mathrm{cad} / \mathrm{air}$

97 py $7.6924 \$ \mathrm{cad} / \mathrm{air}$

98 py $7.5324 \$ \mathrm{cad} / \mathrm{air}$

99 py $1.66 \$ \mathrm{cod} / \mathrm{air}$

$100 \mathrm{~s} \quad 1.04 .220 .05 .0$

$101 \mathrm{~s} \quad 1.04 .220 .010 .0$

$102 \mathrm{~s} \quad 1.04 .220 .015 .0$

$103 \mathrm{~s} \quad 1.04 .220 .020 .0$

$104 \mathrm{~s} \quad 1.04 .220 .025 .0$

$105 \mathrm{~s} \quad 1.04 .220 .030 .0$

$106 \mathrm{~s} \quad 1.04 .220 .035 .0$

$107 \mathrm{~s} \quad 1.04 .220 .040 .0$

$108 \mathrm{~s} \quad 1.04 .220 .045 .0$

$109 \mathrm{~s} \quad 1.04 .220 .050 .0$

$110 \mathrm{~s} \quad 1.04 .220 .0100 .0$

c idum $4 \mathrm{j}-7$

mode $n$

phys:n 2020

sdef cel dl pos fcel d2 axs 010 ext fcel d3

rad fcel d 4 wgt $=2.3 e^{7}$ erg $d 5$

$\mathrm{scl}$ source cell is $\mathrm{Cf}-252$ source in cell $1: 10$ micrograms

sil 11

spl d 1.0

sc2 source location is centered in cell 1

ds2 I -1.4094 .220 .643$

sc3 source extent

ds 3 s 6

sc4 source radius

ds4 $\quad$ s 7

sc5 energy distribution: Cf-252 Watt Spontaneous Fission Spectrum

sp5 $\quad-3 \quad 1.025 \quad 2.926$

sc6 source extent is 1.0 centimeter total length

si6 0.000001

sp6 $\quad-210$

sc7 source radius is 216 centimeters

si7 $0.0 \quad 0.216$ 
WHC-SD-WM-TI-786, Rev. 0

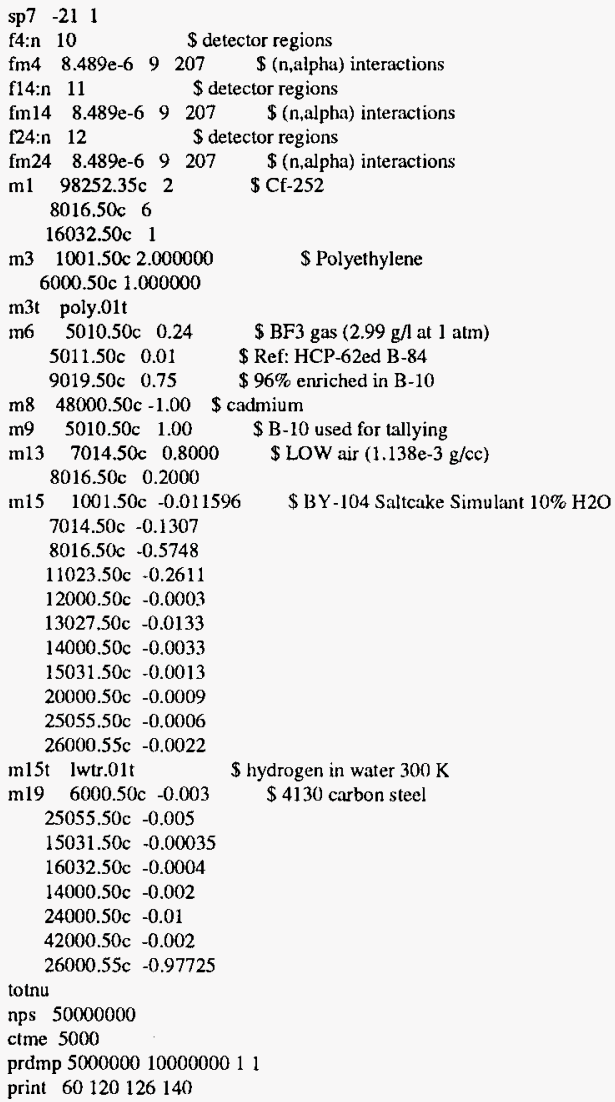




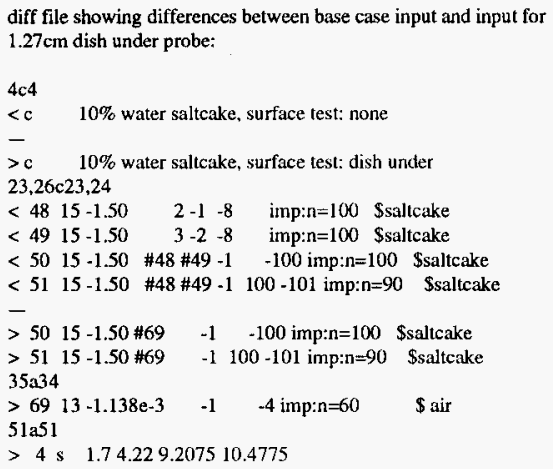


WHC-SD-WM-TI-786, Rev. 0

$>48$ 13 $-1.138 e-8 \quad 4-5 \quad 2-1 \quad-8$ imp:n=100 \$air

$>49 \quad 15-1.50 \quad 4-5 \quad 3-2 \quad-8$ imp:n=100 \$saltcake

$* * * * * * * * * * * * * * * * * * * * * * * * * * * * * * * * * * * * * * * * * * * * * * * * * * * * * * * * * * * * * * * * * * * *$

diff file showing differences between base case (no crack) input

and $10 \mathrm{~cm}$ crack case

$4 c 4$

<c $\quad 10 \%$ water saltcrke, surface test: none (crack)

$>\mathrm{c} \quad 10 \%$ water saltcake, surface test: $10 \times 1$ crack

$23,24 c 23,24$

$<4815-1.50 \quad 4.52-1.8 \quad$ imp: $n=100$ \$saltcake

$<4915-1.50 \quad 4-5 \quad 3-2-8 \quad$ imp: $n=100$ \$saltcake

$>\begin{array}{lllllllll}48 & 13 & -1.138 e-8 & 4 & -5 & 2 & -1 & -8 & \text { imp:n=100 Sair }\end{array}$

$>49 \quad 13-1.138 e-8 \quad 4-5 \quad 3-2 \quad-8 \quad$ imp:n=100 Sair

diff file showing differences between base case (hole) input

and base case (no crack under source) input:

$4 c 4$

$<\mathrm{c} \quad 10 \%$ water saltcake, surface test: none

-

$>$ c $10 \%$ water saltcake, surface test: none (crack under source)

$23,24 \mathrm{c} 23,24$

$<48 \quad 15-1.50 \quad 2-1 \quad-8 \quad$ imp:n=100 Ssaltcake

$<49 \quad 15-1.50 \quad 3-2-8 \quad$ imp: $n=100$ \$saltcake

$>48 \quad 15-1.50 \quad 4-5 \quad 2-1 \quad-8 \quad$ imp:n=100 \$saltcake

$>49 \quad 15-1.50 \quad 4-5 \quad 3-2 \quad-8 \quad$ imp: $n=100$ \$saltcake

$27 \mathrm{c} 27$

$<\begin{array}{lllll}52 & 15-1.50 & -1 & 101-102 \mathrm{imp}: \mathrm{n}=80\end{array}$

$>52 \quad 15-1.50 \quad \# 48$ \#49-1 $101-102$ imp:n=80

$50,51 \div 50,53$

$<2 \mathrm{pz}-1.00$

$<3 \mathrm{pz}-2.00$

$-$

$>2 \mathrm{pz}-5.00$

$>3 \mathrm{pz}-10.00$

$>4 \mathrm{px}-2.00$

$>5 \mathrm{px}-1.00$

$* * * * * * * * * * * * * * * * * * * * * * * * * * * * * * * * * * * * * * * * * * * * * * * * * * * * * * * * * * * * * * * * * * * *$

diff file showing differences between base case (no crack) inpul and $5 \mathrm{~cm}$ crack under source

$4 \mathrm{c4}$

$<\mathrm{c} \quad 10 \%$ water saltcake, surface test: none (crack under source)

$>\mathrm{c} \quad 10 \%$ water saltcake, surface test: $5 \times 1$ crack under source

$23,24 \mathrm{c} 23,24$

$<\begin{array}{llllllll}48 & 15 & -1.50 & 4 & -5 & 2 & -1 & -8\end{array} \quad$ imp:n=100 $\$$ saltcake

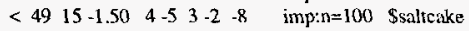

$-$

$>48 \quad 13-1.138 \mathrm{e}-8 \quad 4 \quad-5 \quad 2-1 \quad-8 \quad$ imp $n=100 \quad$ Sair

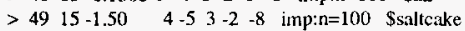


WHC-SD-WM-TI-786, Rev. 0

diff file showing differences between base case (no crack) input and $10 \mathrm{~cm}$ crack under source

$4 c 4$

<c $10 \%$ water saltcake, surface test: none (crack under source)

$>\mathrm{c} \quad 10 \%$ water saltcake, surface test: $10 \times 1 \mathrm{crack}$ under source

$23,24 c 23,24$

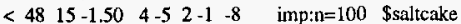

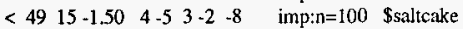

$>\begin{array}{lllllllll}48 & 13 & -1.138 \mathrm{e}-8 & 4 & -5 & 2 & -1 & -8 & \text { imp:n=100 Sair }\end{array}$

$>49 \quad 13-1.138 \mathrm{e}-8 \quad 4-5 \quad 3-2 \quad-8 \quad$ imp:n=100 \$air

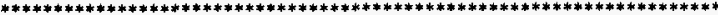

diff file showing differences between base case (hole) input

and base case (no canyon) input:

$4 \mathrm{c} 4$

$<\mathrm{c} \quad 10 \%$ water saltcake, surface test: none

$>\mathrm{c} \quad 10 \%$ water saltcake, canyon geometry

$23,26 c 23,24$

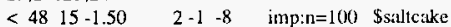

$<\begin{array}{llll}49 & 15 & -1.50 \quad 3-2 & -8\end{array} \quad$ imp: $n=100$ Ssaltcake

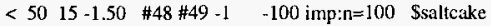

$<51 \quad 15-1.50 \# 48 \# 49-1 \quad 100-101$ imp:n=90 Ssaltcake

$>5015-1.50 \quad-1 \quad-100$ imp:n=100 \$saltcake

$>51 \quad 15-1.50 \quad-1100-101$ imp:n=90

$29,40<27,42$

$<54 \quad 15-1.50 \quad-1 \quad 103-104$ imp: $n=60$

$<5515-1.50 \quad-1104-105$ imp: $n=50$

$<5615-1.50 \quad-1105-106$ imp:n=40)

$<\begin{array}{llll}57 & 15-1.50 \quad-1 & 106-107 \text { imp: } \mathrm{n}=30\end{array}$

$<5815-1.50 \quad-1 \quad 107-108$ imp: $n=15$

$<59 \quad 15-1.50 \quad-1108-109$ imp: $n=8$

$<6015-1.50 \quad-1 \quad 109-110 \mathrm{imp}: \Omega=4$

$<7013-1.138 \mathrm{e}-3 \quad 1 \quad 8-103$ impin $=60 \quad \$$ air

$<71 \quad 13-1.138 \mathrm{e}-3 \quad 1 \quad 103-105$ imp:n=25 \$air

$<7213-1.138 \mathrm{e}-3 \quad 1 \quad 105-107$ imp:n=15 \$air

$<73 \quad 13-1.138 \mathrm{e}-3 \quad 1 \quad 107-109 \mathrm{imp}: \mathrm{n}=4$ \$air

< $7413-1.138 \mathrm{e}-3 \quad 1 \quad 109-110$ imp:n=1 \$air

$>54 \quad 15-1.50 \$ 61$

$>55 \quad 15-1.50 \# 61$

$>5615-1.50 \# 62$

$>57 \quad 15-1.50 \# 62$

$>58 \quad 15-1.50 \# 63$

$>59 \quad 15-1.50 \# 63$

$>60 \quad 15-1.50 \# 64$

$>61 \quad 15-1.50$

$>6215-1.50$

$>63 \quad 15-1.50$

$>64 \quad 15-1.50$

$>7013-1.138 \mathrm{e}-3$

$>71 \quad 13-1.138 \mathrm{e}-3 \quad 1$

$>72 \quad 13-1.138 \mathrm{e}-3 \quad 1$

$>7313-1.138 \mathrm{e}-3 \quad 1$

$>7413-1.138 \mathrm{e}-3$

50,51d51

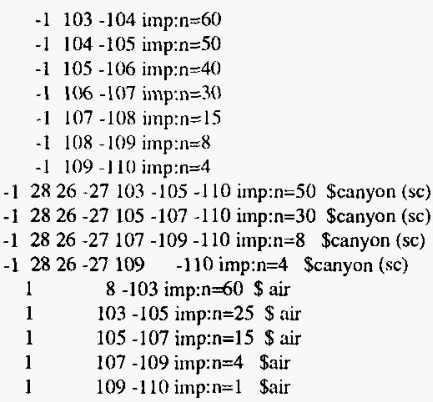


diff file showing differences between base case (no canyon) input and near canyon input:

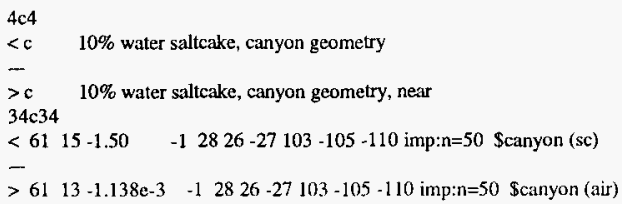

surfab15_t11.inp (base case for density and organic parameter studies, density $=1.5 \mathrm{~g} / \mathrm{cm}^{3}$, no organic) As-Built Surface Neutron Probe 1/22/96, Rev 0

c Det\#1 B-10 TALLY REGION 80-100\% $\begin{array}{lllllll}1 & 6 & -2.34 & 31 & -30 & 27 & -28 \\ \text { imp:n=300 }\end{array}$

c DET\#2 B-10 TALLY REGION $80-100 \%$

$2 \quad 6 \quad-2.34 \quad 67-6670-71$ imp:n=310

c DET\#3 B-10 TALLY REGION 80-100\%

$\begin{array}{lllll}3 & 6 & -2.34 & 78 & -77 \\ 80 & -82 & \text { imp: } n=300\end{array}$

c narrow part of source housing

$44-8.02(97-2.54)(6: 14)$ imp:n=100

$c$ entrance slot to source cavity 
WHC-SD-WM-TI-786, Rev. 0

$513-.000114((16(-86: 87)):(-18-8786))$

$(3-17-1-15) \#(107-106)$ imp:n=100

c probe housing bottom

$6 \quad 4-8.02-43-16 \# 5 \# 55$ imp: $n=100$

c Ar/CO2 Det\#l

$79-.001(-2926-31):(153-3031-29):(-3031-15226)$ imp:n $=300$

c SS Cathode Det\# 1

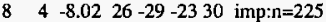

c Polyethylene Det\#1

$93-0.96(-2122-3426)(59: 24:-25)$ imp:n=200

c main cadmium Det\#1

108 -8.65 $(-343521-20)$ imp: $=100$

c top cadmium washer det\#1

$118-8.65(-3635-213839)$ imp $n=100$

c bottom cadmium hat det\# 1

$128-8.65((34-33-202240):(34-3222-37):(-3229-22))$ imp:n=100

c ss clip around det\#1

$134-8.02(20-19-3360)$ imp:n=100

c ss plate screwed to cad shield

$14 \quad 4-8.02(-5149-52954193)$ imp: $n=90$

c cad shield under det\#3

$158-8.65(50-49-525341888990919293) \# 53$ imp: $n=90$

c Aluminum in poly insert of det\# 1

$165-2.6989-242522-2126-34-59$ imp:n=150

c sides of probe housing (bottom third)

$174-8.02((-124-11):(-4-6-114)) \# 5$ \#54 \#55 imp:n=100

c $\mathrm{Ar} / \mathrm{CO} 2 \mathrm{Det} 2$

$189-.001(69-72-67):(15567-66-72):(-15467-66 \quad 69)$ imp: $n=310$

c Cathode Det\#2

$194-8.02 \quad 66-5869-72$ imp: $n=300$

c ss top Det\#2

$\begin{array}{llllll}20 & 4 & -8.02 & -58 & 72 & -73 \\ \text { imp:n }=100\end{array}$

c bottom ss Det\#2

$214 \quad-8.02-5868-69$ imp:n=100

c Polyethylene Det\#2

$223-0.9658-5665-74$ imp: $n=200$

c SS mounting sleeve det\#2

$234-8.02(56-6165-74):(64-65-61)$ imp: $n=200$

c polyimide bottom det\#2

$247 \begin{array}{lllll}-5 & -58 & 65 & -68 & \text { imp: } n=100\end{array}$

c polyimide on cidmium plating

$\begin{array}{lllllll}26 & 7 & 1.4 & 62 & 63 & 44 & -74 \\ \text { imp: } n=100\end{array}$

c cadmium det\#2

$258 \quad-8.65(61-62-7464):(44-64-62)$ imp: $n=140$

c SS mounting sleeve

$274-8.02((4563-41-7544):(-4443-4145)$ :

$(4-43-416345))$ \# 13 imp:n=110

c wide part of probe source housing

$28 \quad 4-8.02(-98-24-56) \# 5$ \#55 imp: $n=100$

c $\mathrm{Ar}+\mathrm{CO} 2$ gas det\#3

$299-.001(81-83-78):(157-8378-77):(-1568178-77)$ imp: $n=300$

c Cathode wall det\#3

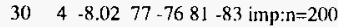

c bottom ss det\#3

$\begin{array}{lllllll}31 & 4 & -8.02 & -76 & 79 & -81 & \text { imp: } n=100\end{array}$

c top ss wall det\#3

$\begin{array}{llllll}32 & 4 & -8.02 & 83 & -84 & -76 \\ \text { imp: } n=100\end{array}$

c polyimide det\#3

$3371.4(76-47-8479):(51-79-47)$ imp:n=200

c ss mounting sleeve det\#3

$344-8.02(47-46-8551)$ imp:n=150

c polyimide around det\#1 
WHC-SD-WM-TI-786, Rev. 0

$35 \quad 7 \quad 1.4 \quad(23-22 \quad 26-29)$ imp: $n=200$

c air space below cad in probe

$3613-.000114(-504-2411960)(5:-8:(-79)) 95$ \#53 inp: $n=100$

$3713-.000114(-504-24120-60)(5:-8:(-79))$ \#53 imp:n=100

$3813-.000114(37-233-19):(-37-232)$ imp: $n=100$

$3913-.000114(-20-2-35)$ imp:n=100

$4013-.000114(63-414-75-45-2):(-634-43):(-63-4543-44)$ imp:n=100

$4113-.000114(36-21-26):(-3835-36):(-21-3935-36)$ imp: $n=100$

c ss screws in cad shield

$42 \quad 4 \quad-8.02-88 \quad 50-49$ imp: $n=100$

$43 \quad 4 \quad-8.02-8950-49$ imp: $n=100$

$44 \quad 4-8.02-9050-49$ imp: $n=100$

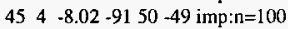

$46 \quad 4 \quad-8.0295-5350-49$ imp:n=100

$47 \quad 4 \quad-8.02-9250-49$ imp: $n=100$

c \#10 threaded rod

$48 \quad 4 \quad-8.02(-12951-97):(-51-955)$ imp: $n=100$

c main thick wall portion of housing

$49 \quad 4-8.02-12211-130$ imp:n=100

c air above cad plate below top of det 33

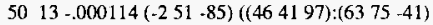

$:(58-6374):(73-58)) 9088$ imp: $n=100$

$c$ around around cad/ss plate

$51 \quad 13-.000114(-25250-5141)$ imp:n=100

c slot in cad/ss plate for wirc pass through

$5213-.000114(-93-5150)$ \#51 imp: $n=100$

c det\#1 stiffener

$534-8.0298-99100-4910]-102$ imp: $n=100$

c source holder grab hole

$54 \quad 13-.000114107-15-104$ imp: $n=100$

c source holder nut

$55 \quad 4 \quad-8.02-106 \quad 104107-15$ imp:n=100

c source holder threads/body

$56 \quad 4 \quad-8.02-6 \quad 15-108$ imp: $n=100$

c source capsule

$574-8.02(-109108-112105):(110-109-105)$ : $(108-111-105)$ imp:n=100

c air around source capsule

$5813-.000114(112-6108-14):(-14109-112)$ imp: $n=100$

c Pd-CF2O3 NEUTRON SOURCE

$591-10.0-113115-114 \quad$ imp: $n=100$

c air around source

$6013-.000114-105111-110$ \#59 imp: $n=100$

c electrical board \#1

$61 \quad 10-1.21 \quad 116-117-2979088$ imp:n=100

c threaded rod

$62 \quad 4-8.0251-129-90$ imp: $n=90$

c threaded rod

$\begin{array}{lllllll}6 & 4 & -8.02 & 51 & -129 & -88 & \text { imp: } n=100\end{array}$

c electrical bostrd $\# 2$

$6410-1.21120-121-2979088 \mathrm{imp}: n=100$

c electrical board \#3

$6510-1.21 \quad 122-123-2979088$ imp: $n=100$

c electrical board \#4

$6610-1.21 \quad 126-127-2979088$ imp: $n=100$

c air above top of det\#3 below first electrical board

$6713-.000114(-285-11690889747):(-4784-116)$ imp: $n=90$

c air between board 1 and ss plate 40

$6813-.000114(-2117-118908897) \mathrm{imp}: n=90$

c air between ss plate 40 and board $\# 2$

$6913-000114(-2119-120908897)$ imp: $n=90$

c air between board \#2 and board \#3 
WHC-SD-WM-TI-786, Rev. 0

$7013-.000114(-2121-122908897) \mathrm{imp}: n=90$

c SS ground Plane $\$ 40$

$714-8.02 \quad 118-119-2979088$ imp.n=90

c SS ground Plane \#41

$724-8.02 \quad 124 \cdot 125-2979088$ imp: $n=90$

c SS ground Plane \#39

$734-8.02 \quad 128-129-2979088$ imp:n=90

c air between board \#3 and SS plate \#41

$7413-.000114(-2123-124908897)$ imp: $n=90$

c air between SS plate \#41 and board \#4

$7513-.000114(-2125-126908897)$ imp: $n=90$

c air between board \#4 \& SS plate \#39

$7613-.000114(-2127 \cdot 128908897)$ imp $: n=90$

c bottom of cablehead

$774-8.02103-130-12131 \# 49$ imp: $n=70$

c air between board \#4 \& SS plate \#39

$78 \quad 13-.000114-2129-103$ imp: $n=70$

c cablehead nut

$794-8.02130-132131-12$ imp: $n=50$

c cablehead neck

$804-8.02 \quad 132+133131 \cdot 134$ imp:n=50

c air around cablehead neck

$8113-.000114132-133134-12 \mathrm{imp}: n=40$

c cable

$8213-.000114 \quad 103-133-131$ imp: $n=50$

$\mathrm{C}$ air around probe

$8313-.000114-2003((1-11):(1211): 133)$ imp:n=100

$8414-1.5 \quad-200-10-354$ imp: $n=1(k)$

$8514-1.5 \quad-200-10-5455$ imp: $n=60$

$8614-1.5 \quad-200-10-55$ imp: $n=30$

$8714-1.5 \quad-20010-354$ imp: $n=90$

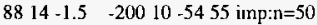

$8914-1.5 \quad-20010-55$ imp: $n=20$

c extended B10 coating bottom of det\#1

$\begin{array}{lllllll}104 & 6 & -2.34 & 31 & -30 & 152 & -27 \\ \text { imp:n}=300\end{array}$

c extended B10 coating top of det\#1

$1056-2.3431 \cdot 3028-153$ imp: $n=300$

c extended B 10 coating bottom of det\#2

$106 \quad 6-2.34 \quad 67-66 \quad 154-70$ imp: $n=30$

c extended B 10 coating top of det $\$ 2$

$107 \quad 6-2.34 \quad 67-6671-155$ imp: $n=300$

c extended B10 coating bottom of det\#2

$\begin{array}{lllllll}108 & 6 & -2.34 & 78 & -77 & 156 & -80 \\ \text { imp: } n=300\end{array}$

c extended B10 coating top of det\#2

$1096-2.3478-7782-157$ imp: $=300$

$110 \quad 13-.000114-40-202234+33 \quad 37$ imp:n=90

c temp outside

1500200 imp: $n=0$

$\begin{array}{ccl}1 & \mathrm{cz} & 4.2138599 \\ 2 & \mathrm{cz} & 3.8963599 \\ 3 & \mathrm{pz} & 0.0000000 \\ 10 & \mathrm{cz} & 25.00 \\ 54 & \mathrm{pz} & -34.000 \\ 55 & \mathrm{pz} & -69.000 \\ 4 & \mathrm{pz} & 0.3175000 \\ 5 & \mathrm{pz} & 1.5367000\end{array}$

c outer source hole

$\begin{array}{rrrrr}6 & \mathrm{c} / \mathrm{y} & 3.0480000 & 0.6604000 & 0.3568700 \\ 7 & \text { px } & 2.5400000 & & \\ 8 & \text { px } & 2.1844000 & & \\ 9 & \text { py } & -0.7112000 & & \end{array}$


WHC-SD-WM-TI-786, Rev. 0

c top of thin wall section of probe housing

$11 \mathrm{pz} \quad 10.426700$

c outer diameter of thick purt (upper 2/3) of probe housing

$12 \quad$ cz 4.3815

$13 \quad$ pz $\quad 44.754799$

14 py 1.5240000

15 py -1.7780000

$16 \quad \mathrm{px} \quad 2.3368000$

17 pz 1.2954000

$18 \quad c / y \quad 2.9718000 \quad 0.6604000 \quad 0.6350000$

$19 \mathrm{c} / \mathrm{y} \quad 0.0000000 \quad 1.7578 \quad 1.41478$

$\begin{array}{lllll}20 & \mathrm{c} / \mathrm{y} & 0.0000000 & 1.76000 & 1.28778\end{array}$

$\begin{array}{lllll}21 & \mathrm{c} / \mathrm{y} & 0.0000000 & 1.76000 & 1.1480800\end{array}$

$\begin{array}{lllll}22 & \mathrm{c} / \mathrm{y} & 0.0000000 & 1.76000 & 0.6400800\end{array}$

$\begin{array}{lllll}23 & \mathrm{c} / \mathrm{y} & 0.0000000 & 1.76000 & 0.6350000\end{array}$

$\begin{array}{llllll}24 & p & 0.3400000 & 0.0000000 & 1.0000000 & 2.3825200\end{array}$

$\begin{array}{llllll}25 & p & 0.3400000 & 0.0000000 & 1.0000000 & 1.0833100\end{array}$

26 py -2.1285200

27 py -0.6299200

28 py 2.3164800

29 py 3.5864799

$\begin{array}{lllll}30 & c / y & 0.0000000 & 1.76000 & 0.5588000\end{array}$

c Inner B-10 lining $0.4 \mathrm{mg} / \mathrm{cm} 2$

$\begin{array}{lllll}31 & \mathrm{c} / \mathrm{y} & 0.0000000 & 1.76000 & 0.5586265\end{array}$

32 py 3.72618

33 py 2.77622

34 py 2.6365200

35 py -3.05562

36 py -2.9159200

$\begin{array}{lllll}37 & \mathrm{c} / \mathrm{y} & 0.0000000 & 1.76000 & 0.77978\end{array}$

$\begin{array}{lllll}38 & c / y & 0.0000000 & 1.76000 & 0.3175000\end{array}$

$\begin{array}{lllll}39 & c / y & 0.0000000 & 2.73260 & 0.3175000\end{array}$

$40 \mathrm{c} / \mathrm{y} \quad 0.8221 .41 \quad 0.3175$

c Hole in Cad under Det\#3 for support rod

$\begin{array}{lllll}41 & \mathrm{c} / \mathrm{z} & \mathbf{2 . 6 9 7 4 8 0 0} & 0.0000000 & 1.26492\end{array}$

43 pz 0.47498

44 pz 0.62738

45 px -3.3400999

$46 \quad \mathrm{CZ} \quad 0.7937500$

$47 \mathrm{cz} \quad 0.6489700$

$48 \quad$ pz $\quad 11.772900$

$49 \quad \mathrm{pz} \quad 4.5084999$

50 pz 4.3433999

c top of ss plate below det\#3

$51 \quad$ pz 4.6659799

c radius of cad/SS shield

$52 \quad \mathrm{cz} \quad 3.8353999$

$\begin{array}{lllll}53 & c / z & 3.0162500 & 0.0000000 & 0.5041900\end{array}$

c inner polyethylene inner Det\#2

c poly outer Det\#2

$\begin{array}{lllll}56 & \mathrm{c} / 2 & -2.6974800 & 0.0000000 & 1.0096500\end{array}$

c poly inner Det\#2

$\begin{array}{lllll}57 & c / z & -2.6974800 & 0.0000000 & 0.6489700\end{array}$

$\begin{array}{lllll}58 & c / z & -2.6974800 & 0.0000000 & 0.6350000\end{array}$

$\begin{array}{llllll}59 & \text { p } & -16.436870 & 0.0000000 & 1.0000000 & 2.3825200\end{array}$

60 py -0.8970000

c inner ss cad-plated peice for det\#2

c SS plated piece outer det\#2

$\begin{array}{lllll}61 & c / 2 & -2.6974800 & 0.0000000 & 1.1112500\end{array}$

c 0.003 " Cad outer Det\#2

$\begin{array}{lllll}62 & \mathrm{c} / \mathrm{z} & -2.6974800 & 0.0000000 & 1.11379\end{array}$

c polyimide outer 
$\begin{array}{lllll}63 & c / 2 & -2.6974800 & 0.0000000 & 1.11887\end{array}$

c Inner bottom cadmium Det\#2

$\begin{array}{lll}64 & \mathrm{pz} & 0.62992\end{array}$

c Inside bottom ss plated peice det\#2

$\begin{array}{lll}65 & \mathrm{pz} & 0.71882\end{array}$

c inner cathode det\#2

$\begin{array}{lllll}66 & c / z & -2.6974800 & 0.0000000 & 0.5588000\end{array}$

c inner B-10 coating det\#2

$\begin{array}{lllll}67 & c / 2 & -2.6974800 & 0.0000000 & 0.5586265\end{array}$

c inner top polyimide det\#2

$\begin{array}{lll}68 & \mathrm{pz} & 0.7239\end{array}$

c inner bottom ss cathode det\#2

c Bottom Active Region DET\#2

$\begin{array}{lll}69 \mathrm{pz} & 0.8001\end{array}$

70 pz 2.1590000

c top active region det\#2

$\begin{array}{lll}71 & \text { pz } & 6.4769999\end{array}$

c Inside top Det\#2

$\begin{array}{lll}72 & \text { pz } & 7.8993999\end{array}$

c Top of Det\#2

73 pz 7.9755999

c top of polyethylene det\#2

$74 \quad \mathrm{pz} \quad 7.7165199$

c top of ss mounting sleeve det\#2

75 pz 7.2008999

c Inner polyimid det\#3

76 cz 0.6438900

c inner cathode Det\#3

$77 \quad$ cz $\quad 0.5676900$

c Inner B-10 lining Del\#3

$\begin{array}{lll}78 \quad c z & 0.5675165\end{array}$

c bottom Det\#3

$79 \quad$ pz 4.6710599

c bottom active region det\#3

$80 \quad$ pz $\quad 6.1696599$

c inside bottom del\#3

$81 \quad \mathrm{pz} \quad 4.7472599$

c top active region det\#3 82 pz 10.487660

c inside top det\#3

$83 \mathrm{pz} \quad 11.910060$

c top det\#3

$84 \quad$ p2 11.986260

c top mounting sleeve det\#3 85 p7. 11.650980

c through source slot $86 \quad \mathrm{pz} \quad 0.6604$

c through source slot 87 px 2.9718

c screw in cad shield X Y R $88 \mathrm{c} / \mathrm{z}-1.51-2.60 .18669$

c screw in cad shield X Y R $89 \mathrm{c} / \mathrm{z}-2.41-1.820 .18669$

c screw in cad shield X Y R $90 \mathrm{c} / \mathrm{z}-1.512 .60 .18669$

c screw in cad shield X Y R $91 \mathrm{c} / \mathrm{z}-0.372 .990 .18669$

c screw in cad shield $X \mathrm{Y} \mathrm{R}$ $92 \mathrm{c} / 22.78-1.180 .18669$

c slot in cad shield X Y R

$93 c / 2 \quad-.45-3.400 .4572$

c $\# 10$ threaded rod OD 
$95 \mathrm{c} / \mathrm{z} 3.0162500 .2413$

c top of thick walled outer housing (17.875 in.)

$96 \mathrm{pz} 45.4025$

c standoff around $\# 10$ threaded rod

$97 \mathrm{c} / \mathrm{z} 3.0162500 .3937$

c left side of det\# 1 stiffener

$98 \mathrm{px} 1.44028$

c right side of det\#1 stiffener

99 px 1.51648

c bottom of det\#1 stiffener

$100 \mathrm{pz} 1.5367$

c front edge of det\#1 stiffener

101 py -1.27

c back edge of det\#1 stiffener

102 py 1.27

$\mathrm{c}$ bottom of cable head

$103 \mathrm{pz} 41.529$

c source holder threaded grab hole radius

$104 \quad c / y \quad 3.0480000 \quad 0.6604000 \quad 0.207$

c source capsule ID

$105 \mathrm{c} / \mathrm{y} \quad 3.0480000 \quad 0.6604000 \quad 0.196$

c source holder nut radius

$106 \quad \mathrm{c} / \mathrm{y} \quad 3.0480000 \quad 0.6604000 \quad 0.40$

c source holder nut end

107 py -2.16

c source holder thread/capsule interface

108 py $\mathbf{0} 0.686$

c source holder capsule end

109 py 0.686

c source capsule inner bottom end

110 py 0.450

c source capsule inner top end

111 py -0.165

c source capsule/holder OD

$112 \mathrm{c} / \mathrm{y} \quad 3.0480000 \quad 0.6604000 \quad 0.3175$

c source OD

$113 \mathrm{c} / \mathrm{y} \quad 3.0480000 \quad 0.6604000 \quad 0.00935$

c source top

114 py 0.15185

c source bottom

115 py 0.13315

c bottom (\#1) electrical board (bottom)

$116 \mathrm{pz} 16.756$

c bottom (\#1) electrical board (top)

$117 \mathrm{pz} 16.914$

c (\#40) electrical SS ground plane (bottom)

$118 \mathrm{pz} 18.971$

c $(\$ 40)$ electrical SS ground plane (top)

$119 \mathrm{pz} 19.129$

c (\#2) electrical board (bottom)

$120 \mathrm{pz} 20.551$

c (\$2) electrical board (top)

121 pz 20.708

c (\#3) electrical board (bottom)

$122 \mathrm{pz} 24.188$

c (\#3) electrical board (top)

$123 \mathrm{pz} 24.345$

c (\#41) electrical SS ground plane (bottom)

$124 \mathrm{pz} 28.307$

c (\#41) electrical SS ground plane (top)

$125 \mathrm{pz} 28.460$

c (\#4) electrical board (bottom) 
WHC-SD-WM-TI-786, Rev. 0

126 pz 29.882

c (\#4) electrical board (top)

$127 \mathrm{pz} 30.04$

c (\#39) electrical SS ground plane (bottom)

128 pz 31.462

c (\#39) electrical SS ground plane (top)

$129 \mathrm{pz} 31.615$

c top shoulder of cable head

130 pz 43.74

c cable $\mathrm{OD}$

$131 \mathrm{cz} 1.06$

c approx top cable head nut

132 pz 46.92

c top of cable head

133 pz 52.73

c OD of cable head neck

$134 \mathrm{cz} 1.4$

c extension of $B 10$ coating at bottom of det\#1

152 py -1.430

c extension of $\mathrm{B} 10$ coating at top of det\# 1

153 py 3.116

c extension of $B 10$ coating at bottom of det\#2

$154 \mathrm{pz} 1.245$

c extension of B10 coating at top of det\#2

155 pz 7.391

c extension of B 10 coating at bottom of det\#3

l56 pz 5.256

c extension of $\mathrm{B} 10$ coating at top of det\#3

157 pz 11,402

c inner B-10 coating $70 \%$ det\#1

$160 \mathrm{c} / \mathrm{y} \quad 0.01 .760 .558679$

c inner B-10 coating 60\% det\#1

$161 \mathrm{c} / \mathrm{y} \quad 0.01 .76 \quad 0.558696$

c inner B-10 coating $50 \%$ det\#1

162 c/y $0.01 .76 \quad 0.558713$

c inner B-10 coating $40 \%$ det\#1

$163 \mathrm{c} / \mathrm{y} \quad 0.01 .76 \quad 0.558731$

c inner B-10 coating $30 \%$ de\# 1

$164 \mathrm{c} / \mathrm{y} \quad 0.01 .76 \quad 0.558748$

c inner B-10 coating $20 \%$ del\#1

$\begin{array}{llllll}165 & c & 0.0 & 1.76 & 0.558766\end{array}$

c inner B-10 coating $10 \%$ de।\#1

$166 \quad \mathrm{c} / \mathrm{y} \quad 0.01 .76 \quad 0.558783$

c inner B-10 coating $70 \%$ det\#2

$\begin{array}{llllll}167 & c / z & -2.69748 & 0.0 & 0.558679\end{array}$

c inner B-10 coating $60 \%$ det\#2

$\begin{array}{lllll}168 & c / L & -2.69748 & 0.0 & 0.558696\end{array}$

c inner B-10 coating 50\% det\#2

$\begin{array}{lllll}169 & c / 2 & -2.69748 & 0.0 & 0.558713\end{array}$

c inner B-10 coating $40 \%$ det 2

$\begin{array}{llllll}170 & \mathrm{c} / \mathrm{z} & -2.69748 & 0.0 & 0.558731\end{array}$

c inner B-10 coating $30 \%$ del\#2

$\begin{array}{llllll}171 & \mathrm{c} / \mathrm{z} & -2.69748 & 0.0 & 0.558748\end{array}$

c inner B- 10 coating $20 \%$ del $\$ 2$

$\begin{array}{lllll}172 & c / z & -2.69748 & 0.0 & 0.558766\end{array}$

c inner B- 10 coating $10 \%$ det\#2

$\begin{array}{lllll}173 & \mathrm{c} / \mathrm{z} & -2.69748 & 0.0 & 0.558783\end{array}$

c inner B-10 coating $70 \%$ det\#3

$174 \mathrm{cz} \quad 0.567569$

c inner B-10 coating $60 \%$ deı 3

$175 \mathrm{cz} \quad 0.567586$

$c$ inner B-10 coating 50\% det $\# 3$ 
WHC-SD-WM-TI-786, Rev. 0

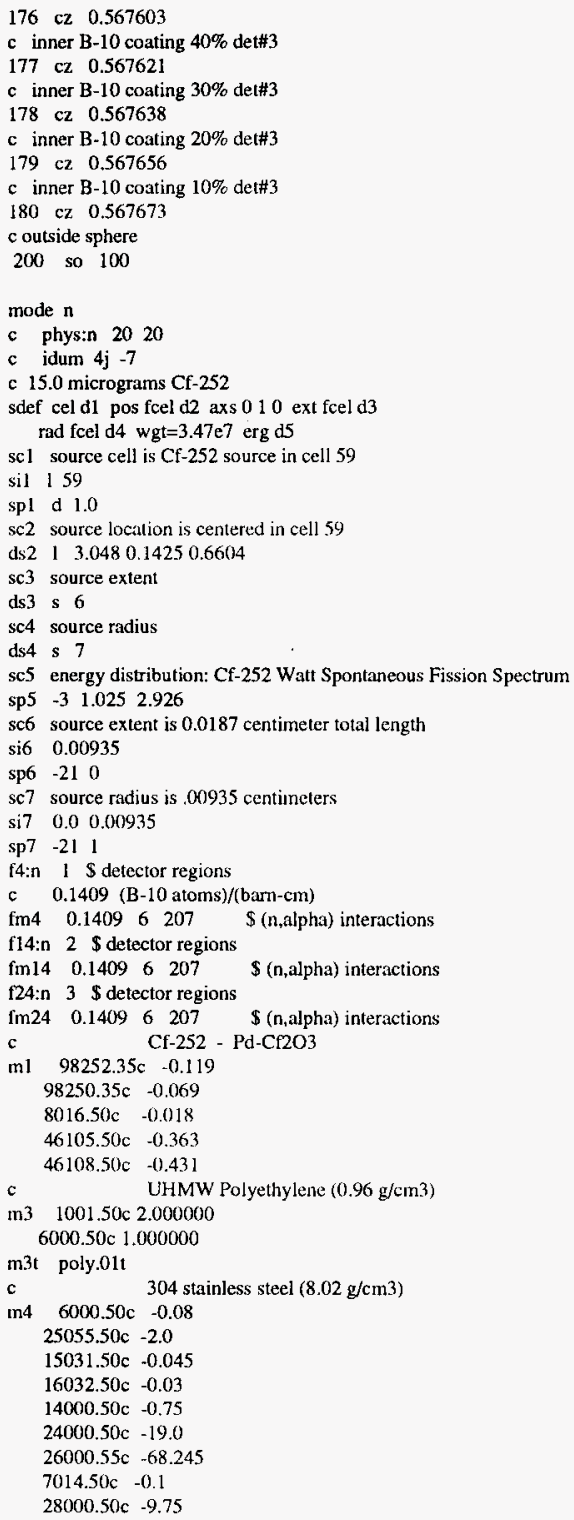


WHC-SD-WM-TI-786, Rev. 0

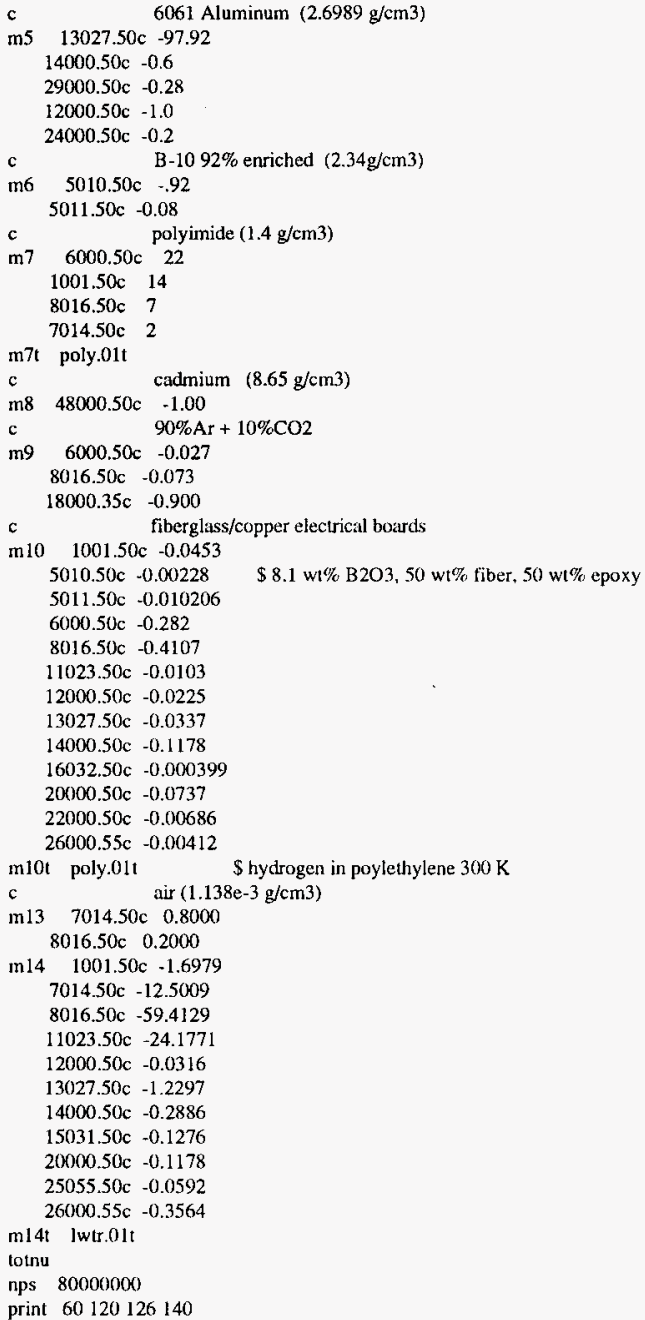


WHC-SD-WM-TI-786, Rev. 0

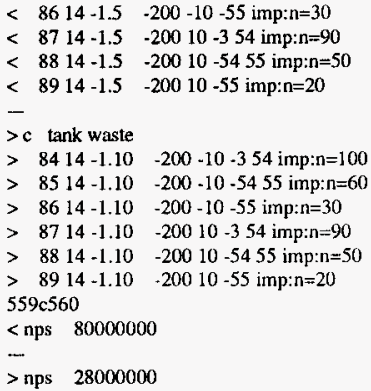

surfab15-1.2_t1 1.inp (waste density $=1.2 \mathrm{~g} / \mathrm{cm}^{3}$ ) $162,167 \mathrm{cl} 162,168$

$<8414-1.5-200-10-354 \mathrm{imp}: n=100$

$<8514-1.5 \quad-200-10-5455 \mathrm{imp}: \mathrm{n}=60$

$<8614-1.5-200-10-55$ imp: $n=30$

$<8714-1.5-20010-354$ imp: $n=90$

$<8814-1.5-20010-5455$ imp:n=50

$<8914-1.5-20010-55$ imp:n=20

$>$ c tank waste

$>8414-1.20 \quad-200-10-354$ imp: $n=100$

$>\quad 8514-1.20-200-10-5455$ imp: $n=60$

$>\quad 8614-1.20-200-10-55$ imp: $n=30$

$>\quad 8714-1.20 \quad-20010-354$ imp: $n=90$

$>\quad 8814-1.20-20010-5455$ imp: $n=50$

$>\quad 8914-1.20 \quad-20010-55$ imp: $n=20$

$559 \mathrm{c} 560$

$<$ nps 80000000

--

$>\mathrm{nps} \quad 28000000$

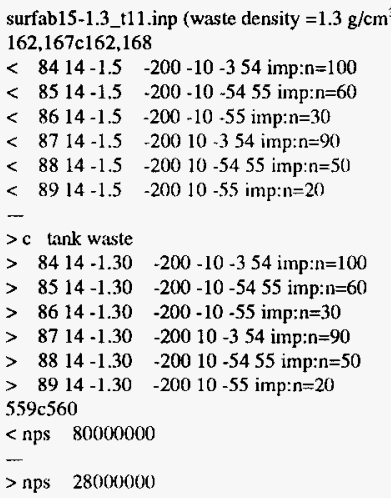


WHC-SD-WM-TI-786, Rev, 0

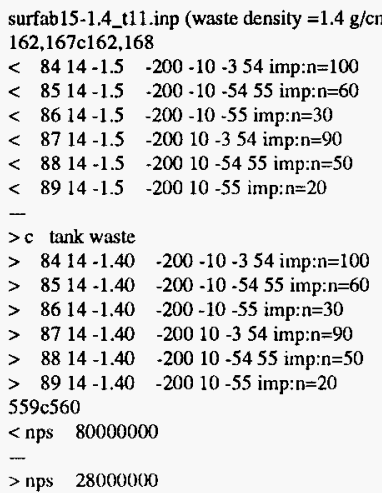

surfab15-1.6_t11.inp (waste density $=1.6 \mathrm{~g} / \mathrm{cm}^{3}$ ) $162,167 \mathrm{c} 162,168$

$<8414-1.5-200-10-354$ imp: $n=100$

$<8514-1.5-200-10-5455$ imp: $n=60$

$<8614-1.5-200-10-55$ imp:n=30

$<8714-1.5-20010-354$ imp: $n=90$

$<8814-1.5-20010-5455$ imp: $n=50$

$<8914-1.5-20010-55$ imp:n=20

$>c$ tank waste

$>8414-1.60-200-10-354$ imp: $n=100$

$>8514-1.60-200-10-5455$ imp: $n=60$

$>8614-1.60-200-10-55$ imp: $n=30$

$>8714-1.60-20010-354 \mathrm{imp}: n=90$

$>8814-1.60-20010-5455$ imp: $n=50$

$>\quad 8914-1.60-20010-55$ imp: $n=20$

$559 \mathrm{c} 560$

$<$ nps 80000000

$>$ nps 28000000

surfab15-1.7_t11.inp (waste density $=1.7 \mathrm{~g} / \mathrm{cm}^{3}$ ) $162.167 \mathrm{c} 162.168$

$<8414-1.5-200-10-354$ imp: $n=100$

$<8514+1.5-200-10-5455$ imp: $n=60$

$<8614-1.5+200+10-55$ imp: $n=30$

$<8714-1.5-20010-354$ imp: $n=90$

$<8814-1.5-20010-5455$ imp:n=50

$<\quad 8914-1.5 \quad-20010-55$ imp:n=20

$>$ c tank waste

$>8414-1.70-200-10-354$ imp: $n=100$

$>8514-1.70-200-10-5455$ imp: $n=60$

$>\quad 8614-1.70-200-10-55$ imp: $n=30$

$>\quad 8714-1.70-20010-3.54$ imp: $n=90$

$>8814-1.70 \quad-20010-5455 \mathrm{imp}: \mathrm{n}=50$

$>\quad 8914-1.70-20010-55$ imp: $n=20$

$559 \mathrm{c560}$ 
surfab15-1.8_t11.inp (waste density $=1.8 \mathrm{~g} / \mathrm{cm}^{3}$ ) $162,167 \mathrm{cl} 162,168$

$<8414-1.5-200-10-354$ imp: $n=100$

$<8514-1.5-200-10-5455$ imp: $n=60$

$<8614-1.5-200-10-55$ imp: $n=30$

$<8714-1.5-20010-354$ imp:n=90

$<8814-1.5-20010-5455$ imp:n=50

$<8914-1.5 \quad-20010-55$ imp: $n=20$

-

$>c$ tank waste

$>8414-1.80-200-10-354$ imp: $n=100$

$>8514-1.80-200-10-5455$ imp: $n=60$

$>8614-1.80-200-10-55$ imp: $n=30$

$>\quad 8714-1.80-20010-354$ imp: $n=90$

$>\quad 8814-1.80-20010-5455 \mathrm{imp}: n=50$

$>8914-1.80-20010-55$ imp: $n=20$

$559 \mathrm{c} 560$

< nps 80000000

$>$ nps 28000000

surfab15-1.9_t11.inp (waste density $=1.9 \mathrm{~g} / \mathrm{cm}^{3}$ ) $162,167 \mathrm{c} 162,168$

$<8414-1.5-200-10-354$ imp: $n=100$

$<8514-1.5-200-10-5455$ imp: $n=60$

$<8614-1.5-200-10-55$ imp: $n=30$

$<8714-1.5-20010-354$ imp:n=90

$<8814-1.5 \quad-20010-5455$ imp: $n=50$

$<8914-1.5 \quad-20010-55$ imp: $n=20$

$>c$ tank waste

$>8414-1.90-200-10-354$ imp: $n=100$

$>8514-1.90 \quad-200-10+5455$ imp: $n=60$

$>8614-1.90-200-10-55$ imp: $n=30$

$>\quad 8714-1.90-20010-354$ imp: $n=90$

$>\quad 8814-1.90 \quad-20010-5455 \mathrm{imp}: n=50$

$>8914-1.90-20010-55$ imp: $n=20$

$559 \mathrm{c} 560$

$<$ nps 80000000

$>$ nps 28000000

surfab0_tl1.inp (base case for moisture dependance cases: 0 wt\% water)

As-Built Surface Neutron Probe 1/22/96, Rev 0

c Det\#1 B-10 TALLY REGION 80-100\%

$\begin{array}{lllllll}1 & 6 & -2.34 & 31 & -30 & 27 & -28 \text { imp: } n=300\end{array}$

c DET\#2 B-10 TALLY REGION $80-100 \%$

$26-2.34 \quad 67-6670-71$ imp: $n=310$

c DET\#3 B-10 TALLY REGION 80-100\%

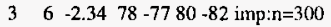

c narrow part of source housing

$44-8.02(97-2-54)(6: 14)$ imp:n $=100$ 
WHC-SD-WM-TI-786, Rev. 0

c entrance slot to source cavity

$513-.000114((16(-86: 87)):(-18-8786))$

$(3-17-1-15) \#(107-106)$ imp $: n=100$

c probe housing bottom

$6 \quad 4 \quad-8.02-43-16$ \#5 \#55 imp:n=100

c $\mathrm{Ar} / \mathrm{CO} 2 \mathrm{Det \# 1}$,

$79-.001(-2926-31):(153-3031-29):(-3031-15226)$ imp: $n=300$

c SS Cathode Det\# 1

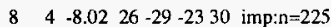

c Polyethylene Det\#1

$93-0.96(-2122-3426)(59: 24:-25)$ imp:n=200

c main cadmium Det\#1

$10 \quad 8 \quad-8.65(-343521-20)$ imp: $n=100$

c top cadmium washer det\# 1

$118-8.65(-3635-213839)$ imp: $n=100$

c bottom cadmium hat det\# 1

$128-8.65((34-33-202240):(34-3222-37):(-3229-22))$ imp: $n=100$

c ss clip around del\#1

$134-8.02(20-19-3360)$ imp: $n=100$

c ss plate screwed to cad shield

$14 \quad 4-8.02(-5149-52954193)$ imp:n=90

c cad shield under del\#3

$158 \quad-8.65(50-49-525341888990919293) \# 53$ imp: $n=90$

c Aluminum in poly insert of det\#1

$165-2.6989-242522-2126-34-59$ imp: $n=150$

c sides of probe housing (bottom third)

$174-8.02((-124-11):(-4-6-1 \quad 14))$ \#5 \#54 \#55 imp:n=100

c $\mathrm{Ar} / \mathrm{CO} 2$ Det\#2

$189-.001(69-72-67):(15567-66-72):(-15467-6669)$ imp:n=310

c Cathode Det\#2

$194-8.02 \quad 66-5869-72$ imp:n=300

c ss top Det\#2

$20 \quad 4 \quad-8.02 \quad-58 \quad 72-73$ imp:n=100

c bottom ss Det\#2

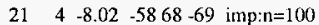

c Polyethylene Det\#2

$22 \quad 3-0.9658-5665-74$ imp: $n=200$

c SS mounting sleeve det $\# 2$

$234-8.02(56-61 \quad 65-74):(64-65-61)$ imp: $n=200$

c polyimide bottom det\#2

$24 \quad 7 \quad 1.4-5865-68$ imp: $n=100$

c polyimide on cadmium pliting

$2671.462-6344-74$ imp:n=100

c cadmium det $\# 2$

$258-8.65(61-62-7464):(44-64-62)$ imp: $n=140$

c SS mounting sleeve

$27 \quad 4-8.02((4563-41-7544):(-44-43-4145)$ :

(4 $-43-416345)$ ) \# 13 imp: $n=110$

c wide part of probe source housing

$28 \quad 4-8.02(-98-24-56) \# 5$ \#55 imp:n=100

c $\mathrm{Ar}+\mathrm{CO} 2$ gas det\#3

$299-.001(81-83-78):(157+8378-77):(-1568178-77)$ imp:n=300

c Cathode wall det\#3

$304-8.02 \quad 77-7681-83$ imp:n=200

c bottom ss det\#3

$\begin{array}{llllll}31 & 4 & -8.02 & -76 & 79 & -81 \\ \text { inp: } n=100\end{array}$

c top ss wall det\#3

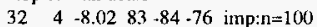

c polyimide det\#3

$\left.\begin{array}{lllll}33 & 7.4(76 & -47 & -84 & 79\end{array}\right):(51-79-47)$ imp: $n=200$

c ss mounting sleeve det\#3

$34 \quad 4-8.02(47-46-8551)$ imp: $n=150$ 
WHC-SD-WM-TI-786, Rev. 0

c polyimide around det\#1

$3571.4(23-22 \quad 26-29)$ imp $: n=200$

c air space below cad in probe

$3613-.000114(-504-2411960)(5:-8:(-79)) 95$ \#53 imp:n=100

$3713-.000114(-504-24120-60)(5:-8:(-79)) \# 53$ imp: $n=100$

$3813-.000114(37-233-19):(-37-232)$ imp: $n=100$

$39 \quad 13-.000114(-20-2-35)$ imp:n=100

$4013-.000114(63-414-75-45-2):(-634-43):(-63-4543-44)$ imp:n=100

$41 \quad 13-000114(36-21-26):(-3835-36):(-21-3935-36)$ imp:n=100

c ss screws in cad shield

$424-8.02-8850-49$ imp: $n=100$

$43 \quad 4-8.02-8950-49$ imp: $n=100$

$44 \quad 4-8.02-9050-49$ imp: $n=100$

$45 \quad 4-8.02-9150-49$ imp $n=100$

$46 \quad 4 \quad-8.0295-53 \quad 50-49$ imp: $n=100$

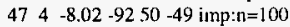

c \#10 threaded rod

$48 \quad 4-8.02(-12951-97):(-51-955)$ imp:n=100

c main thick wall portion of housing

$494-8.02-12211-130$ imp: $n=100$

c air above cad plate below top of det\#3

$50 \quad 13-.000114(-251-85)((464197):(6375-41)$

$:(58-6374):(73-58)) 9088$ imp: $n=100$

c around around cad/ss plate

$51 \quad 13-.000114(-25250-5141)$ imp:n=100

c slot in cad/ss plate for wire pass through

$5213-.000114(-93-5150) \# 51$ imp:n=100

c det\#l stiffener

$53 \quad 4-8.0298-99100-49101-102$ imp:n=100

c source holder grab hole

$54 \quad 13-.000114107-15-104$ imp: $n=100$

c source holder nut

$55 \quad 4 \quad-8.02-106104107-15$ imp: $n=100$

c source holder threads/body

$56 \quad 4 \quad-8.02-615-108$ imp: $n=100$

c source capsule

$57 \quad 4-8.02(-109108-112105):(110+109-105)$ :

(108-111-105) imp: $n=100$

c air around source capsule

$5813-.000114(112-6108-14):(-14109-112)$ imp: $n=100$

c Pd-CF2O3 NEUTRON SOURCE

59 ! $-10.0-113115-114 \quad$ imp: $n=100$

$c$ air around source

$6013-.000114-105111-110 \# 59$ imp: $n=100$

c electrical bostrd \#1

$61 \quad 10-1.21 \quad 116-117-2979088 \mathrm{imp}: n=100$

c threaded rod

$\begin{array}{llllll}62 & 4 & -8.02 & 51 & -129 & -90 \\ \text { imp: } n=90\end{array}$

c threaded rod

$\begin{array}{llllll}6 & 4 & -8.02 & 51 & -129 & -88 \mathrm{imp}: \mathrm{n}=1(00\end{array}$

c electrical board \#2

$6410-1.21 \quad 120-121-2979088 \mathrm{imp}: \mathrm{n}=100$

c electrical board \#3

$65 \quad 10-1.21 \quad 122-123-2979088$ imp: $n=100$

c electrical board \#4

$6610-1.21 \quad 126-127-2979088$ imp: $17=100$

c air above top of det\#3 below first electrical board

$6713+.000114(-285-11690889747):(-4784+116)$ imp:n $=90$

c air between board 1 and ss plate 40

$6813-.000114(-2117-118908897)$ imp: $n=90$

c air between ss plate 40 and board \#2

$6913-.000114(-2119-120908897)$ imp:n=90 
WHC-SD-WM-TI-786, Rev. 0

c air between board \#2 and board \#3

$7013-000114(-2121-122908897)$ imp: $n=90$

c SS ground Plane \#40

$714-8.02 \quad 118-119-2979088$ imp:n=90

c SS ground Plane \#41

$724-8.02 \quad 124-125-2979088$ imp:n=90

c SS ground Plane \#39

$734-8.02128-129-2979088$ imp: $n=90$

c air between board \#3 and SS plate \#41

$7413-.000114(-2123-1249088$. 97$)$ imp: $n=90$

c air between SS plate \#41 and board \#4

$7513-.000114(-2125-126908897)$ imp: $n=90$

c air between board \#4 \& SS plate \#39

$7613-.000114(-2127-128908897)$ imp $n=90$

c boltom of cableheat

$774-8.02103-130-12131 \# 49$ imp: $n=70$

c air between board \#4 \& SS plate \#39

$78 \quad 13-.000114-2129-103$ imp: $n=70$

c cablehead nut

$794-8.02130-132131-12$ imp: $n=50$

c cablehead neck

804 -8.02 $132-133131-134 \mathrm{imp}: \mathrm{n}=50$

c air around cablehead neck

$8113-.000114132-133134-12$ imp: $n=40$

c cable

$8213-.000114 \quad 103-133-131$ imp: $n=50$

C air around probe

$8313-.000114-2003((1-11):(1211): 133)$ imp:n=100)

$8414-1.5 \quad-200-10-354$ imp:n=100

$8514-1.5 \quad-200-10-5455$ imp: $n=60$

$8614-1.5 \quad-200-10-55$ imp: $n=30$

$8714-1.5 \quad-20010-354$ imp: $n=90$

$88 \quad 14-1.5 \quad-200 \quad 10-5455$ imp:n=50

$8914-1.5 \quad-20010-55$ imp: $n=20$

c extended B 10 coating bottom of det\#1

$104 \quad 6 \quad-2.34 \quad 31-30 \quad 152-27$ imp: $n=300$

c extended B10 coating top of det\#1

$1056-2.3431-3028-153$ imp: $n=300$

c extended B 10 coating bottom of det $\# 2$

$106 \quad 6 \cdot 2.3467-66 \quad 154-70$ imp: $n=300$

c extended B10 coating top of det $\# 2$

$1076-2.3467-6671+155$ imp: $n=300$

c extended B 10 coating boltom of det\#2

$\begin{array}{lllllll}108 & 6 & -2.34 & 78 & -77 & 156 & -80\end{array}$ imp: $n=300$

c extended $\mathrm{B} 10$ coating top of det\#2

$1096-2.34 \quad 78-7782-157$ imp: $n=300$

$110 \quad 13 \cdot .000114-40-2022 \quad 34-33 \quad 37$ imp:n=90

c temp outside

$150 \quad 0 \quad 200$ imp: $n=0$

$\begin{array}{ccl}1 & \mathrm{cz} & 4.2138599 \\ 2 & \mathrm{cz} & 3.8963599 \\ 3 & \mathrm{pz} & 0.0000000 \\ 10 & \mathrm{cz} & 25.00 \\ 54 & \mathrm{pz} & -34.000 \\ 55 & \mathrm{pz} & -69.000 \\ 4 & \mathrm{pz} & 0.3175000 \\ 5 & \mathrm{pz} & 1.5367000\end{array}$

c outer source hole

$\begin{array}{lllll}6 & \mathrm{c} / \mathrm{y} & 3.0480000 & 0.6604000 & 0.3568700 \\ 7 & \mathrm{px} & 2.5400000 & & \\ 8 & \mathrm{px} & 2.1844000 & & \end{array}$


WHC-SD-WM-TI-786, Rev. 0

9 py -0.7112000

c top of thin wall section of probe housing

11 pz 10.426700

c outer diameter of thick part (upper 2/3) of probe housing

$12 \mathrm{cz} \quad 4.3815$

$13 \quad$ pz 44.754799

14 py 1.5240000

15 py -1.7780000

$16 \quad$ px 2.3368000

$17 \quad \mathrm{pz} \quad 1.2954000$

$\begin{array}{lllll}18 & \mathrm{c} / \mathrm{y} & 2.9718000 & 0.6604000 & 0.6350000\end{array}$

$19 \mathrm{c} / \mathrm{y} \quad 0.0000000 \quad 1.7578 \quad 1.41478$

$\begin{array}{lllll}20 & \mathrm{c} / \mathrm{y} & 0.0000000 & 1.76000 & 1.28778\end{array}$

$\begin{array}{lllll}21 & \mathrm{c} / \mathrm{y} & 0.0000000 & 1.76000 & 1.1480800\end{array}$

$\begin{array}{lllll}22 & c / y & 0.0000000 & 1.76000 & 0.6400800\end{array}$

$\begin{array}{lllll}23 & \mathrm{c} / \mathrm{y} & 0.0000000 & 1.76000 & 0.6350000\end{array}$

$\begin{array}{llllll}24 & \mathrm{p} & 0.3400000 & 0.0000000 & 1.0000000 & 2.3825200 \\ 25 & \mathrm{p} & 0.3400000 & 0.0000000 & 1.0000000 & 1.0833100\end{array}$

26 py $-2.1285200 \quad 0.000000-1.0000000-1.0833100$

27 py -0.6299200

28 py 2.3164800

29 py 3.5864799

$\begin{array}{lllll}30 & \mathrm{c} / \mathrm{y} & 0.0000000 & 1.76000 & 0.5588000\end{array}$

c Inner B-10 lining $0.4 \mathrm{mg} / \mathrm{cm} 2$

$\begin{array}{lllll}31 & \text { c/y } & 0.0000000 & 1.76000 & 0.5586265 \\ 32 & \text { py } & 3.72618 & & \\ 33 & \text { py } & 2.77622 & & \\ 34 & \text { py } & 2.6365200 & & \\ 35 & \text { py } & -3.05562 & & \\ 36 & \text { py } & -2.9159200 & & \\ 37 & \text { c/y } & 0.0000000 & 1.76000 & 0.77978 \\ 38 & \text { c/y } & 0.0000000 & 1.76000 & 0.3175000 \\ 39 & \text { c/y } & 0.0000000 & 2.73260 & 0.3175000 \\ 40 & \text { c/y } 0.8221 .410 .3175 & \end{array}$

c Hole in Cad under Det\$3 for support rod

$\begin{array}{lllll}41 & \mathrm{c} / 2 & -2.6974800 & 0.0000000 & 1.26492 \\ 43 & \mathrm{pz} & 0.47498 & & \\ 44 & \mathrm{pz} & 0.62738 & & \\ 45 & \mathrm{px} & -3.3400999 & & \\ 46 & \mathrm{cz} & 0.7937500 & & \\ 47 & \mathrm{cz} & 0.6489700 & & \\ 48 & \mathrm{pz} & 11.772900 & & \\ 49 & \mathrm{pz} & 4.5084999 & & \\ 50 & \mathrm{pz} & 4.3433999 & & \\ \mathrm{c} \text { top of ss plate below det } \$ 3 & & \\ 51 & \mathrm{pz} & 4.6659799 & & \\ \mathrm{c} \text { radius of cad/SS shield } & & \\ 52 & \mathrm{cz} & 3.8353999 & & \\ 53 & \mathrm{c} / \mathrm{z} & 3.0162500 & 0.0000000 & 0.5041900\end{array}$

c inner polyethylene inner Det\#2

c poly outer Del\#2

$\begin{array}{lllll}56 & \mathrm{c} / \mathrm{z} & -2.6974800 & 0.0000000 & 1.0096500\end{array}$

c poly inner Det\#2

$\begin{array}{cccccc}57 & c / z & -2.6974800 & 0.0000000 & 0.6489700 & \\ 58 & c / z & -2.6974800 & 0.0000000 & 0.6350000 & \\ 59 & p & -16.436870 & 0.0000000 & 1.0000000 & 2.3825200 \\ 60 & \text { py } & -0.8970000 & & & \end{array}$

c inner ss cad-plated peice for det\#2

c SS plated piece outer det\#2

$61 \mathrm{c} / 2 \quad-2.6974800 \quad 0.0000000 \quad 1.1112500$

c 0.003 " Cad outer Del\#2

$\begin{array}{lllll}62 & \mathrm{c} / \mathrm{z} & -2.6974800 & 0.0000000 & 1.11379\end{array}$ 
WHC-SD-WM-TI-786, Rev. 0

c polyimide outer

$\begin{array}{lllll}63 & c / z & -2.6974800 & 0.0000000 & 1.11887\end{array}$

c Inner bottom cadmium Deł\#2

$64 \quad \mathrm{pz} \quad 0.62992$

c Inside bottom ss plated peice det\#2

65 pz 0.71882

c inner cathode det 2

$\begin{array}{lllll}66 & c / z & -2.6974800 & 0.0000000 & 0.5588000\end{array}$

c inner B-10 coating det\#2

$67 \quad \mathrm{c} / \mathrm{z} \quad-2.6974800 \quad 0.0000000 \quad 0.5586265$

c inner top polyimide det\#2

$\begin{array}{lll}68 & \text { pz } & 0.7239\end{array}$

c inner bottom ss cathode det\#2

c Bottom Active Region DET\#2

$\begin{array}{lll}69 & \text { pz } & 0.8001\end{array}$

70 pz 2.1590000

c top active region det\#2

71 pz 6.4769999

c Inside top Det\#2

72 pz 7.8993999

c Top of Det\#2

73 pz 7.9755999

c top of polyethylene det $\$ 2$

74 pz 7.7165199

c top of ss mounting sleeve det\#2

$75 \quad$ pz 7.2008999

c Inner polyimid det\#3

$\begin{array}{lll}76 & \mathrm{cz} & 0.6438900\end{array}$

c inner cathode Det\# 3

$\begin{array}{lll}77 \quad c z & 0.5676900\end{array}$

c Inner B-10 lining Det\#3

$\begin{array}{lll}78 \quad \mathrm{cz} & 0.5675165\end{array}$

c bottom Det\#3

$79 \quad \mathrm{pz} \quad 4.6710599$

c bottom active region det\#3

80 pz 6.1696599

c inside bottom det\#3

81 pz 4.7472599

c top active region det\#3

82 pz 10.487660

c inside top det\#3

$83 \quad$ pz $\quad 11.910060$

C top det\#3

$84 \quad$ pz 11.986260

c top mounting sleeve det\#3

85 pz $\quad 11.650980$

c through source slot

$86 \quad$ pz 0.6604

c through source slot

87 px 2.9718

c screw in cad shield X Y R

$88 \mathrm{c} / \mathrm{z}-1.51-2.60 .18669$

c screw in cad shield X Y R

$89 c / z-2.41-1.820 .18669$

c screw in cad shield $X Y R$ $90 \mathrm{c} / \mathrm{z}-1.512 .60 .18669$

c screw in cad shield $X Y R$

$91 \mathrm{c} / \mathrm{z}-0.372 .990 .18669$

c screw in cad shield X Y R

$92 \mathrm{c} / 2 \quad 2.78-1.180 .18669$

c slot in cad shield X Y R

$93 \mathrm{c} / \mathrm{z} \quad-.45-3.400 .4572$ 
WHC-SD-WM-TI-786, Rev. 0

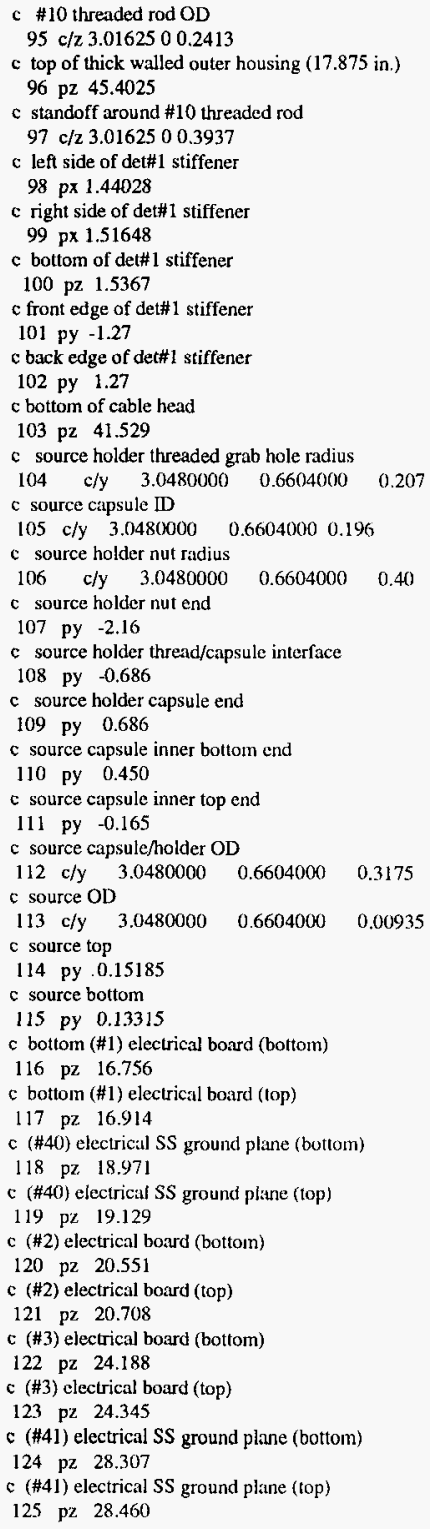


WHC-SD-WM-TI-786, Rev. 0

c (\#4) electrical board (bottom)

$126 \mathrm{pz} 29.882$

c (\#4) electrical board (top)

$127 \mathrm{pz} 30.04$

c (\#39) electrical SS ground plane (bottom)

$128 \mathrm{pz} 31.462$

c (\#39) electrical SS ground plane (Iop)

129 pz 31.615

c top shoulder of cable head

$130 \mathrm{pz} 43.74$

c cable OD

$131 \mathrm{cz} 1.06$

c approx top cable head nut

$132 \mathrm{pz} 46.92$

c top of cable head

$133 \mathrm{pz} \quad 52.73$

c OD of cable head neck

$134 \mathrm{cz} 1.4$

c extension of B 10 coating at bottom of det\#1

152 py -1.430

c extension of B10 coating at top of det\#]

153 py 3.116

c extension of B 10 coating at bottom of det\#2

$154 \mathrm{pz} 1.245$

c extension of B10 coating at top of det\#2

$155 \mathrm{pz} 7.391$

c extension of B 10 coating at bottom of det\#3

$156 \mathrm{pz} 5.256$

c extension of B 10 coating at top of del\#3

$157 \mathrm{pz} \quad 11.402$

c inner B-10 coating $70 \%$ det\#]

$\begin{array}{lllll}160 & c / y & 0.0 & 1.76 & 0.558679\end{array}$

c inner B-10 coating $60 \%$ det\#1

$161 \mathrm{c} / \mathrm{y} \quad 0.01 .760 .558696$

c inner B-10 coating 50\% det\#1

$162 \mathrm{c} / \mathrm{y} \quad 0.01 .76 \quad 0.558713$

c inner B-10 coating $40 \%$ det\#1

$163 \mathrm{c} / \mathrm{y} \quad 0.01 .760 .558731$

c inner B-10 coating 30\% det\#1

$164 \mathrm{c} / \mathrm{y} \quad 0.01 .76 \quad 0.558748$

c inner B-10 coating $20 \%$ det\#1

$165 \mathrm{c} / \mathrm{y} \quad 0.01 .76 \quad 0.558766$

c inner B-10 coating $10 \%$ det\# 1 $\begin{array}{lllll}166 & \mathrm{c} / \mathrm{y} & 0.0 & 1.76 & 0.558783\end{array}$

c inner B-10 coating $70 \%$ det\#2

$\begin{array}{lllll}167 & \mathrm{c} / \mathrm{z} & -2.69748 & 0.0 & 0.558679\end{array}$

c inner B-10 coating $60 \%$ del 2

$\begin{array}{lllll}168 & \mathrm{c} / \mathrm{z} & -2.69748 & 0.0 & 0.558696\end{array}$

c inner B-10 coating $50 \%$ det\#2

$169 \mathrm{c} / \mathrm{z}-2.69748 \quad 0.0 \quad 0.558713$

$c$ inner B-10 coating $40 \%$ det\#2

$\begin{array}{lllll}170 & \mathrm{c} / \mathrm{z} & -2.69748 & 0.0 & 0.558731\end{array}$

$c$ inner B-10 coating 30\% det\#2

$171 \mathrm{c} / \mathrm{z}-2.69748 \quad 0.0 \quad 0.558748$

c inner B-10 coating $20 \%$ det 2

$172 \mathrm{c} / \mathrm{z}-2.69748 \quad 0.0 \quad 0.558766$

c inner B-10 coating $10 \%$ de $\# 2$

$173 \mathrm{c} / \mathrm{z}-2.69748 \quad 0.0 \quad 0.558783$

c inner B-10 coating $70 \%$ det 3

$174 \mathrm{cz} 0.567569$

c inner B-10 coating $60 \%$ det $\$ 3$

$175 \mathrm{cz} \quad 0.567586$ 
WHC-SD-WM-TI-786, Rev. 0

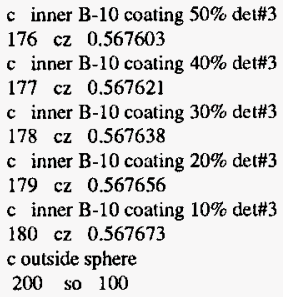


WHC-SD-WM-TI-786, Rev. 0

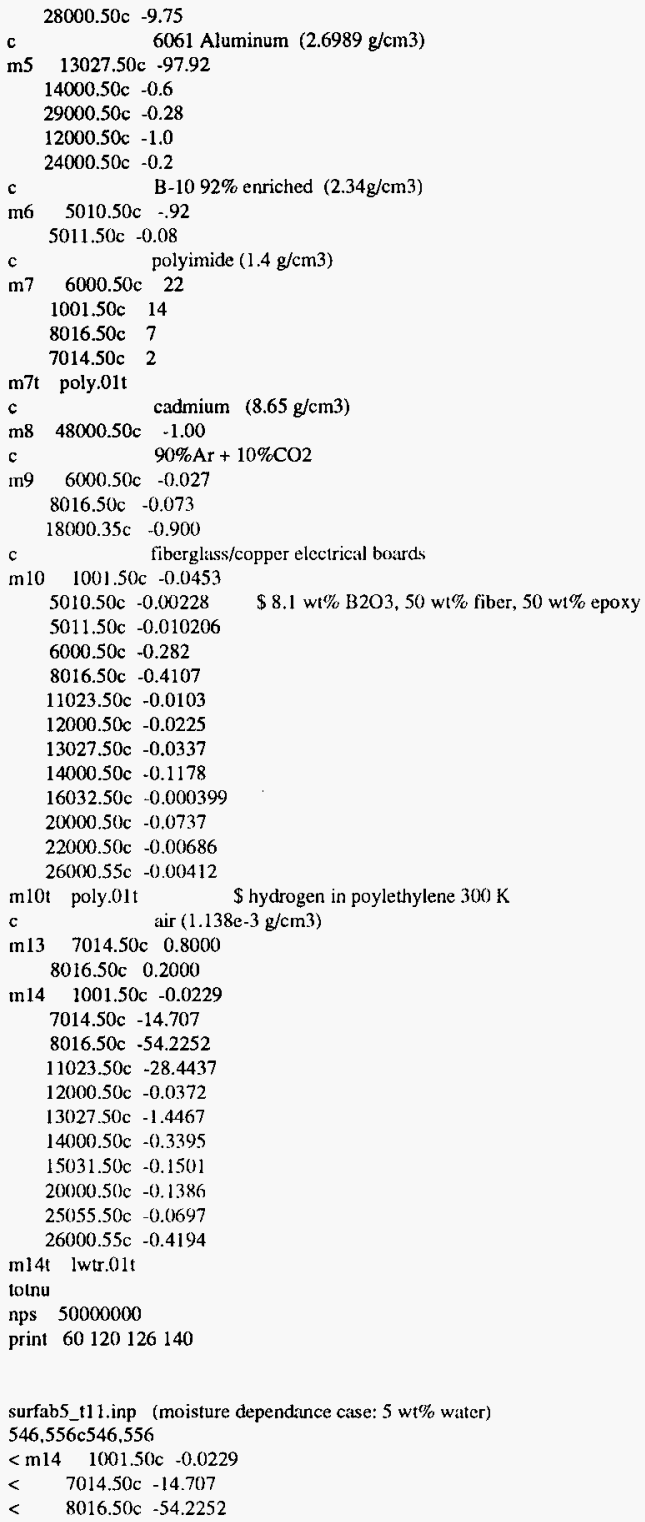


WHC-SD-WM-TI-786, Rev. 0

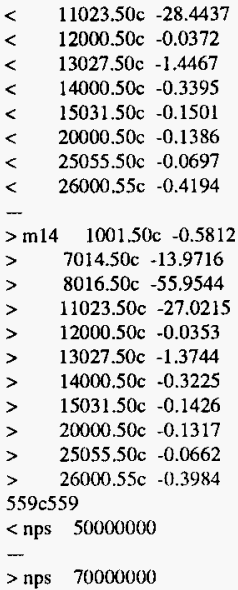

surfab10_t11.inp (moisture dependance case: $10 \mathrm{w1} \%$ water) $546,556 \mathrm{c} 546,556$

$<\mathrm{m} 14 \quad 1001.50 \mathrm{c}-0.0229$

$<\quad 7014.50 \mathrm{c}-14.707$

$<\quad 8016.50 \mathrm{c}-54.2252$

$<\quad 11023.50 \mathrm{c}-28.4437$

$<\quad 12000.50 \mathrm{c} \quad 0.0372$

$<\quad 13027.50 \mathrm{c}-1.4467$

$<\quad 14000.50 c-0.3395$

$<\quad 15031.50 \mathrm{c}-0.1501$

< $20000.50 c-0.1386$

$<\quad 25055.50 \mathrm{c}-0.0697$

< $26000.55 \mathrm{c}-0.4194$

$-$

$>\mathrm{m} 14 \quad 1001.50 \mathrm{c}-1.1396$

$>\quad 7014.50 \mathrm{c}-13.2363$

$>\quad 8016.50 \mathrm{c}-57.6837$

$>\quad 11023.50 \mathrm{c}-25.5993$

$>\quad 12000.50 \mathrm{c}-0.0335$

$>\quad 13027.50 \mathrm{c}-1.3021$

$>\quad 14000.50 \mathrm{c}-0.3056$

$>\quad 15031.50 \mathrm{c}-0.1351$

$>\quad 20000.50 \mathrm{c}-0.1248$

$>\quad 25055.50 \mathrm{c}-0.0627$

$>\quad 26000.55 \mathrm{c}-0.3774$

$559 \mathrm{c} 559$

$<$ nps 50000000

$\rightarrow$

$>$ nps 40000000

surfab15_t11.inp (moisture dependance case: 15 wi\% water) $546,556 \mathrm{c} 546.556$

$<\mathrm{ml4} \quad 1001.50 \mathrm{c} \cdot 0.0229$

$<\quad 7014.50 c-14.707$ 
WHC-SD-WM-TI-786, Rev. 0

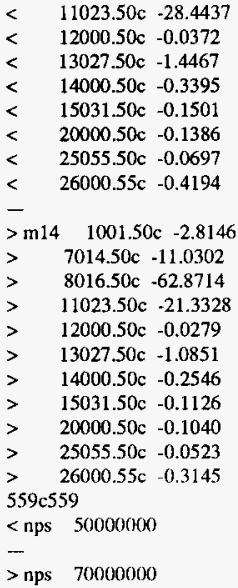

surfab30_tl1.inp (moisture dependance case: $30 \mathrm{wt} \%$ water) $546,556 \mathrm{c} 546,556$

$<\mathrm{m} 14 \quad 1001.50 \mathrm{c} \quad \cdot 0.0229$

< 7014.50c -14.707

$<\quad 8016.50 \mathrm{c}-54.2252$

$<\quad 11023.50 \mathrm{c}-28.4437$

$<\quad 12000.50 \mathrm{c}-0.0372$

$<\quad 13027.50 \mathrm{c}-1.4467$

$<\quad 14000.50 \mathrm{c}-0.3395$

$<\quad 15031.50 \mathrm{c}-0.1501$

$<\quad 20000.50 \mathrm{c}-0.1386$

< $25055.50 \mathrm{c}-0.0697$

< 26000.55 c -0.4194

$-$

$>\mathrm{m} 14 \quad 1001.50 \mathrm{c}-3.3730$

$>\quad 7014.50 \mathrm{c}-10.2949$

$>\quad 8016.50 \mathrm{c}-64.6007$

$>\quad 11023.50 \mathrm{c}-19.9106$

$>\quad 12000.50 \mathrm{c}-0.0260$

$>\quad 13027.50 \mathrm{c}-1.0127$

$>\quad 14000.50 c-0.2377$

$>\quad 15031.50 \mathrm{c}-0.1051$

$>\quad 20000.50 \mathrm{c}-0.0970$

$>\quad 25055.50 \mathrm{c}-0.0488$

$>\quad 26000.55 \mathrm{c} \quad 0.2935$

$559 \mathrm{c} 559$

$<$ nps 50000000

-

$>$ nps 35000000

surfab40_t11.inp (moisture dependance case: $40 \mathrm{wt} \%$ water) $546,556 \mathrm{c} 546,556$

$<\mathrm{ml4} 1001.50 \mathrm{c}-0.0229$

$<\quad 7014.50 \mathrm{c}-14.707$

$<\quad 8016.50 \mathrm{c}-54.2252$

< $\quad 11023.50 c-28.4437$ 
WHC-SD-WM-TI-786, Rev. 0

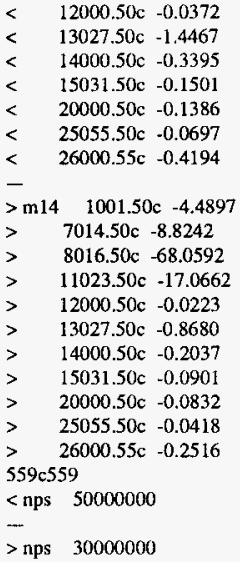

surfab50_tl1.inp (moisture dependance case: $50 \mathrm{wt} \%$ water) $546,556 \mathrm{c} 546,556$

$<\operatorname{mi4} 1001.50 \mathrm{c}-0.0229$

$<\quad 7014.50 \mathrm{c}-14.707$

$<\quad 8016.50 \mathrm{c}-54.2252$

$<\quad 11023.50 \mathrm{c}-28.4437$

$<\quad 12000.50 \mathrm{c}-0.0372$

$<\quad 13027.50 \mathrm{c}-1.4467$

$<\quad 14000.50 \mathrm{c}-0.3395$

$<\quad 15031.50 \mathrm{c}-0.1501$

< $\quad 20000.50 \mathrm{c}-0.1386$

< 25055.50c -0.0697

< $26000.55 \mathrm{c}-0.4194$

$\begin{array}{llll}- & \mathrm{m} 14 & 1001.50 \mathrm{c} & -5.6064\end{array}$

$>\quad 7014.50 \mathrm{c}-7.3535$

$>\quad 8016.50 \mathrm{c}-71.5177$

$>\quad 11023.50 \mathrm{c}-14.2218$

$>\quad 12000.50 \mathrm{c}-0.0186$

$>\quad 13027.50 \mathrm{c}-0.7234$

$>\quad 14000.50 \mathrm{c}-0.1698$

$>\quad 15031.50 \mathrm{c}-0.0751$

$>\quad 20000.50 c-0.0693$

$>\quad 25055.50 \mathrm{c}-0.0348$

$>\quad 26000.55 \mathrm{c}-0.2097$

$559 \mathrm{c} 559$

< nps 50000000

-

$>$ nps 25000000

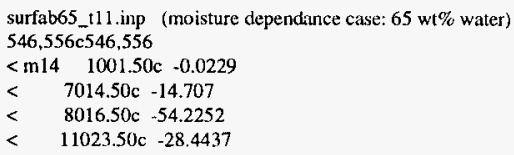


WHC-SD-WM-TI-786, Rev. 0

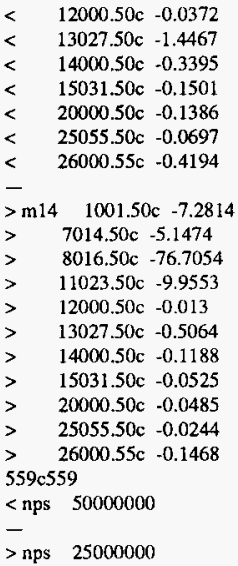

surfab15_tl1-org l.inp (total organic concentration: I wt\%) $546,556 \mathrm{c} 546,557$

$<\mathrm{m} 14 \quad 1001.50 \mathrm{c}-1.6979$

$<\quad 7014.50 c-12.5009$

$<\quad 8016.50 \mathrm{c}-59.4129$

$<\quad 11023.50 \mathrm{c}-24.1771$

$<\quad 12000.50 \mathrm{c}-0.0316$

$<\quad 13027.50 \mathrm{c}-1.2297$

$<\quad 14000.50 \mathrm{c}-0.2886$

$<\quad 15031.50 \mathrm{c}-0.1276$

$<\quad 20000.50 \mathrm{c}-0.1178$

< $25055.50 c+0.0592$

$<\quad 26000.55 \mathrm{c}-0.3564$

$-$

$>\mathrm{ml} 1001.50 \mathrm{c}-1.7822 \quad \$ 15 \% \mathrm{H} 2 \mathrm{O}, 1 \%$ organic

$>\quad 6000.50 c-0.518$

$>\quad 7014.50 \mathrm{c}-12.3661$

$>\quad 8016.50 \mathrm{c}-59.1276$

$>\quad 11023.50 \mathrm{c}-23.9776$

$>\quad 12000.50 \mathrm{c}-0.0312$

$>\quad 13027.50 \mathrm{c}-1.2153$

$>\quad 14000.50 \mathrm{c}-0.2852$

$>\quad 15031.50 \mathrm{c}-0.1700$

$>\quad 20000.50 \mathrm{c}-0.1164$

$>\quad 25055.50 \mathrm{c}-0.0585$

$>\quad 26000.55 \mathrm{c}-0.3523$

$559 \mathrm{c} 560$

$<$ nps 80000000

-

$>$ nps $\quad 40000000$

surfab15_t11-org2.inp (total organic concentration: 2 wi\%) $546,556 \mathrm{c} 546,557$

$<\mathrm{ml4} \quad 1001.50 \mathrm{c}-1.6979$

$<\quad 7014.50 \mathrm{c}-12.5009$

$<\quad 8016.50 \mathrm{c}-59.4129$

$<\quad 11023.50 \mathrm{c}-24.1771$ 
WHC-SD-WM-TI-786, Rev. 0

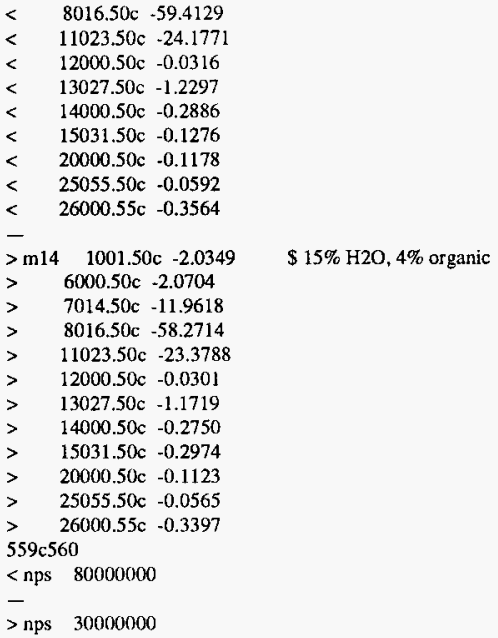

surfab15_111-org6.inp (total organic concentration: 6 w1\%) $546,556 \mathrm{c} 546,557$

$<\mathrm{mI} 4 \quad 1001.50 \mathrm{c}-1.6979$

$<\quad 7014.50 \mathrm{c}-12.5009$

$<\quad 8016.50 \mathrm{c}-59.4129$

$<\quad 11023.50 \mathrm{c}-24.1771$

$<\quad 12000.50 \mathrm{c}-0.0316$

$<\quad 13027.50 \mathrm{c}-1.2297$

$<\quad 14000.50 \mathrm{c}-0.2886$

$<\quad 15031.50 \mathrm{c}-0.1276$

$<\quad 20000.50 \mathrm{c}-0.1178$

$<\quad 25055.50 \mathrm{c}-0.0592$

< 26000.55c -0.3564

-

$>\mathrm{ml} 14 \quad 1001.50 \mathrm{c}-2.2034$

$>\quad 6000.50 \mathrm{c}-3.1055$

$>\quad 7014.50 c-11.6922$

$>\quad 8016.50 c-57.7006$

$>\quad 11023.50 \mathrm{c}-22.9797$

$>\quad 12000.50 \mathrm{c}-0.0294$

$>\quad 13027.50 \mathrm{c}-1.1429$

$>\quad 14000.50 \mathrm{c}-0.2682$

$>\quad 15031.50 \mathrm{c}-0.3823$

$>\quad 20000.50 \mathrm{c}-0.1095$

$>\quad 25055.50 c-0.0551$

$>\quad 26000.55 \mathrm{c}+0.3313$

$559 \mathrm{c} 560$

< nps 80000000

$>$ nps 28000000

surfab15_t11-org8.inp (total organic concentration: $8 \mathrm{wt} \%$ ) $546,556 \mathrm{c} 546,557$

$\$ 15 \% \mathrm{H} 2 \mathrm{O}, 6 \%$ organic 
WHC-SD-WM-TI-786, Rev. 0

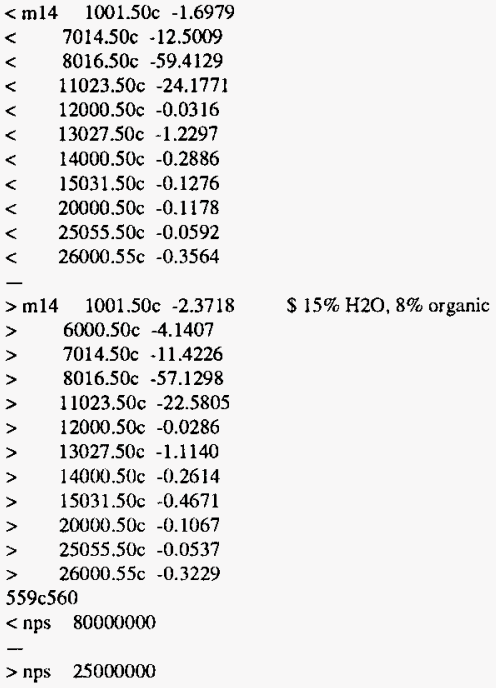

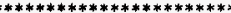

surfab4_t13.inp (no anomaly base case for following material geometry/probe placement anomaly cases)

As-Built Surface Neutron, Cd d\#1 .055", Cd d\#2,006". Stand\#4 19wi\%

c Det\#1 B-10 TALLY REGION 80-100\%

$\begin{array}{llllll} & 6 & -2.34 & 31 & -16027-28 \text { imp: } n=300\end{array}$

c DET\#2 B-10 TALLY REGION 80-100\%

$26-2.34 \quad 67-16770-71$ imp: $n=310$

c DET\#3 B-10 TALLY REGION 80-100\%

$36-2.3478-17480-82$ imp: $n=300$

c narrow part of source housing

$4 \quad 4-8.02(97-2-54)(6: 14)$ imp: $n=100$

c entrance siot to source cavity

$513-.000114((16(-86: 87)):(-18-8786))$

$(3-17-1-15) \#(107-106)$ imp:n=100

c probe housing bottom

$64-8.02-43-16 \# 5 \# 55$ imp: $n=100$

c $\mathrm{Ar} / \mathrm{CO} 2 \mathrm{Det} 1$

$79-.001(-2926-31):(153-3031-29):(-3031-15226)$ imp:n=300

c SS Cathode Det\# 1

$8 \quad 4-8.02 \quad 26-29-2330$ imp: $n=225$

c Polyethylene Det\#1

$93-0.96(-2122-3426)(59: 24:-25)$ imp: $n=200$

c main cadmium Det\#1

$108-8.65(-343521-20)$ imp: $n=100$

c top cadmium washer det\#1

$118+8.65(-3635-213839)$ imp: $n=100$

c bottom cadmium hat det\# 1

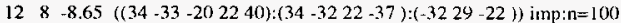

c ss clip around de!\# 1

$134-8.02(20-19-3360)$ imp: $n=100$

c ss plate screwed to cad shield

$14 \quad 4-8.02(-5149-52954193)$ imp:n=90 
WHC-SD-WM-TI-786, Rev. 0

c cad shield under det\#3

$158-8.65(50-49-525341888990919293) \# 53$ imp:n=90

c Aluminum in poly insert of det\#1

$165-2,699-242522-2126-34-59$ imp: $n=150$

c sides of probe housing (bottom third)

$174-8.02((-124-11):(-4-6-114)) \# 5 \# 54 \# 55$ imp: $n=100$

c $\mathrm{Ar} / \mathrm{CO} 2 \mathrm{Det} 2$

$189-.001(69-72-67):(15567-66-72):(-15467-6669)$ imp:n=310

c Cathode Det\#2

$194 \quad-8.02 \quad 66-5869-72$ imp:n=300

c ss top Det\#2

$20 \quad 4 \quad-8.02 \quad-5872-73$ imp: $n=100$

c bottom ss Det\#2

$21 \quad 4 \quad-8.02 \quad-5868 \quad-69$ imp: $n=100$

c Polyethylene Det\#2

$223-0.9658-5665-74 \mathrm{imp}: \mathrm{n}=200$

c SS mounting sleeve det\#2

$234-8.02(56-6165-74):(64-65-61)$ imp:n=200

c polyimide bottom det $\$ 2$

$2471.4-5865-68$ imp: $n=100$

c polyimide on cadmium plating

$\begin{array}{llllllll}26 & 7 & 1.4 & 62 & -63 & 44 & -74 & \text { imp: } n=100\end{array}$

c cadmium det\#2

$258-8.65(61-62-7464):(44-64-62)$ imp: $n=140$

c SS mounting sleeve

$274-8.02((4563-41-7544):(-4443-4145)$ :

$(4-43-416345))$ \# 13 imp: $n=110$

c wide part of probe source housing

$284-8.02(-98-24-56)$ \#5 \#55 imp $: n=100$

c $\mathrm{Ar}+\mathrm{CO} 2$ gas det\#3

$299-.001(81-83-78):(157-8378-77):(-1568178-77)$ imp: $n=300$

c Cathode wall det\#3

$\begin{array}{lllllll}30 & 4 & -8.02 & 77 & -76 & 81 & -83 \\ \text { imp: } n=200\end{array}$

c bottom ss det\#3

$31 \quad 4 \quad-8.02 \quad-7679-81$ imp:n=100

c top ss wall det\#3

$\begin{array}{llllll}32 & 4 & -8.02 & 83 & -84 & -76 \\ \text { imp: } n=100\end{array}$

c polyimide det\#3

$3371.4(76-47-8479):(51-79-47)$ imp:n=200

c ss mounting sleeve det\#3

$34 \quad 4-8.02(47-46-8551)$ imp: $n=150$

c polyimide around det\#1

$35 \quad 7 \quad 1.4 \quad(23-22 \quad 26-29)$ imp: $n=200$

c air space below cad in probe

$3613-.000114(-504-2411960)(5:-8:(-79) 95 \# 53$ imp:n=100

$3713-.000114(-504-24120-60)(5:-8:(-79)) \# 53$ imp:n $=100$

$3813-.000114(37-233-19):(-37-232)$ imp: $n=100$

$3913-.000114(-20-2-35)$ imp: $n=100$

$4013-.000114(63-414-75-45-2):(-634-43):(-63-4543-44)$ imp: $n=100$

$4113-.000114(36-21-26):(-38 \quad 35-36):(-21-3935-36)$ imp: $n=100$

c ss screws in cad shield

$424-8.02-8850-49$ imp: $n=100$

$434-8.02-8950-49$ imp: $n=100$

$44 \quad 4 \quad-8.02-9050-49$ imp: $n=100$

$454-8.02-9150-49 \mathrm{imp}: n=100$

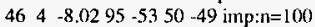

$474+8.02-9250-49$ imp: $n=100$

c \#10 threaded rod

$484-8.02(-12951-97):(-51-955)$ imp:n=100

c main thick wall portion of housing

$494-8.02-12211-130$ imp: $n=100$

c air above cad plate below top of det\#3 
WHC-SD-WM-TI-786, Rev. 0

$5013-.000114(-251-85)((464197):(6375-41)$

$:(58-6374):(73-58)) 9088$ imp:n=100

$c$ around around $\mathrm{cad} / \mathrm{ss}$ plate

$5113-.000114(-25250-5141)$ imp: $n=100$

c slot in cad/ss plate for wire pass through

$5213-000114(-93-5150) \# 51$ imp:n=100

c det\#1 stiffener

$53 \quad 4 \quad-8.0298-99100-49101-102$ imp: $n=100$

c source holder grab hole

$5413-.000114107-15-104$ imp:n=100

c source holder nut

$55 \quad 4-8.02-106104107-15$ imp:n=100

c source holder threads/body

$56 \quad 4-8.02-615-108$ imp: $n=100$

c source capsule

$574-8.02(-109108-112105):(110-109-105)$ :

(108-111-105) imp:n=100

c air around source capsule

$5813-.000114(112-6108-14):(-14109-112)$ imp:n=100

c Pd-Cr2O3 NEUTRON SOURCE

$591-10.0-113115-114 \quad$ imp: $n=100$

$c$ air around source

$6013-.000114-105111-110 \# 59$ imp: $n=100$

c electrical board $\# 1$

$6110-1.2] \quad 116-117-2979088$ imp: $n=90$

c threaded rod

$62 \quad 4 \quad-8.02 \quad 51-129-90 \mathrm{imp}: n=100$

c threaded rod

$63 \quad 4-8.02 \quad 51-129-88$ imp: $n=100$

c electrical board \#2

$6410-1.21 \quad 120-121-2979088$ imp: $n=100$

c electrical board \#3

$6510-1.21 \quad 122-123-2979088$ imp: $n=100$

c electrical board \#4

$6610-1.21 \quad 126-127-2979088$ imp: $n=100$

c air above top of det\#3 below first electrical board

$6713-.000114(-285-11690889747):(-4784-116)$ imp:n=90

c air between board 1 and ss plate 40

$6813-.000114(-2117-118908897)$ imp: $n=90$

c air between ss plate 40 and board \#2

$6913-.000114(-2119-120908897) \mathrm{imp}: n=90$

c air between board \#2 and board \#3

$7013-000114(-2121-122908897)$ imp: $n=90$

c SS ground Plane \#40

$714-8.02118-119-2979088$ imp: $n=90$

c SS ground Plane \#41

$724-8.02 \quad 124-125-2979088$ imp:n=90

c SS ground Plane \#39

$734-8.02 \quad 128-129-2979088$ imp: $n=90$

c air between board \#3 and SS plate \#41

$7413+000114(-2123-124908897)$ imp: $n=90$

$c$ air between SS plate \#41 and board \#4

$7513-.000114(-2125-126908897)$ imp: $n=90$

c air between board \#4 \& SS plate \#39

$7613-.000114(-2127-128908897)$ imp:n=90

c bottom of cablehend

$774-8.02103-130-12131$ \#49 imp: $n=70$

c air between board \#4 \& SS plate \#39

$78 \quad 13-.000114-2129-103$ imp:n=70

c cablehead nut

$794-8.02130-132131-12$ imp:n=50

c cablehead neck 
WHC-SD-WM-TI-786, Rev. 0

$804-8.02132-133131-134$ imp:n=50

c air around cablehead neck

$8113-.000114132-133134-12$ imp: $n=40$

c cable

$8213-.000114 \quad 103-133-131$ imp: $n=50$

c air around probe above barrel lip

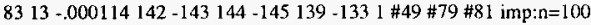

c top $0-3 \mathrm{~cm}$ layer of hydrated alumina + sand (inner cylinder)

$842-1.605-140146-135-151 \mathrm{imp}: n=100$

c $3-6 \mathrm{~cm}$ layer of hydrated alumina + sand (inner cylinder)

852 - $1.605-146147-135-151$ imp: $n=100$

c 6-9cm layer of hydrated alumina + sand (inner cylinder)

$862-1.605-147148-135-151$ imp: $n=90$

c $9-20 \mathrm{~cm}$ layer of hydrated alumina + sand (inner cylinder)

$872-1.605-148149-135-151$ imp:n=75

c $20-30 \mathrm{~cm}$ layer of hydrated alumina + sand (inner cylinder)

$882-1.605-149150-135-151$ imp: $n=60$

c $30 \mathrm{~cm}$-bottom layer of hydrated alumina + sand (inner cylinder)

$892-1.605-150137-135-151$ imp:n=50

c Aluminum barrel (upper sides)

$905-2.699(-1.391 .35-136149)$ imp: $n=9$ (]

c Aluminum lid (top)

$915-2.699-3140-135$ imp: $n=100$

c Air inside barrel

$92 \quad 13-.0001143-139-1351 \# 49$ imp: $n=100$

c poly under barrel (inner cylinder)

$933-0.96141-138-151$ imp: $n=30$

c air around barrel

$9413-.000114136138-139142-143144-145$ imp: $n=40$

c Aluminum bartel (bottom)

$955-2.699-135138-137$ imp: $n=40$

c top 0-3cm layer of hydrated alumina + sand (outer ring)

$962-1.605-140146-135151 \mathrm{imp}: 1=100$

c $3-6 \mathrm{~cm}$ layer of hydrated alumina + satnd (outer ring)

$972-1.605-146147-135151$ imp: $n=90$

c $6-9 \mathrm{~cm}$ layer of hydrated alumina + sand (outer ring)

$982-1.605-147148-135151 \mathrm{imp}: n=80$

c $9-20 \mathrm{~cm}$ layer of hydrated alumina + sand (outer ring)

$992-1.605-148149-135151$ imp: $n=65$

c $20-30 \mathrm{~cm}$ layer of hydrated alumina + sand (outer ring)

$1002-1.605-149150-135151$ imp: $n=50$

c $30 \mathrm{~cm}$-bottom layer of hydrated alumina + sand (outer ring)

$1012-1.605-150137-135151$ imp: $n=40$

c poly under barrel (outer)

$1023-0.96141-138 \quad 142-143 \quad 144-145 \quad 151$ imp: $n=20$

c Aluminum barrel (bottom sides)

$1035-2.699(138135-136-149)$ imp:n=50

c extended $B 10$ coating botton of det\#1

$104 \quad 6 \quad-2.34 \quad 3 !-30 \quad 152-27$ imp: $n=300$

c extended B10 coating top of det\#1

$1056-2.3431+3028-153$ imp:n=300

c extended B10 coating bottom of det\#2

$106 \quad 6-2.34 \quad 67-66154-70$ imp:n=300

c extended B 10 coating top of det\#2

$107 \quad 6-2.34 \quad 67-6671-155$ imp:n=300

c extended $\mathrm{B} 10$ coating bottom of det\#2

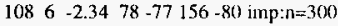

c extended B 10 coating top of det\#2

$109 \quad 6 \quad-2.34 \quad 78-7782-157$ imp: $n=3(0)$

c hole in cad det\#l lor temp sensor

$110 \quad 13-.000114-40-2022.34-3337$ imp: $n=90$

c DET\#1 B-10 TALLY REGION 70\% 
WHC-SD-WM-TI-786, Rev. 0

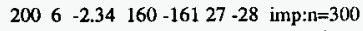

c DET\#1 B-10 TALLY REGION 60\%

$201 \quad 6 \quad-2.34 \quad 161-16227-28$ imp:n=300

c DET\#1 B-10 TALLY REGION $50 \%$

$202 \quad 6 \quad-2.34 \quad 162-16327-28$ imp: $n=300$

c DET\#1 B-10 TALLY REGION $40 \%$

$\begin{array}{lllllll}203 & 6 & -2.34 & 163 & -164 & 27 & -28 \\ \text { imp:n}=300\end{array}$

c DET\#1 B-10 TALLY REGION 30\%

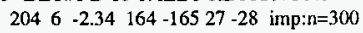

c DET\#1 B-10 TALLY REGION 20\%

$205 \quad 6 \quad-2.34 \quad 165-16627-28$ imp: $n=300$

c DET\#1 B-10 TALIY REGION $10 \%$

$206 \quad 6 \quad-2.34 \quad 166-3027-28$ imp: $n=300$

c DET\#2 B-10 TALLY REGION $70 \%$

$2076-2.34167-16870-71$ imp:n=310

c DET\#2 B-10 TALLY REGION 60\%

$\begin{array}{lllllll}208 & 6 & -2.34 & 168 & -169 & 70 & -71 \\ \text { imp: } n=310\end{array}$

c DET\#2 B-10 TALLY REGION 50\%

$2096-2.34 \quad 169-17070-71$ imp:n=310

c DET\#2 B-10 TALLY REGION 40\%

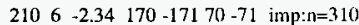

c DET 2 B-10 TALLY REGION $30 \%$

$\begin{array}{lllllll}211 & 6 & -2.34 & 171 & -172 & 70 & -71 \\ \text { imp: } n=310\end{array}$

c DET $\# 2$ B-10 TALLY REGION $20 \%$

$212 \quad 6 \quad-2.34 \quad 172-17370-71$ imp: $n=310$

c DET\#2 B-10 TALLY REGION 10\%

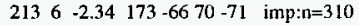

c DET\#3 B-10 TALLY REGION 70\%

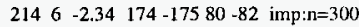

c DET\#3 B-10 TALLY REGION $60 \%$

$215 \quad 6 \quad-2.34 \quad 175-176 \quad 80-82 \mathrm{imp}: n=300$

c DET\#3 B-10 TALLY REGION $50 \%$

$216 \quad 6-2.34 \quad 176-17780-82$ imp: $n=300$

c DET\#3 B-10 TALLY REGION $40 \%$

$\begin{array}{lllllll}217 & 6 & -2.34 & 177 & -178 & 80 & -82 \\ \text { imp } n=300\end{array}$

c DET\#3 B-10 TALLY REGION 30\%

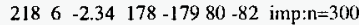

c DET\#3 B-10 TALLY REGION $20 \%$

$219 \quad 6 \quad-2.34 \quad 179-18080-82$ imp: $n=300$

c DET\#3 B-10 TALLY REGION $10 \%$

$220 \quad 6 \quad-2.34 \quad 180-7780-82$ imp: $n=300$

c outside (void)

$1500 \quad-141:-142: 143 ;-144: 145: 133$ imp:n=0

$\begin{array}{lll}1 & \mathrm{cz} & 4.2138599\end{array}$

$2 \quad \mathrm{cz} \quad 3.8963599$

3 pz 0.0000000

4 pz 0.3175000

5 pz 1.5367000

c outer source hole
$\begin{array}{lllll}6 & c / y & 3.0480000 & 0.6604000 & 0.3568700\end{array}$
7 px 2.5400000
8 px 2.1844000
9 py -0.7112000

c top of thin wall section of probe housing

11 pz 10.426700

c outer diameter of thick part (upper $2 / 3$ ) of probe housing

$12 \mathrm{cz} 4.3815$

13 pz 44.754799

14 py 1.5240000

15 py -1.7780000

16 px 2.3368000 
WHC-SD-WM-TI-786, Rev. 0

\begin{tabular}{lccllll}
17 & $\mathrm{pz}$ & 1.2954000 & & & \\
18 & $\mathrm{c} / \mathrm{y}$ & 2.9718000 & 0.6604000 & 0.6350000 & \\
19 & $\mathrm{c} / \mathrm{y}$ & 0.0000000 & 1.7578 & 1.41478 & \\
20 & $\mathrm{c} / \mathrm{y}$ & 0.0000000 & 1.76000 & 1.28778 & \\
21 & $\mathrm{c} / \mathrm{y}$ & 0.0000000 & 1.76000 & 1.1480800 & \\
22 & $\mathrm{c} / \mathrm{y}$ & 0.0000000 & 1.76000 & 0.6400800 & \\
23 & $\mathrm{c} / \mathrm{y}$ & 0.0000000 & 1.76000 & 0.6350000 & \\
24 & $\mathrm{p}$ & 0.3400000 & 0.0000000 & 1.0000000 & 2.3825200 \\
25 & $\mathrm{p}$ & 0.3400000 & 0.0000000 & 1.0000000 & 1.0833100 \\
26 & $\mathrm{py}$ & -2.1285200 & & & \\
27 & py & -0.6299200 & & & \\
28 & py & 2.3164800 & & & \\
29 & py & 3.5864799 & & & \\
30 & $\mathrm{c} / \mathrm{y}$ & 0.0000000 & 1.76000 & 0.5588000 & \\
\hline
\end{tabular}

c Inner B-10 lining $0.4 \mathrm{mg} / \mathrm{cm} 2$

$\begin{array}{lllll}31 & c / y & 0.0000000 & 1.76000 & 0.5586265 \\ 32 & \text { py } & 3.72618 & & \\ 33 & \text { py } & 2.77622 & & \\ 34 & \text { py } & 2.6365200 & & \\ 35 & \text { py } & -3.05562 & & \\ 36 & \text { py } & -2.9159200 & & \\ 37 & c / y & 0.0000000 & 1.76000 & 0.77978 \\ 38 & c / y & 0.0000000 & 1.76000 & 0.3175000 \\ 39 & c / y & 0.0000000 & 2.73260 & 0.3175000 \\ 40 & c / y & 0.8221 .410 .3175 & \end{array}$

c Hole in Cad under Det $\$ 3$ for support rod

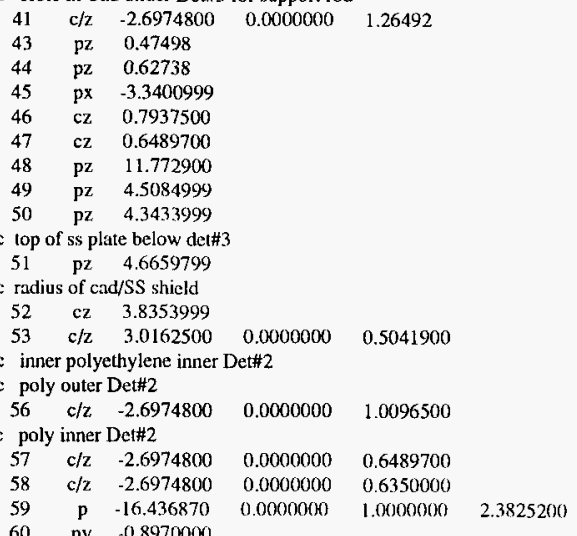

c inner ss cad-plated peice for det\#2

c SS plated piece outer det\#2

$61 \quad \mathrm{c} / \mathrm{z} \quad-2.6974800 \quad 0.0000000 \quad 1.1112500$

c $0.003^{\prime \prime}$ Cad outer Del\#2

$\begin{array}{lllll}62 & \mathrm{c} / \mathrm{z} & -2.6974800 & 0.0000000 & 1.11379\end{array}$

c polyimide outer

$\begin{array}{lllll}63 & \mathrm{c} / \mathrm{z} & -2.6974800 & 0.0000000 & 1.11887\end{array}$

c Inner bottom cadmium Det\#2

$64 \quad \mathrm{pz} \quad 0.62992$

c Inside bottom ss plated peice det\#2

$\begin{array}{lll}65 \mathrm{pz} & 0.71882\end{array}$

c inner cathode det\#2

$\begin{array}{lllll}66 & \mathrm{c} / \mathrm{z} & -2.6974800 & 0.0000000 & 0.5588000\end{array}$

c inner B-10 coating det\#2 
$\begin{array}{lllll}67 & c / 2 & -2.6974800 & 0.0000000 & 0.5586265\end{array}$

c inner top polyimide det\#2

$\begin{array}{lll}68 & \text { pz } & 0.7239\end{array}$

c inner bottom ss cathode det\#2

c Bottom Active Region DET\#2

69 pz 0.8001

$70 \quad$ pz 2.1590000

c top active region det\#2

$\begin{array}{lll}71 & \text { pz } & 6.4769999\end{array}$

c Inside top Det\#2

$\begin{array}{lll}72 & \text { pz } & 7.8993999\end{array}$

c Top of Det\#2

73 pz 7.9755999

c top of polyethylene det\#2

74 pz 7.7165199

c top of ss mounting sleeve det\#2

$75 \quad$ pz 7.2008999

c Inner polyimid det\#3

$\begin{array}{lll}76 & \mathrm{cz} & 0.6438900\end{array}$

c inner cathode Det\#3

$77 \quad \mathrm{cz} \quad 0.5676900$

c Inner B-10 lining Det\#3

$\begin{array}{lll}78 \quad \mathrm{cz} & 0.5675165\end{array}$

c bottom Det\#3

79 pz 4.6710599

c bottom active region det\#3

80 pz 6.1696599

c inside bottom det\#3

81 pz 4.7472599

c top active region det\#3

82 pz 10.487660

c inside top det\#3

83 p2 11.910060

c top det\#3

$84 \quad \mathrm{pz} \quad \mathrm{I} 1.986260$

c top mounting sleeve det\#3

$85 \quad$ pz $\quad 11.650980$

c through source slot 86 pz 0.6604

c through source slot 87 px 2.9718

c screw in cad shield $X$ Y R $88 \mathrm{c} / \mathrm{z}-1.51-2.60 .18669$

c screw in cad shield X Y R $89 \mathrm{c} / \mathrm{z}-2.41-1.820 .18669$

c screw in cad shield X Y R $90 \mathrm{c} / \mathrm{z}-1.512 .60 .18669$

c screw in cad shield X Y R $91 \mathrm{c} / \mathrm{z} \quad-0.372 .990 .18669$

c screw in cad shield X Y R $92 \mathrm{c} / \mathrm{z} 2.78-1.180 .18669$

c slot in cad shield X Y R $93 \mathrm{c} / 2 \quad-.45-3.400 .4572$

c $\# 10$ threaded rod OD

$95 \mathrm{c} / 23.0162500 .2413$

$c$ top of thick walled outer housing (17.875 in.) $96 \mathrm{pz} 45.4025$

c standoff around $\# 10$ threaded rod $97 \mathrm{c} / 23.0162500 .3937$

c left side of det\#1 stiffener 98 px 1.44028

c right side of del\#l stiffener 
WHC-SD-WM-TI-786, Rev. 0

$99 \mathrm{px} 1.51648$

c bottom of det\#l stiffener

$100 \mathrm{pz} 1.5367$

$c$ front edge of det\# 1 stiffener

101 py -1.27

c back edge of det\#1 stiffener

102 py 1.27

$c$ bottom of cable head

$103 \mathrm{pz} 41.529$

c source holder threaded grab hole radius

$104 \mathrm{c} / \mathrm{y} \quad 3.0480000 \quad 0.6601000 \quad 0.207$

c source capsule ID

$105 \mathrm{c} / \mathrm{y} \quad 3.0480000 \quad 0.6604000 \quad 0.196$

c source holder nut radius

$\begin{array}{lllll}106 & c / y & 3.0480000 & 0.6604000 & 0.40\end{array}$

c source holder nut end

107 py -2.16

c source holder thread/capsule interface

108 py -0.686

c source holder capsule end

109 py 0.686

c source capsule inner bottom end

110 py 0.450

c source capsule inner top end

111 py -0.165

c source capsule/holder OD

$112 \mathrm{c} / \mathrm{y} \quad 3.0480000 \quad 0.6604000 \quad 0.3175$

c source OD

$113 \mathrm{c} / \mathrm{y} \quad 3.0480000 \quad 0.6604000 \quad 0.00935$

c source top

114 py 0.15185

c source bottom

115 py 0.13315

c bottom ( $\# 1$ ) electrical board (bottom)

$116 \mathrm{pz} 16.756$

c bottom (\#1) electrical board (top)

117 pz 16.914

c (\#40) electrical SS ground plane (bottom)

$118 \mathrm{pz} 18.971$

c (\#40) electrical SS ground plane (top)

119 p2 19.129

c (\#2) electrical board (bottom)

120 pz 20.551

c (\$2) electrical board (top)

121 pz 20.708

c (\#3) electrical board (bottom)

$122 \mathrm{pz} 24.188$

c (\#3) electrical board (top)

$123 \mathrm{pz} 24.345$

c (\#41) electrical SS ground plane (bottom)

124 pz 28.307

c (\#41) electrical SS ground plane (top)

125 pz 28.460

c $(\$ 4)$ electrical bo:ud (bottom)

126 pz 29.882

c (\#4) electrical board (top)

$127 \mathrm{pz} 30.04$

c $(\# 39)$ electrical SS ground plane (bottom)

$128 \mathrm{pz} 31.462$

c (\#39) electrical SS ground plane (1op)

$129 \mathrm{pz} 31.615$

c top shoulder of cable head 
WHC-SD-WM-TI-786, Rev. 0

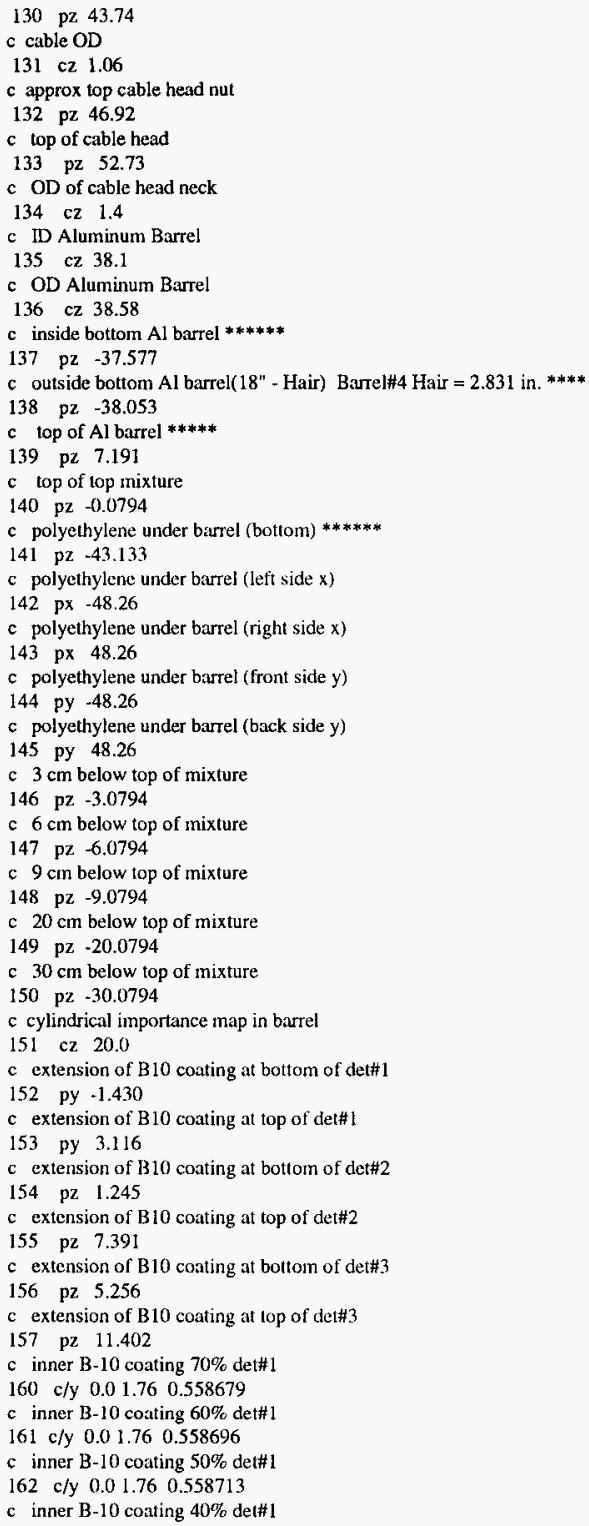


WHC-SD-WM-TI-786, Rev. 0

$163 \mathrm{c} / \mathrm{y} \quad 0.01 .76 \quad 0.558731$

c inner B-10 coating $30 \%$ det\$1

$164 \mathrm{c} / \mathrm{y} \quad 0.01 .76 \quad 0.558748$

$c$ inner B-10 coating $20 \%$ del\#1

$165 \mathrm{c} / \mathrm{y} \quad 0.01 .76 \quad 0.558766$

c inner B-10 coating $10 \%$ det\#1

$\begin{array}{lllll}166 & \mathrm{c} / \mathrm{y} & 0.0 & 1.76 & 0.558783\end{array}$

$c$ inner B-10 coating $70 \%$ det\#2

$\begin{array}{llllll}167 & \mathrm{c} / \mathrm{z} & -2.69748 & 0.0 & 0.558679\end{array}$

c inner B-10 coating $60 \%$ det $\# 2$

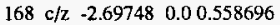

c inner B-10 coating 50\% det\#2

$\begin{array}{llllll}169 & \mathrm{c} / \mathrm{z} & -2.69748 & 0.0 & 0.558713\end{array}$

c inner B-10 coating $40 \%$ det\#2

$\begin{array}{lllll}170 & \mathrm{c} / \mathrm{z} & -2.69748 & 0.0 & 0.558731\end{array}$

c inner B-10 coating 30\% det $\$ 2$

$171 \mathrm{c} / \mathrm{z} \quad-2.69748 \quad 0.0 \quad 0.558748$

c inner B-10 coating $20 \%$ det $\$ 2$

$172 \mathrm{c} / \mathrm{z}-2.697480 .0 \quad 0.558766$

c inner B-10 coating $10 \%$ det\#2

$173 \quad \mathrm{c} / \mathrm{z} \quad-2.69748 \quad 0.0 \quad 0.558783$

c inner B-10 coating $70 \%$ det\#3

$174 \mathrm{cz} \quad 0.567569$

c inner B-10 coating $60 \%$ det\#3

$175 \mathrm{cz} \quad 0.567586$

c inner $B-10$ coating $50 \%$ det\#3

176 cz 0.567603

c inner B-10 coating 40\% det\#3

$177 \mathrm{cz} 0.567621$

c inner $B-10$ coating $30 \%$ det $\# 3$

$178 \mathrm{cz} 0.567638$

c inner B-10 coating $20 \%$ det\#3

$179 \mathrm{cz} \quad 0.567656$

c inner B-10 coating 10\% det\#3

$180 \mathrm{cz} \quad 0.567673$

c outside sphere

$200 \mathrm{cz} 70$

mode $\mathbf{n}$

phys:n 2020

c 15.0 micrograms $\mathrm{Cf}-252$

sdef cel d1 pos fcel d 2 axs 010 ext fcel d 3

rad fcel d4 $\mathrm{wgt}=3.47 \mathrm{e} 7 \mathrm{erg} \mathrm{d} 5$

sc1 source cell is Cf-252 source in cell 59

si1 159

spl d 1.0

$\mathrm{sc2}$ source location is centered in cell 59

ds2 I 3.0480 .14250 .6604

sc3 source extent

ds 3 s 6

sc4 source radius

ds4 47

sc5 energy distribution: $\mathrm{C}-252$ Wat Spontaneous Fission Spectrum

$\begin{array}{llll}\text { sp5 } & -3 & 1.025 & 2.926\end{array}$

sc6 source extent is 0.0187 centimeter total length

si6 0.00935

sp6 -210

sc7 source radius is .00935 centimeters

si7 0.00 .00935

sp7 $-21 \quad 1$

e0 $4 \mathrm{e}-7$ 7e-7 $1.5 \mathrm{e}-6$ 3e-6 $1 \mathrm{e}-5$ 1e-4 12.220

f4:n 1200201202203204205206 t \$ detector regions 
WHC-SD-WM-TI-786, Rev. 0

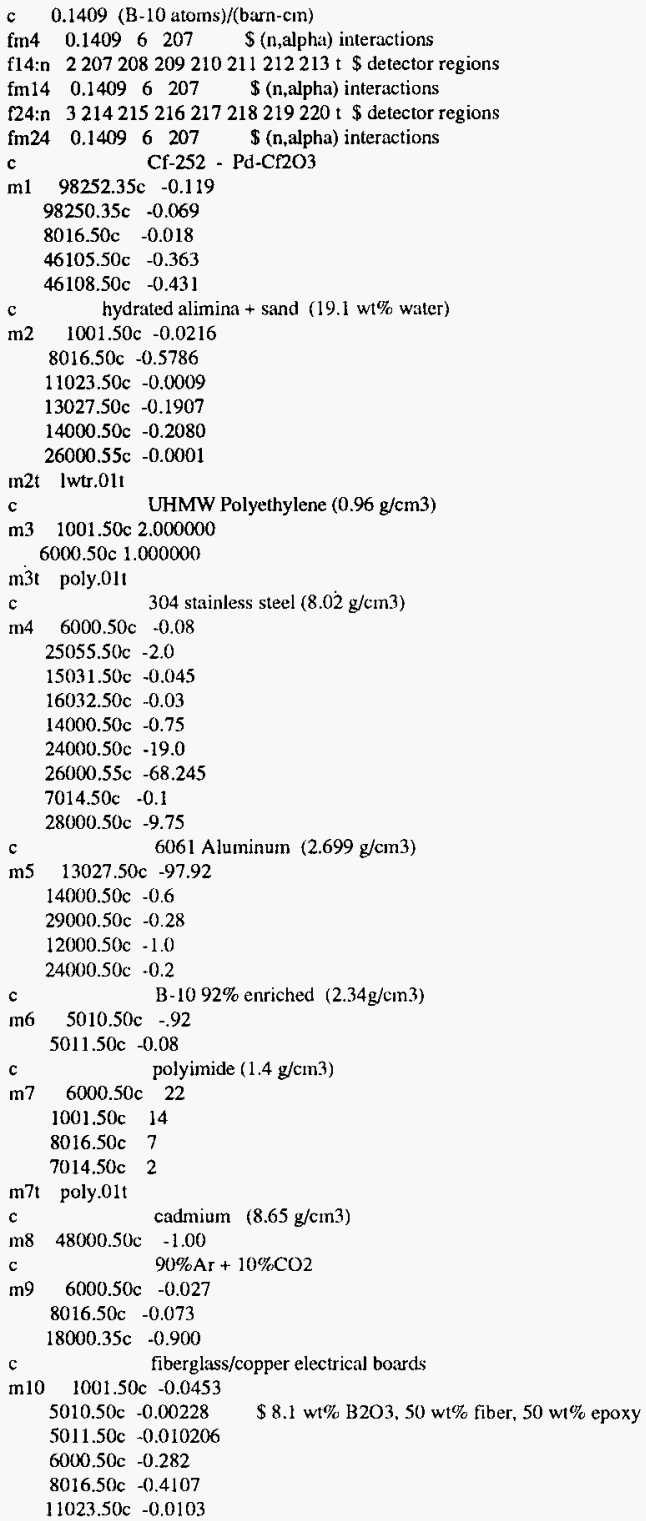


WHC-SD-WM-TI-786, Rev. 0

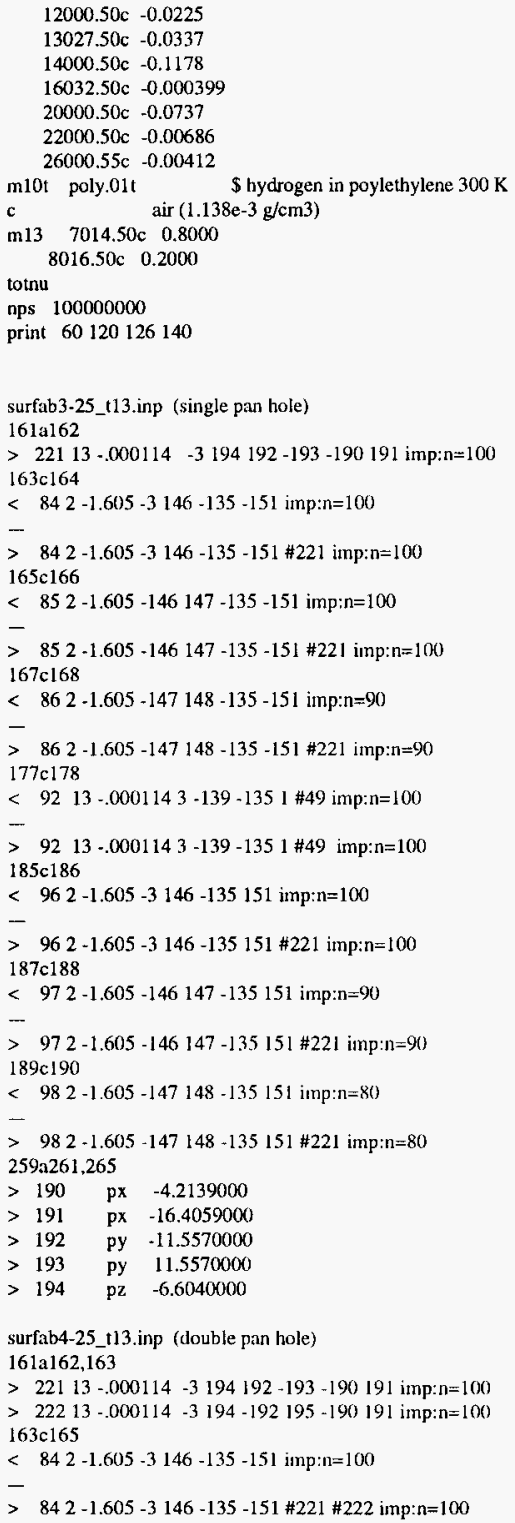




\section{WHC-SD-WM-TI-786, Rev. 0}

$165 \mathrm{c} 167$

$<852-1.605-146147-135-151$ imp: $n=100$

$-$

$>852-1.605-146147-135-151 \# 221 \# 222$ imp: $n=10$ )

$167 \mathrm{cl} 169$

$<862-1.605-147148-135-151$ imp:n=90

-

$>862-1.605-147148-135-151 \# 221 \# 222$ imp:n=90

$177 \mathrm{c} 179$

$<9213-.0001143-139-1351 \# 49$ imp:n=100

$-$

$>9213-.0001143-139-1351 \# 49$ imp:n=100

$185 \mathrm{c} 187$

$<962-1.605-3146-135151$ imp: $n=100$

$>962-1.605-3146-135151 \# 221 \# 222$ imp: $n=100$

$187 \mathrm{c} 189$

$<\quad 972-1.605-146147-135151$ imp: $n=90$

-

$>972 \cdot 1.605 \cdot 146147 \cdot 135151 \# 221 \# 222 \mathrm{imp}: \mathrm{n}=90$

$189 \mathrm{c} 191$

$<982-1.605-147148-135151 \mathrm{imp}: \mathrm{n}=80$

-

$>982-1.605-147148-135151 \# 221 \# 222$ imp: $n=80$

$259 \mathrm{a} 262,267$

$>190$ px -4.21390000

$>191$ px -16.4059000

$>192$ py 0.0000000

$>193$ py 23.1140000

$>195$ py -23.1140000

$>194$ pz -6.6040000

surfab5_t13.inp (hill \#1)

$161 \mathrm{a} 162$

$>2212-1.58 \quad 3-194192-193190-191$ imp: $n=100$

$177 \mathrm{c} 178$

$<9213-.0001143-139-1351 \# 49$ imp:n=100

$>9213-.0001143-139-1351 \# 49 \# 221$ imp: $n=100$ $259 \mathrm{a} 261,265$

$>190 \quad \mathrm{px} \quad 4.2139000$

$>191$ px 16.4059000

$>192$ py -11.5570000

$>193$ py 11.5570000

$>194 \mathrm{pz} 6.6040000$

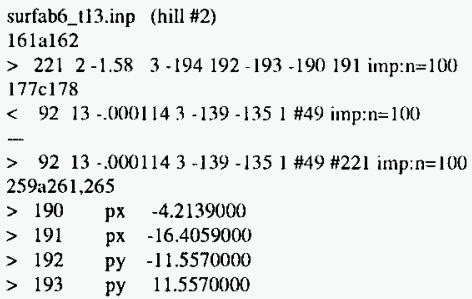


WHC-SD-WM-TI-786, Rev, 0

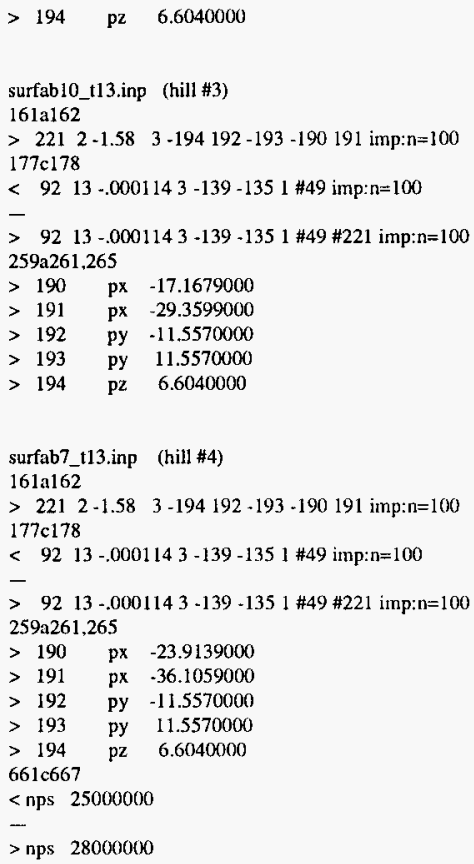


WHC-SD-WM-TI-786, Rev. 0

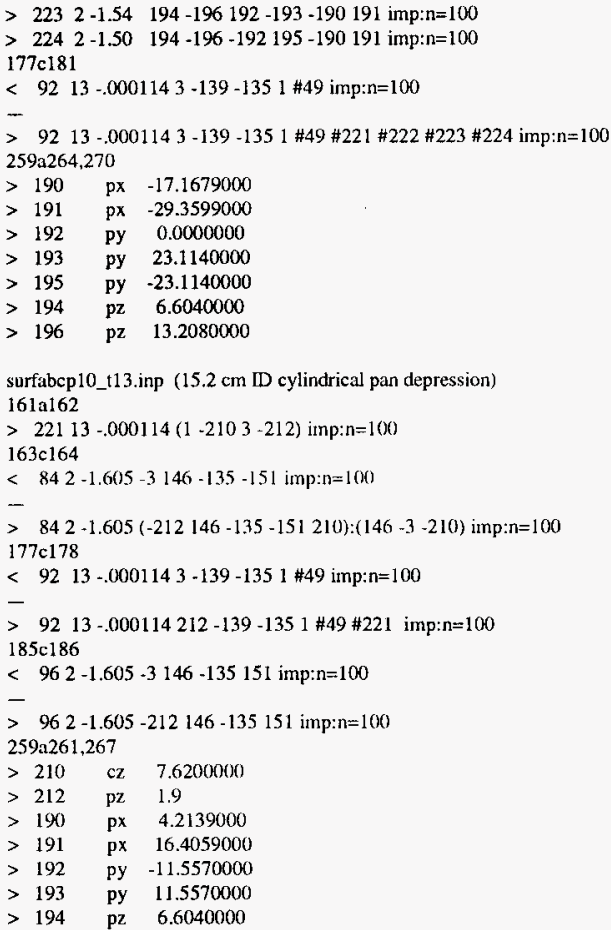

surfabcp11_t13.inp (20.3 cm ID cylindrical pan depression) $161 \mathrm{a} 162$ 
WHC-SD-WM-TI-786, Rev. 0

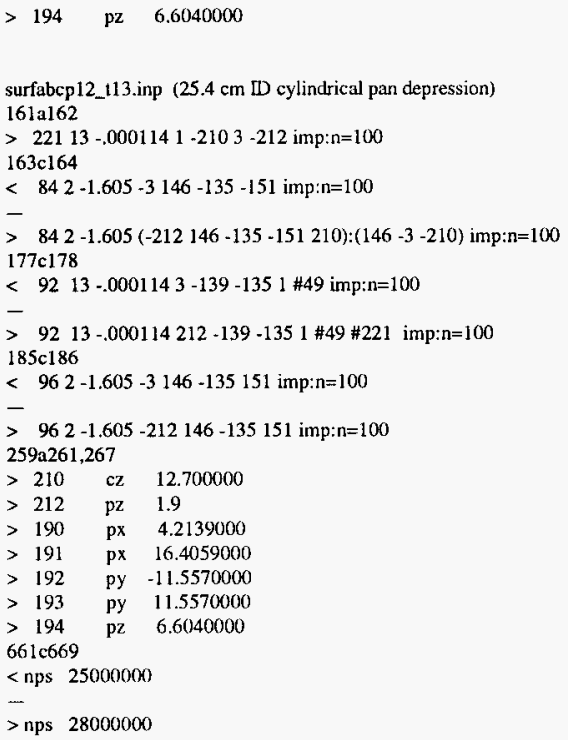

surfabsub1.5_t13.inp (probe bottom submerged $1.5 \mathrm{~cm}$ below surface) $162,163 \mathrm{c} 162$

<c top 0-3cm layer of hydrated alumina + sand (inner cylinder)

$<842-1.605-3146-135-151$ imp:n=100 
WHC-SD-WM-TI-786, Rev. 0

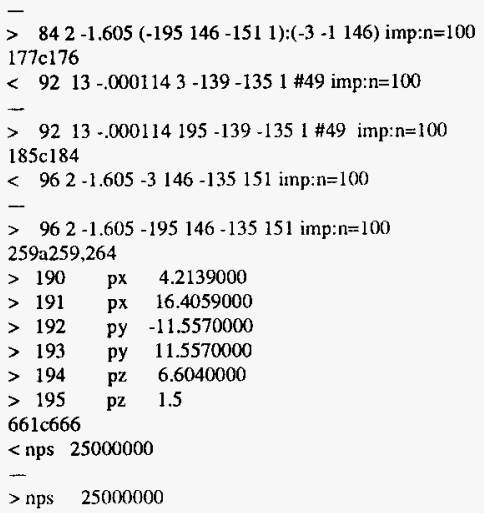


WHC-SD-WM-TI-786, Rev. 0

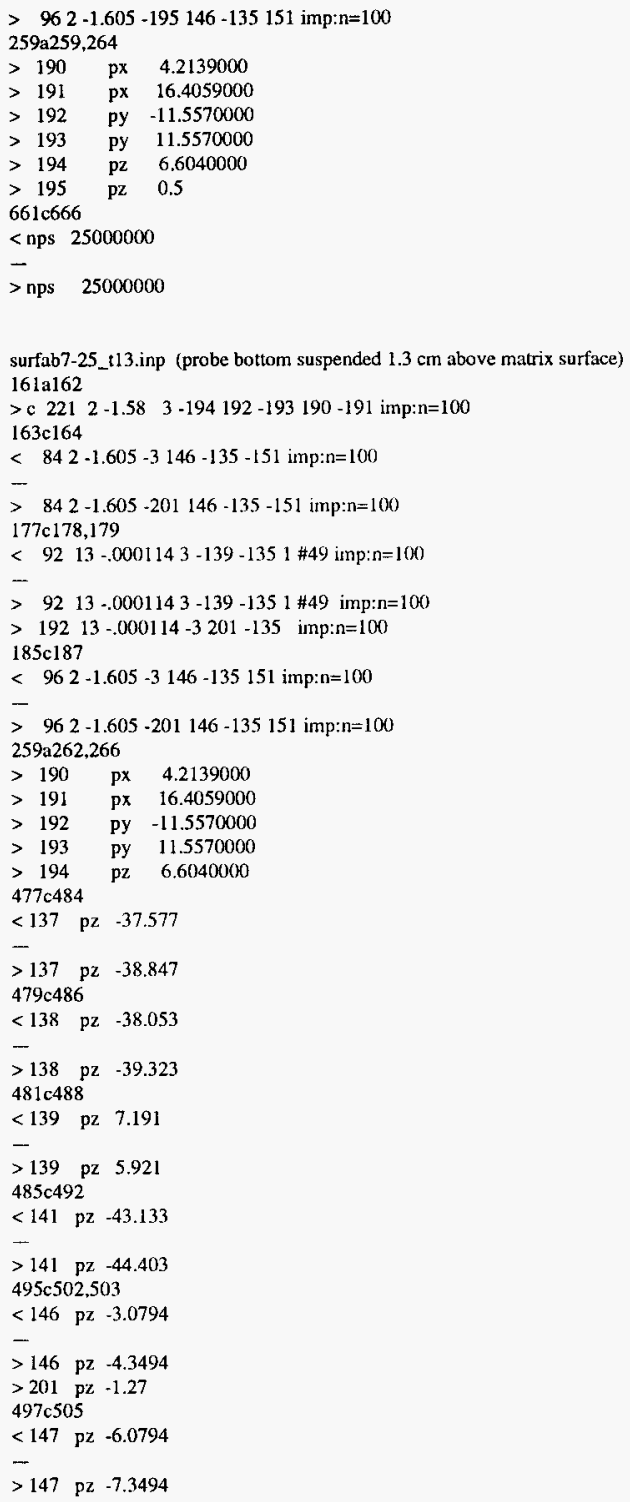


WHC-SD-WM-TI-786, Rev. 0

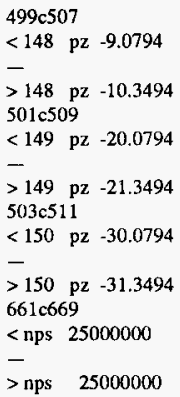


WHC-SD-WM-TI-786, Rev. 0

$$
\begin{aligned}
& <147 \text { pz }-6.0794 \\
& >147 \text { pz }-8.6194 \\
& 499 c 507 \\
& <148 \text { pz }-9.0794 \\
& >148 \mathrm{pz}-11.6194 \\
& \text { 501c509 } \\
& <149 \text { pz }-20.0794 \\
& >149 \mathrm{pz}-22.6194 \\
& 503 \mathrm{c} 511 \\
& <150 \mathrm{pz}-30.0794 \\
& >150 \text { pz }-32.6194 \\
& 661 c 669 \\
& \text { < nps } 25000000 \\
& >\text { nps } 60000000
\end{aligned}
$$

surfab9-25_t13.inp (probe bottom suspended $3.8 \mathrm{~cm}$ above matrix surface)

$161 \mathrm{a} 162$

>c $2212 \cdot 1.58 \quad 3-194192-193190-191 \mathrm{imp}: n=100$

$163 \mathrm{cl} 164$

$<842-1.605-3146-135-151$ imp:n=100

$>842-1.605-201146-135-151 \mathrm{imp}: \mathrm{n}=100$

$177 \mathrm{c} 178,179$

$<9213-.0001143+139+1351 \# 49$ inp: $n=100$

$>9213-.0001143 \cdot 139+1351$ 1 \#49 imp:n=100

$>19213-.000114-3201-135$ imp: $n=100$

$185 \mathrm{c} 187$

$<962-1.605-3146-135151$ imp: $n=100$

$>962-1.605-201146-135151$ imp:n=100

$259 \mathrm{a} 262,266$

$>190$ px 4.2139000

$>191$ px 16.4059000

$>192$ py -11.5570000

$>193$ py 11.5570000

$>194$ pz 6.6040000

$477 \mathrm{c} 484$

$<137$ pz $\quad-37.577$

$-$

$>1.37$ pz -41.387

$479 \mathrm{c} 486$

$<138$ pz $\quad-38.053$

$>138 \mathrm{pz} \quad-41.863$

$481 \mathrm{c} 488$

$<139$ pz 7.191

$-$

$>139 \mathrm{pz} 3.381$

$485 \mathrm{c} 492$

$<141$ p2 -43.133

$>141$ pz -46.943

$495 \mathrm{c} 502.503$

$<146$ pz -3.0794 
WHC-SD-WM-TI-786, Rev. 0

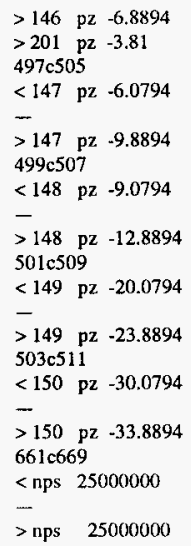


WHC-SD-WM-TI-786, Rev. 0

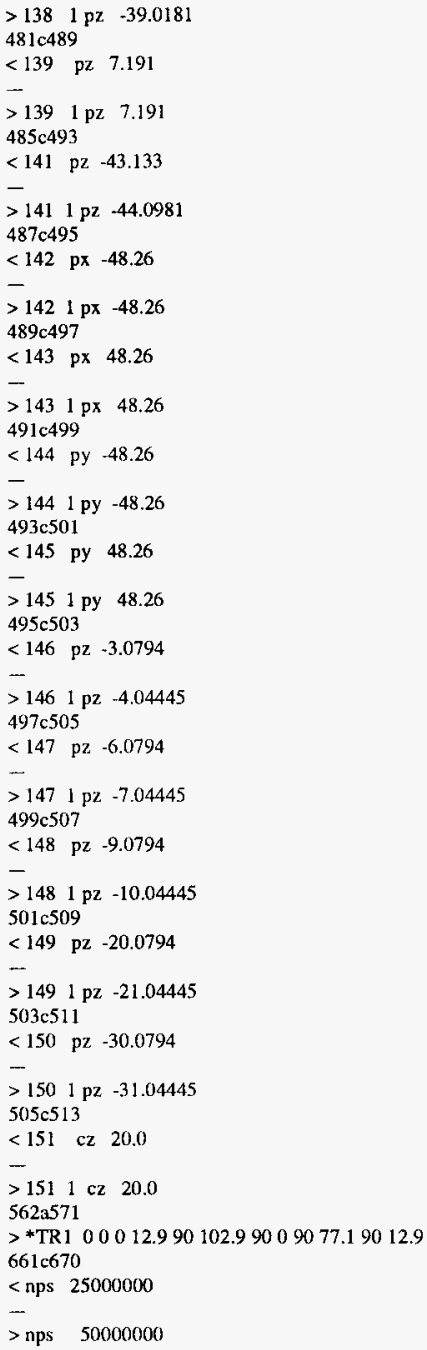


WHC-SD-WM-TI-786, Rev. 0

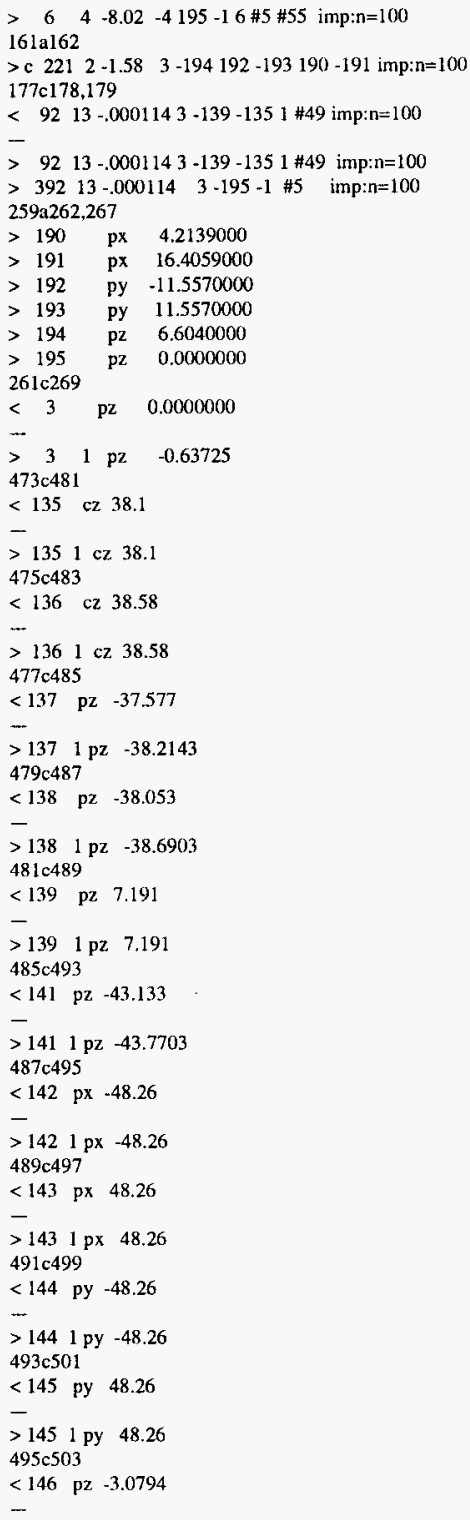


WHC-SD-WM-TI-786, Rev. 0

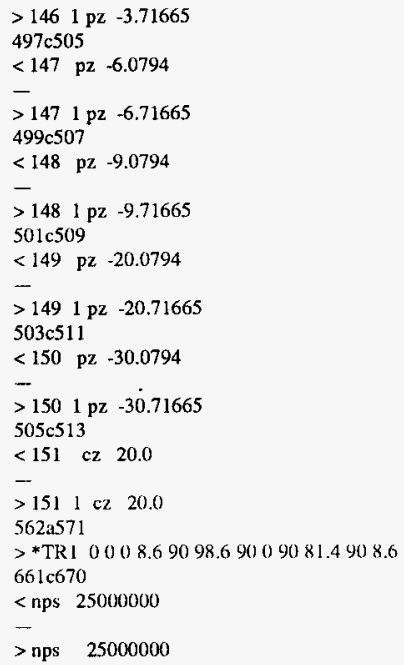


WHC-SD-WM-TI-786, Rev. 0

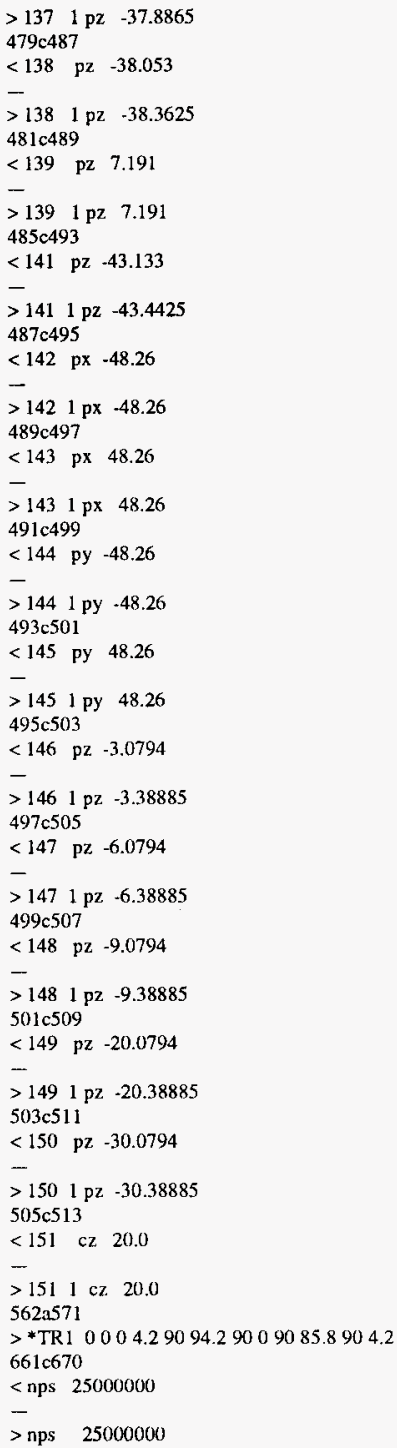


WHC-SD-WM-TI-786, Rev. 0

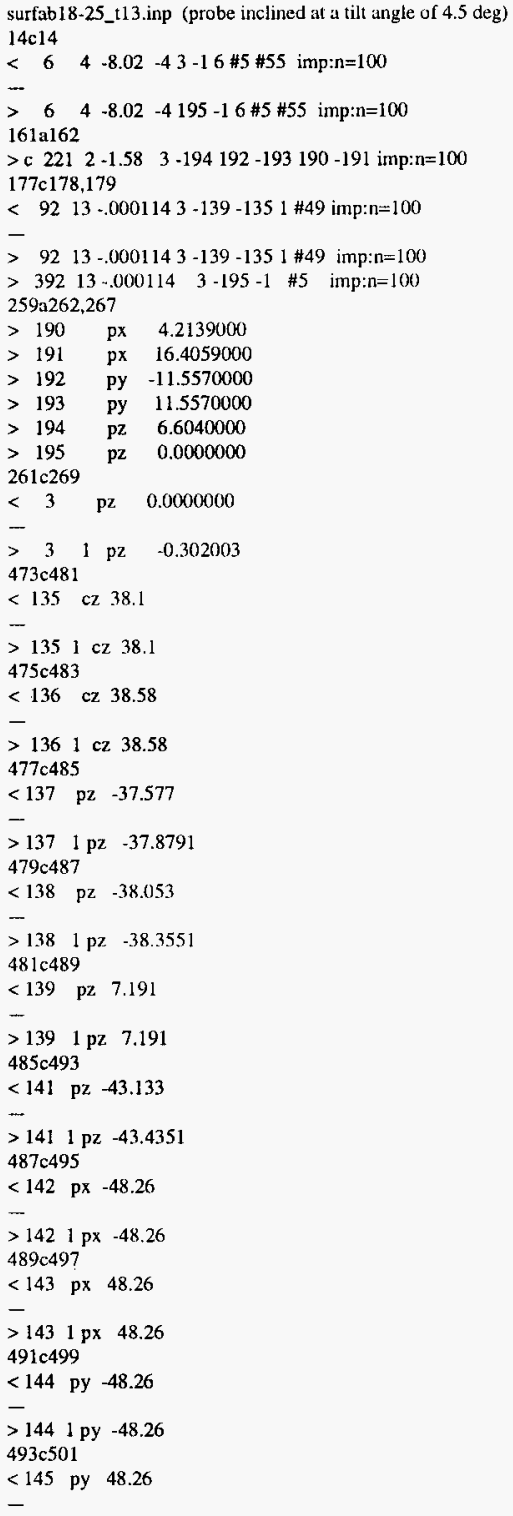


WHC-SD-WM-TI-786, Rev. 0

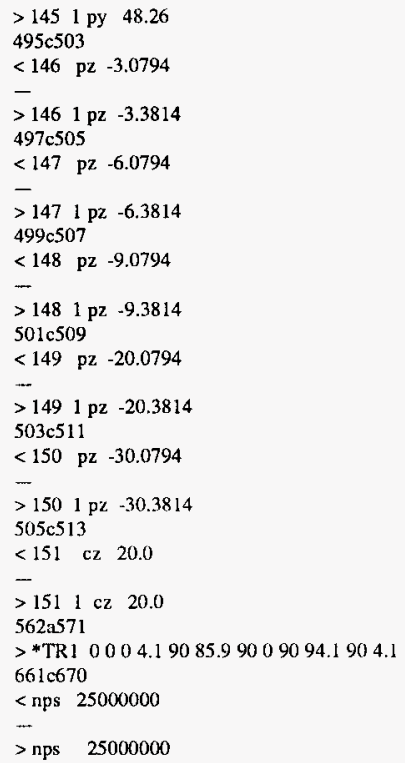


WHC-SD-WM-TI-786, Rev. 0

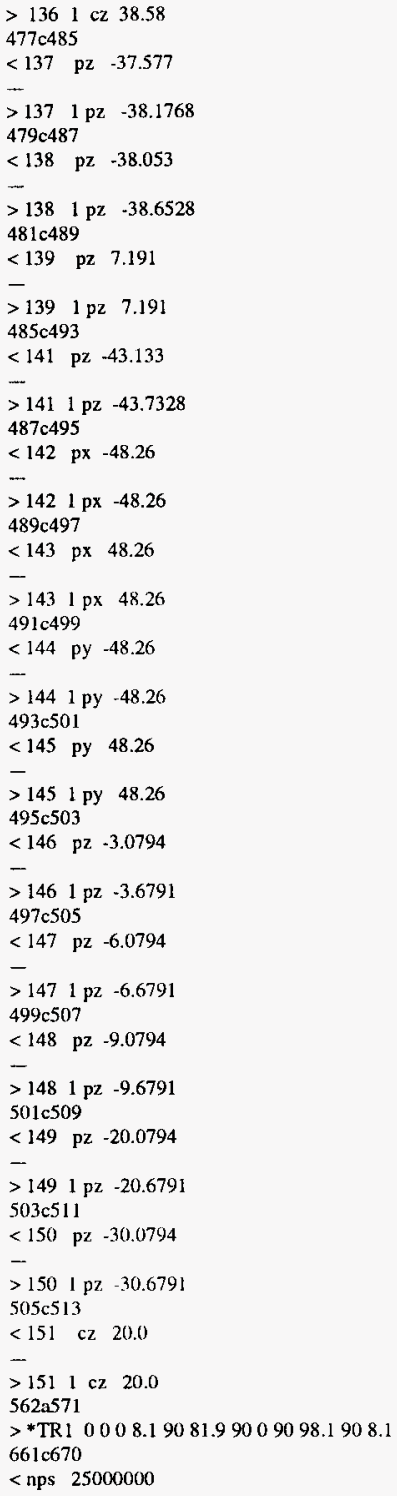


WHC-SD-WM-TI-786, Rev. 0

$>$ nps $\quad 50000000$ 


\section{DISTRIBUTION SHEET}

\begin{tabular}{|c|c|c|c|c|c|}
\hline \multirow{2}{*}{$\begin{array}{l}\text { To } \\
\text { Distribution }\end{array}$} & \multirow{2}{*}{\multicolumn{3}{|c|}{$\begin{array}{l}\text { From } \\
\text { Special Initiatives \& } \\
\text { Applications }\end{array}$}} & \multicolumn{2}{|l|}{ Page 1 of 1} \\
\hline & & & & \multicolumn{2}{|c|}{ Date $10 / 25 / 96$} \\
\hline \multicolumn{4}{|c|}{ Project Title/Work Order } & \multicolumn{2}{|c|}{ EDT No. 618553} \\
\hline \multicolumn{4}{|c|}{$\begin{array}{l}\text { Moisture Measurement Perturbations of the Surface Neutron Probe } \\
\text { Resulting from Waste Material Properties and Arrangements }\end{array}$} & \multicolumn{2}{|l|}{ ECN No. } \\
\hline Name & MSIN & $\begin{array}{l}\text { Text } \\
\text { With All } \\
\text { Attach. }\end{array}$ & Text Only & $\begin{array}{l}\text { Attach./ } \\
\text { Appendix } \\
\text { Only }\end{array}$ & $\begin{array}{l}\text { EDT/ECN } \\
\text { Only }\end{array}$ \\
\hline $\begin{array}{l}\text { H. Babad } \\
\text { J. M. Bates } \\
\text { R. J. Cash } \\
\text { K. L. Drury } \\
\text { S. H. Finfrock } \\
\text { C. E. Hanson } \\
\text { J. E. Meacham } \\
\text { G. F. Vargo, Jr. } \\
\text { W. T. Watson (2) } \\
\text { D. W. Wootan } \\
\text { Central Files (Orig }+1)\end{array}$ & $\begin{array}{l}H 6-26 \\
K 7-15 \\
S 7-14 \\
H 5-09 \\
H 0-31 \\
H 5-09 \\
S 7-14 \\
H 5-09 \\
H 0-31 \\
H 0-31 \\
A 3-88\end{array}$ & $\begin{array}{l}x \\
x \\
x \\
x \\
x \\
x \\
x \\
x \\
x \\
x \\
x\end{array}$ & & & \\
\hline
\end{tabular}

